\title{
Stereospecific control of the metal-centred chirality of rhodium(III) and iridium(III) complexes bearing tetradentate $\mathrm{CNN}^{\prime} \mathrm{P}$ ligands $\dagger$
}

\author{
María Carmona, ${ }^{\text {a }}$ Ricardo Rodríguez, ${ }^{, a}$ Isabel Méndez, ${ }^{a}$ Vincenzo Passarelli,,,a,b \\ Fernando J. Lahoz, ${ }^{a}$ Pilar García-Orduña ${ }^{\mathrm{a}}$ and Daniel Carmona*,a \\ Received ........ \\ DOI:
}

Ligands LH1-LH3 have been prepared by two successive condensation/reduction steps. These ligands react with $\mathrm{MCl}_{3}(\mathrm{M}=\mathrm{Rh}$, Ir) rendering the trichlorido complexes $\left[\mathrm{MCl}_{3}\left(\kappa^{3} N, N^{\prime}, P-\mathbf{L H}\right)\right](\mathrm{M}=\mathrm{Rh}, \mathbf{L H}=\mathbf{L H 1}(\mathbf{1}), \mathbf{L H} 2$ (2), LH3 (3); M = Ir, LH = LH1, (4)) as racemic mixtures of fac and mer isomers. Only one of the two possible fac isomers was detected. The mer isomer of the rhodium compounds 1-3 quantitatively isomerizes to the more stable fac isomer, whereas the mer isomer of the iridium complex 4 does not. DFT calculations indicate a dissociative pathway for this isomerization. In the presence of acetate or trifluoroacetate, complexes 1-3 or 4, respectively, undergo cyclometallation of their free benzylic arm affording the corresponding dichlorido compounds $\left[\mathrm{MCl}_{2}\left(\kappa^{4} C, N, N^{\prime}, P-\mathbf{L}\right)\right](\mathrm{M}=\mathrm{Rh}, \mathbf{L}=\mathbf{L 1}$ (5), $\mathbf{L 2}$ (6), L3 (7); $\mathrm{M}=\mathrm{Ir}, \mathbf{L}=\mathbf{L 1}(\mathbf{8}))$. Only one of the three possible enantiomeric pairs of coordination isomers was detected. The configuration at the stereogenic centres, namely the metal and the iminic nitrogen atom is stereospecifically predetermined. DFT

\footnotetext{
${ }^{a}$ Instituto de Síntesis Química y Catálisis Homogénea (ISQCH), CSIC - Universidad de Zaragoza, Departamento de Química Inorgánica, Pedro Cerbuna 12, 50009 Zaragoza, Spain, E-mail: dcarmona@unizar.es (D. C.), riromar@unizar.e, (R. R.), passarel@unizar.es (V. P.)

${ }^{b}$ Centro Universitario de la Defensa, Ctra. Huesca s/n, 50090 Zaragoza, Spain

$\dagger$ Electronic supplementary information (ESI) available: Preparation and characterization of the imines I1-I3 and amines A1-A3. Selected NMR spectra of compound 5. X-ray crystallographic information files containing full details of the structural analysis of complexes 1, 3, 5, 6, 7 and 8 (CIF format): CCDC Atomic coordinates of calculated structures. Energies from relaxed PSE calculations: CCDC 15452611545266. For ESI and crystallographic data in CIF or other electronic format see DOI:
} 
calculations reveal that the cyclometallation follows an acetate-assisted mechanism and indicate that the isolated isomers are the most stable. Complexes $\mathbf{1 - 8}$ have been characterized by analytical and spectroscopic means and by the determination of the crystal structures of the complexes 1, 3 and 5-8 by X-ray diffractometry. 


\section{Introduction}

Nowadays, the most efficient and versatile methodology for the preparation of enantioenriched compounds relies on the employment of transition metal complexes as asymmetric catalysts. ${ }^{1}$ Indeed, over the last decades, a wide variety of chemical transformations has been accomplished under the control of chiral metal-containing catalysts. $^{2}$

By far, the most developed strategy in this area is based on the association of chiral enantiopure organic ligands with metal ions. Chirality is located in a coordination atom or, more frequently, in the ligand backbone and the asymmetric environment created around the metal (where the substrates react) is enough to achieve high enantiomeric excesses. ${ }^{1,3}$ However, higher stereoselectivities would be expected if the metal atom itself were a stereogenic centre in an enantiopure compound. In fact, in some efficient catalysts, chirality does not only reside in the ligand but also in the metal. These catalysts generally form diastereoselectively by chiral induction from enantiopure ligands and metals usually exhibit octahedral or pseudo-octahedral geometries. Relevant examples are complexes containing $\mathrm{N}_{4},{ }^{4} \mathrm{~N}_{2} \mathrm{O}_{2}{ }^{5}$ or $\mathrm{N}_{2} \mathrm{P}_{2}{ }^{6}$ chiral tetradentate ligands as well as half-sandwich compounds of the type ${ }^{7}\left[\left(\eta^{\mathrm{n}}-\text { ring }\right) \mathrm{M}\left(L L^{*}\right) \mathrm{L}\right]^{\mathrm{n}+}$ in which $\mathrm{LL}^{*}$ represents a chiral bidentate ligand.

However, examples of only chiral-at-metal catalysts are scarce most probably due to the limitation that entails the preparation of a single stereoisomer through asymmetric synthesis ${ }^{8}$ or chiral resolution. ${ }^{9}$ The simultaneous requirement for the metal of configurational stability and free, or potentially available, coordination sites makes this preparation a very challenging task. ${ }^{10}$ Only a few catalysts of this type have been developed. ${ }^{9 e}$ Typically, they consist of octahedral compounds bearing two bidentate achiral NN or CN ligands which impart "propeller" chirality to the complex. 
In 2003, Fontecave et al. reported that chiral-at-metal bis-diimine Ru(II) complexes catalyse the oxidation of sulfides to sulfoxides by hydrogen peroxide with up to $18 \%$ e. e. ${ }^{11}$ This result demonstrated that complexes which are chiral only at metal can be used for asymmetric catalysis. In the very last years, the group of Meggers and Gong has developed a family of rhodium(III) ${ }^{9 \mathrm{~d}, 12}$ and iridium(III) ${ }^{9 \mathrm{~b}, \mathrm{e}, 13}$ complexes that efficiently catalyses a variety of organic transformations, such as Michael, ${ }^{9 \mathrm{~d}, 12 \mathrm{~b}}$ Friedel-Crafts ${ }^{9 \mathrm{e}, 13 \mathrm{~b}}$ or conjugate additions, ${ }^{9 \mathrm{~b}}$ hydrogen transfer reactions, ${ }^{13}$ dehydrogenative cross-coupling reactions between two $\mathrm{C}\left(\mathrm{sp}^{3}\right)-\mathrm{H}$ groups, ${ }^{12 \mathrm{c}}$ or alkylynation reactions, ${ }^{12 \mathrm{a}}$ achieving high levels of enantioselectivity.

With all these concerns in mind, we envisaged the possibility of studying the application as asymmetric catalysts of chiral-at-metal octahedral complexes derived from chiral but unresolved tripodal tetradentate ligands. As far as we know, no chiral resolution of octahedral complexes derived from optically not resolved chiral tetradentate ligands has been reported until now. In order to control the stereochemistry of the resulting complexes, the stereochemical richness of octahedral coordination makes very convenient to introduce steric constrains within the ligands. Tripodal tetradentate ligands would offer relatively rigid and well-defined frameworks and provide two mutually cis coordination sites. Taking into account these considerations, we chose the potentially tetradentate ligands depicted in Scheme 1 as ligands to build up octahedral complexes of the $\mathrm{d}^{6}$ metal ions $\mathrm{Rh}^{+3}$ and $\mathrm{Ir}^{+3}$.

The four coordination points would be the aminic and pyridinic nitrogen atoms, the phosphorus and one of the aromatic carbons of the benzyl substituent. The presence of four distinct coordination atoms in a tripodal tetradentate ligand guarantees the stereogenicity of the metal in complexes with a $\kappa^{4} C, N, N^{\prime}, P$ coordination mode. The coordinated aminic nitrogen is also a stereogenic centre and, as we will see in this 
paper, the chirality of the molecule is predetermined: ${ }^{14}$ a determined absolute configuration at nitrogen corresponds to an established absolute metal configuration. Furthermore, the coordination features of these ligands suggest a high stability of the configuration at the metal.

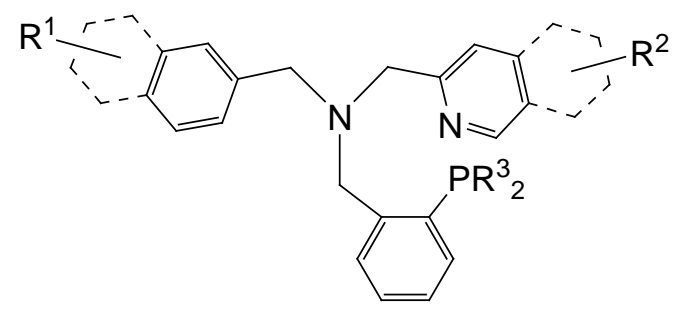

Scheme 1 Tripodal tetradentate ligands.

Notably, the ligands can be prepared by successive inclusion of the three substituents at the central nitrogen in a stepwise manner and, therefore, the stereoelectronic properties of the ligands can be modulated at will within a wide scope.

In the present paper, we disclose a synthetic route to rhodium and iridium dichlorido complexes of formula $\left[\mathrm{MCl}_{2}\left(\kappa^{4} C, N, N^{\prime}, P-\mathbf{L}\right)\right](5-8)$ where $\mathbf{L H}$ represents a tetradentate tripodal ligand of the type collected in Scheme 1. Trichlorido intermediates of stoichiometry $\left[\mathrm{MCl}_{3}\left(\kappa^{3} N, N^{\prime}, P-\mathbf{L H}\right)\right](\mathbf{1 - 4})$ have been isolated and characterized. The kinetic and thermodynamic relative stability of the possible stereoisomers of the new complexes have been studied by DFT methods. From experimental and theoretical data, a plausible mechanism has been proposed for the metallation reaction that complexes 14 undergo to afford dichloridos 5-8.

The chiral resolution of the dichlorido complexes and the application of derived solvate complexes as catalyst precursors for enantioselective organic transformations will be reported in due course. 


\section{Results and discussion}

\section{Synthesis of the ligands}

Ligands LH1-LH3 could be prepared in a straightforward manner (Scheme 2). Condensation of pyridine-2-carboxaldehyde with benzylamines ${ }^{15}$ renders imines I1-I3 that are reduced to the corresponding amines A1-A3 by treatment with methanolic $\mathrm{NaBH}_{4}$ solutions ${ }^{16}$ (see ESI). Subsequent one-pot condensation of amines A1-A3 with 2-(diphenylphosphino)benzaldehyde followed by reduction with $\mathrm{NaBH}(\mathrm{AcO})_{3}{ }^{17}$ afforded ligands LH1-LH3 in high overall yield.

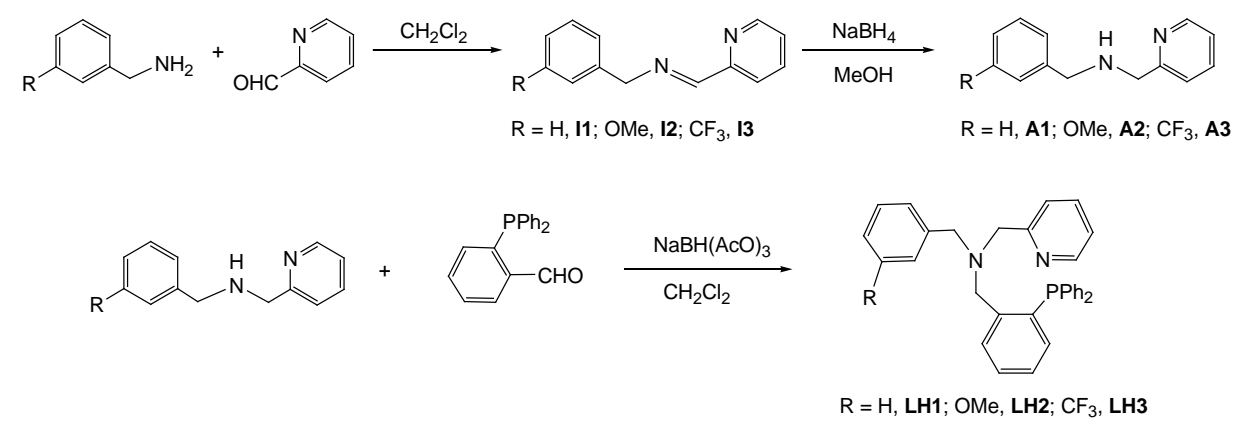

Scheme 2 Synthesis of the ligands.

Synthesis of the trichlorido compounds $\left[\mathrm{MCl}_{3}\left(\kappa^{3} N, N^{\prime}, P-\mathrm{LH}\right)\right](\mathrm{M}=\mathrm{Rh}, \mathrm{LH}=\mathrm{LH} 1$ (1), LH2 (2), LH3 (3); M = Ir, LH = LH1 (4))

Trichlorido complexes 1-4 were prepared by treating $\mathrm{RhCl}_{3} \cdot \mathrm{xH}_{2} \mathrm{O}$ or $\mathrm{IrCl}_{3} \cdot \mathrm{xH}_{2} \mathrm{O}$ with stoichiometric amounts of the corresponding ligand in refluxing ethanol, overnight for the rhodium compounds 1-3 or during 4 days for the iridium complex 4 (Eq. 1). The long required reaction times (especially for the iridium compound) may be due to the low solubility of the reagents under the reaction conditions.

Analytical and spectroscopic data indicate that the isolated solid consists of a $c a$. 31:69 (1), 40:60 (2), 29:71 (3) and 80:20 (4) mixture of two isomers derived from the 


$$
\begin{aligned}
& \mathrm{MCl}_{3}+\mathrm{LH} \stackrel{\mathrm{EtOH}, \Delta}{\longrightarrow} \quad\left[\mathrm{MCl}_{3}\left(\kappa^{3} N, N^{\prime}, P-\mathrm{LH}\right)\right] \quad \text { Eq. } 1 \\
& \mathrm{M}=\mathrm{Rh}, \mathrm{LH}=\mathrm{LH} 1 \text { (1), LH2 (2), LH3 (3) } \\
& M=I r, \text { LH = LH1 (4) }
\end{aligned}
$$

coordination to the metal of the two nitrogens and the phosphorus atom of the ligand. From a stereochemical point of view, it is important to note that a $\kappa^{3} N, N^{\prime} P$ coordination mode strongly hampers the inversion at the aminic nitrogen. Moreover, in an octahedral $\mathrm{MCl}_{3} \mathrm{NN}$ 'P compound the metal may also be stereogenic. All the possible isomers of complexes 1-4 (an enantiomeric pair of mer and two enantiomeric pairs of fac diastereomers) are depicted in Scheme 3 labelled with their corresponding stereochemical descriptors. ${ }^{18}$

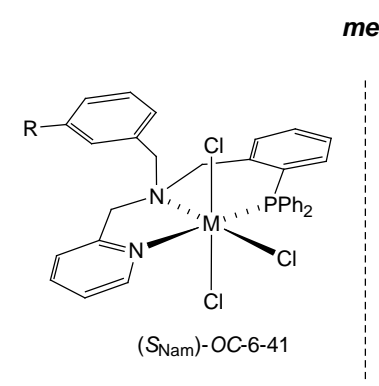

$M=R h, R=H(1 a), O M e(2 a)$ $\mathrm{CF}_{3}(3 \mathrm{a})$ $\mathrm{M}=\mathrm{Ir}, \mathrm{R}=\mathrm{H}(\mathbf{4} \mathbf{a})$

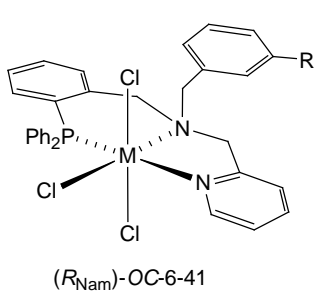

$M=R h, R=H\left(1 a^{\prime}\right)$, OMe $\left(2 a^{\prime}\right)$ $\mathrm{CF}_{3}\left(3 \mathrm{a}^{\prime}\right)$ $M=I r, R=H\left(4 a^{\prime}\right)$

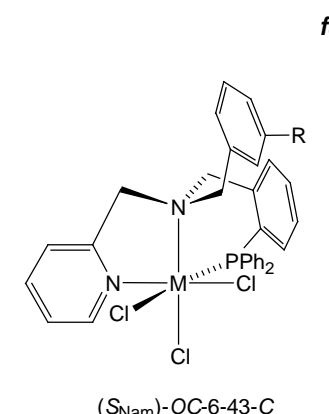

$\left(S_{\text {Nam }}\right)-O C-6-43-C$

$M=R h, R=H(\mathbf{1 b})$, OMe (2b), $\mathrm{CF}_{3}$ (3b) $\mathrm{M}=\mathrm{Ir}, \mathrm{R}=\mathrm{H}(\mathbf{4 b})$

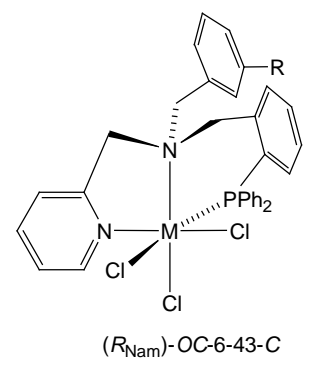

$\mathrm{M}=\mathrm{Rh}, \mathrm{R}=\mathrm{H}(\mathbf{1 c}), \mathrm{OMe}(\mathbf{2 c})$ $\mathrm{M}=\mathrm{Rh}$, $\mathrm{M}=\mathrm{Ir}, \mathrm{R}=\mathrm{H}(4 \mathrm{c})$ fac

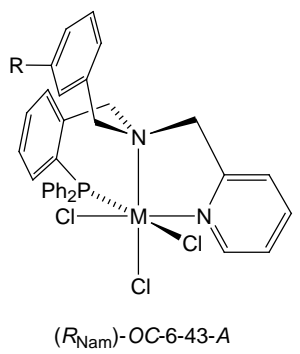

$M=R h, R=H\left(1 b^{\prime}\right), O M e\left(\mathbf{b}^{\prime}\right)$ $\mathrm{CF}_{3}\left(\mathbf{3 b}^{\prime}\right)$ $M=I r, R=H\left(4 b^{\prime}\right)$

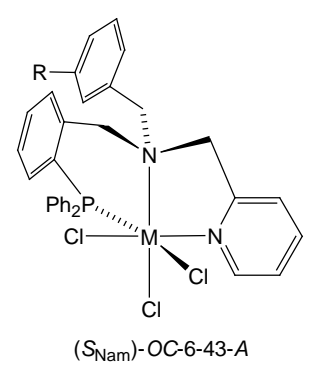

$M=R h, R=H\left(1 c^{\prime}\right), O M e\left(2 c^{\prime}\right)$ $\mathrm{M}=\mathrm{Rh}, \mathrm{R}$
$\mathrm{CF}_{3}\left(3 \mathrm{c}^{\prime}\right)$ $\mathrm{M}=\mathrm{Ir}, \mathrm{R}=\mathrm{H}\left(\mathbf{4 \mathrm { c } ^ { \prime } )}\right.$

Scheme 3 Trichlorido isomers.

The complexes were characterized by analytical and spectroscopic means (see Experimental Section). Assignment of the NMR signals was verified by twodimensional homonuclear and heteronuclear correlations. The ${ }^{31} \mathrm{P}\left\{{ }^{1} \mathrm{H}\right\}$ NMR spectrum 
of each mixture of rhodium isomers consisted of two doublets, at ca. 30.5 and 27.5 ppm, respectively, exhibiting $J(\mathrm{RhP})$ coupling constants in the 107-116 Hz range. The ${ }^{31} \mathrm{P}\left\{{ }^{1} \mathrm{H}\right\}$ NMR spectrum of the isolated mixture of the two isomers of the iridium compound 4 consisted of two singlets one at $-20.96 \mathrm{ppm}$ and the other at $-22.76 \mathrm{ppm}$. In all the complexes, the three pairs of methylene protons of the ligands become diastereotopic as a consequence of the coordination and resonate as anisochronous $A B$ or AX systems.

The proton- 6 of the pyridine moiety of the minor isomer of the rhodium complexes 1-3 and that of the major isomer of the iridium complex 4 presents a coupling constant to the phosphorus of about $5 \mathrm{~Hz}$. This coupling was not detected for the other isomers. As only in the mer isomers the phosphorus atom is trans to the pyridinic nitrogen, reasonably the less abundant rhodium and the most abundant iridium isomers are the pair of mer diastereomers. Assuming this assignment, only one of the two possible pairs of fac diastereomers is present in the isolated mixture but, at this point, we are not able to discriminate which of the two possible pairs of fac isomers has been obtained.

The mer isomers 1a-3a of the rhodium compounds completely convert into the corresponding fac isomers by refluxing overnight suspensions of the obtained mixture of both isomers, in dichloromethane or in ethanol. However, according to NMR observations, the isomerization of the mer iridium compound $\mathbf{4 a}$ is negligible under these conditions or even after 24 hours at $135{ }^{\circ} \mathrm{C}$ in 2-ethoxyethanol. The composition of a mer/fac mixture of complex 4 changes from 80/20 to 70/30 molar ratio by heating overnight a decahydronaphthalene suspension at $170{ }^{\circ} \mathrm{C}$. 


\section{Molecular structures of the compounds $\left[\mathrm{RhCl}_{3}\left(\kappa^{3} N, N^{\prime}, P-\mathrm{LH}\right)\right](\mathrm{LH}=\mathrm{LH} 1$ (1b/1b'), LH3 (3b/3b'))}

In order to unequivocally ascertain the structure of the isolated fac isomers, the crystal structures of complexes $\mathbf{1} \mathbf{b}$ and $\mathbf{3 b}$ have been determined by X-ray diffractometric methods. Single crystals have been obtained from dichloromethane solutions of the compounds, after complete isomerization of the isolated solids to the fac isomer. A view of the molecular structures of both complexes is depicted in Figure 1 (only one of the two enantiomers is shown) and relevant characteristics of the metal coordination spheres are summarized in Table 1. Both complexes share structural features. They exhibit a distorted-octahedral coordination environment with the rhodium atom bonded to the phosphorus and the aminic $\left(\mathrm{N}_{\mathrm{am}}, \mathrm{N}(1)\right)$ and pyridinic $\left(\mathrm{N}_{\mathrm{py}}, \mathrm{N}(2)\right)$ nitrogen atoms of the $\mathbf{L H}$ ligand. Three chlorido ligands complete a fac disposition around the metal. Both complexes crystallize in the $P-1$ centrosymmetric space group and therefore their unit cell $(Z=2)$ contain a pair of fac diastereomeric enantiomers specifically the $\left(S_{\text {Nam }}\right)$ -

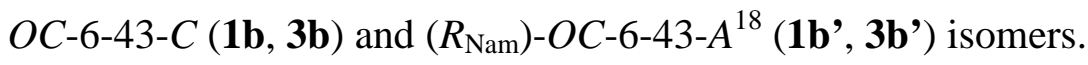

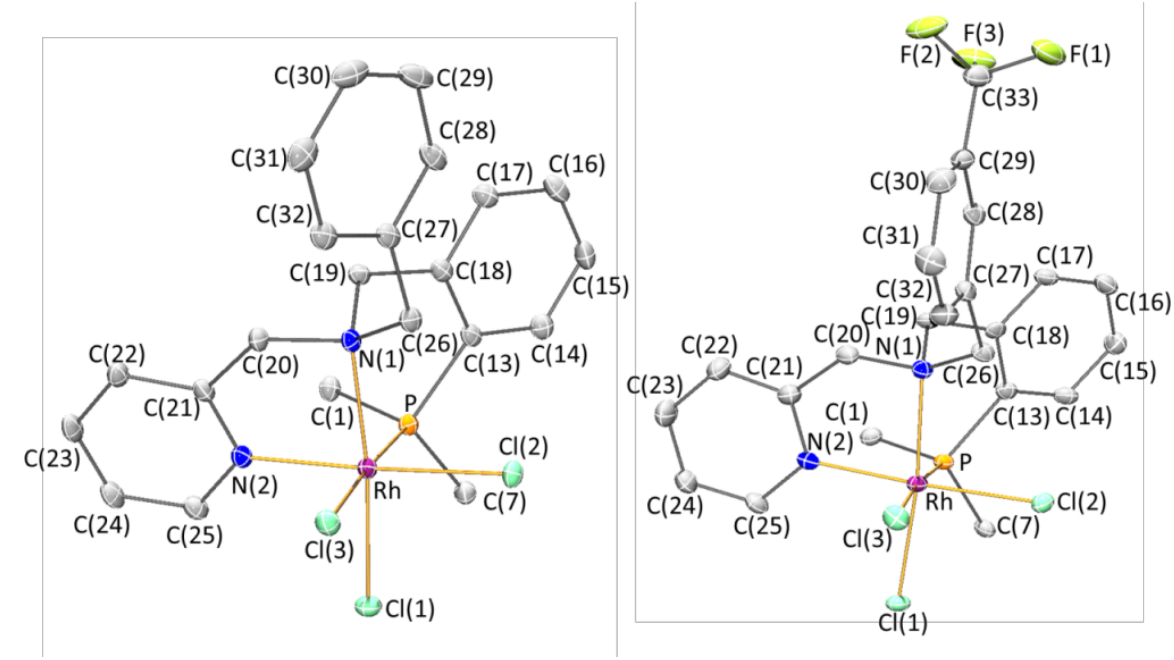

Fig. 1 Molecular structure of the complexes $\mathbf{1 b}$ and $\mathbf{3 b},\left(S_{\mathrm{Nam}}\right)-\mathrm{OC}-6-43-\mathrm{C}$ enantiomer. For clarity hydrogen atoms have been omitted and only the ipso carbon of the phenyls of the $\mathrm{PPh}_{2}$ group have been included. 
Table 1 Bond lengths $(\AA)$ and angles $\left(^{\circ}\right)$ for complexes $\mathbf{1 b} / \mathbf{1} \mathbf{b}$ ' and $\mathbf{3 b} / \mathbf{3} \mathbf{b}$ '

\begin{tabular}{|l|l|c|l|l|c|}
\hline & \multicolumn{1}{|c|}{$\mathbf{1 b} / \mathbf{1 b} \mathbf{b}^{\prime}$} & $\mathbf{3 b} / \mathbf{3 b}$ & & \multicolumn{1}{|c|}{$\mathbf{1 b / 1 b ^ { \prime }}$} & $\mathbf{3 b / 3 b}$ \\
\hline $\mathrm{Rh}-\mathrm{Cl}(1)$ & $2.3406(5)$ & $2.3309(8)$ & $\mathrm{Cl}(2)-\mathrm{Rh}-\mathrm{Cl}(3)$ & $90.338(17)$ & $88.50(3)$ \\
\hline $\mathrm{Rh}-\mathrm{Cl}(2)$ & $2.3440(5)$ & $2.3433(8)$ & $\mathrm{Cl}(2)-\mathrm{Rh}-\mathrm{P}$ & $86.608(17)$ & $86.98(3)$ \\
\hline $\mathrm{Rh}-\mathrm{Cl}(3)$ & $2.4331(5)$ & $2.4299(9)$ & $\mathrm{Cl}(2)-\mathrm{Rh}-\mathrm{N}(1)$ & $93.60(4)$ & $93.63(7)$ \\
\hline $\mathrm{Rh}-\mathrm{P}$ & $2.2805(5)$ & $2.2780(9)$ & $\mathrm{Cl}(2)-\mathrm{Rh}-\mathrm{N}(2)$ & $174.65(5)$ & $173.92(8)$ \\
\hline $\mathrm{Rh}-\mathrm{N}(1)$ & $2.1488(15)$ & $2.164(3)$ & $\mathrm{Cl}(3)-\mathrm{Rh}-\mathrm{P}$ & $176.724(17)$ & $174.57(3)$ \\
\hline $\mathrm{Rh}-\mathrm{N}(2)$ & $2.0366(15)$ & $2.052(3)$ & $\mathrm{Cl}(3)-\mathrm{Rh}-\mathrm{N}(1)$ & $87.73(4)$ & $89.41(8)$ \\
\hline $\mathrm{Cl}(1)-\mathrm{Rh}-\mathrm{Cl}(2)$ & $92.086(17)$ & $92.53(3)$ & $\mathrm{Cl}(3)-\mathrm{Rh}-\mathrm{N}(2)$ & $86.54(5)$ & $87.39(8)$ \\
\hline $\mathrm{Cl}(1)-\mathrm{Rh}-\mathrm{Cl}(3)$ & $88.797(17)$ & $89.67(3)$ & $\mathrm{P}-\mathrm{Rh}-\mathrm{N}(1)$ & $93.64(4)$ & $93.88(8)$ \\
\hline $\mathrm{Cl}(1)-\mathrm{Rh}-\mathrm{P}$ & $90.129(18)$ & $87.52(3)$ & $\mathrm{P}-\mathrm{Rh}-\mathrm{N}(2)$ & $96.59(5)$ & $97.35(8)$ \\
\hline $\mathrm{Cl}(1)-\mathrm{Rh}-\mathrm{N}(1)$ & $173.35(4)$ & $173.74(8)$ & $\mathrm{N}(1)-\mathrm{Rh}-\mathrm{N}(2)$ & $81.93(6)$ & $81.85(11)$ \\
\hline $\mathrm{Cl}(1)-\mathrm{Rh}-\mathrm{N}(2)$ & $92.20(5)$ & $91.93(8)$ & & & \\
\hline
\end{tabular}

It is noteworthy to point out that the $\mathrm{Rh}-\mathrm{Cl}(1)$ and $\mathrm{Rh}-\mathrm{Cl}(2)$ bond lengths are similar (close to $2.34 \AA$ ) but, due to the stronger structural trans influence of phosphanes compared to amines or pyridines, the $\mathrm{Rh}-\mathrm{Cl}(3)$ bond length is significantly longer, about $2.43 \AA$ A. Similar disparity between $\mathrm{Rh}-\mathrm{Cl}$ bond lengths has been reported in related complexes. Thus, while in a tris(2-pyridylmethyl)amine rhodium complex, ${ }^{19}$ $\mathrm{Rh}-\mathrm{Cl}$ distances of 2.332(1) and 2.362(1) $\AA$ have been measured for $\mathrm{Rh}(\mathrm{III})-\mathrm{Cl}$ bonds trans to $\mathrm{N}_{\mathrm{py}}$ and $\mathrm{N}_{\mathrm{am}}$ atoms, respectively, a Rh-Cl distance of 2.425(14) $\AA$ has been reported for the $\mathrm{Rh}(\mathrm{III})-\mathrm{Cl}$ bond trans to the $\mathrm{PPh}_{3}$ group in $\left[\mathrm{RhCl}_{3}\left(N, N^{\prime}-1\right.\right.$-alkyl-2(naphthyl- $\alpha$-azo) $\left.\left(\mathrm{PPh}_{3}\right)\right] .{ }^{20}$ The Rh-N bond distances of $\mathbf{1} \mathbf{b} / \mathbf{1} \mathbf{b}$ ' and $\mathbf{3 b} / \mathbf{3 b}$ ' lie in the range 2.0366(15)-2.164(3) $\AA$, with the $\mathrm{Rh}-\mathrm{N}_{\mathrm{am}}$ elongated compared to the $\mathrm{Rh}-\mathrm{N}_{\mathrm{py}}$ bond length.

The tridentate coordination of the $\mathbf{L H}$ ligand gives rise to the formation of two fused five- and six-membered metallacycles. The former adopts a ${ }^{2} \mathrm{E}$ envelop conformation in both complexes $\mathbf{1 b}$ and $\mathbf{3 b}$, with a distortion towards twisted ${ }^{2} \mathrm{~T}_{3}$ in 
3b. ${ }^{21 \mathrm{c}}$ In both complexes, the six-membered ring is strongly puckered as indicated by the high puckering amplitude (0.816(2) $\AA$ in $\mathbf{1 b}$ and 0.825(3) $\AA$ in $\mathbf{3 b}) .^{21 \mathrm{~d}}$ The out-ofplane deformation of the metallacycle ${ }^{21 d}$ could be described as a ${ }^{2,5} \mathrm{~B}$ boat conformation in both isomers. As a consequence of crystal symmetry enantiomeric conformations are observed for 1b’ and 3b’.

The main structural difference between complexes $\mathbf{1 b}$ and $\mathbf{3 b}$ concerns the geometrical arrangement of the benzyl substituent of the ligand $\mathbf{L H}$ as evidenced by Rh$\mathrm{N}(1)-\mathrm{C}(26)-\mathrm{C}(27)$ and $\mathrm{N}(1)-\mathrm{C}(26)-\mathrm{C}(27)-\mathrm{C}(28)$ torsion angles of $-164.36(13)^{\circ}$ and $-142.6(2)^{\circ}$ and of $-98.7(2)^{\circ}$ and $-84.2(2)^{\circ}$ in $\mathbf{1 b}$ and $\mathbf{3 b}$, respectively. Probably, packing interactions are responsible for this behaviour.

\section{DFT calculations on the trichlorido complexes 1-4}

DFT calculations were carried out in order to assess the relative stability of the isomers of the complexes $\left[\mathrm{MCl}_{3}\left(\kappa^{3} N, N^{\prime}, P-\mathbf{L H}\right)\right](\mathbf{1 - 4})$. Table 2 shows the relative free energy values for the mer (1a-4a) and the fac (1b-4b and $\mathbf{1 c}-\mathbf{4 c})$ isomers of both rhodium and iridium complexes. For the fac isomers $\mathbf{1 b}-\mathbf{4 b}$, two conformations of the six-membered Rh-P-C-C-C-N ring, namely ${ }^{2,5} \mathrm{~B}$ and $\mathrm{B}_{2,5}$, have been encountered.

In agreement with the crystal structures of compounds $\mathbf{1 b}$ and $\mathbf{3 b}$, in all the cases, the pair of fac enantiomers $\left(S_{\mathrm{Nam}}\right)-O C-6-43-C$ and $\left(R_{\mathrm{Nam}}\right)-O C-6-43-A(\mathbf{1 b}-\mathbf{4 b})$ with a ${ }^{2,5} \mathrm{~B}$ conformation of the Rh-P-C-C-C-N ring is more stable than the pair of mer enantiomers $\left(S_{\text {Nam }}\right)$-OC-6-41 and $\left(R_{\text {Nam }}\right)$-OC-6-41 (1a-4a). Interestingly, the pair of the ( $\left.S_{\text {Nam }}\right)$-OC-6-43-C and $\left(R_{\mathrm{Nam}}\right)$-OC-6-43-A enantiomers with a $\mathrm{B}_{2,5}$ conformation of the Rh-P-C-C-C-N ring was found to be slightly less stable than the pair with a ${ }^{2,5} \mathrm{~B}$ conformation. Also, the pair of fac enantiomers $\left(S_{\mathrm{Nam}}\right)-O C-6-43-A$ and $\left(R_{\mathrm{Nam}}\right)-O C-6-43-$ 
$C(\mathbf{1 c}-\mathbf{4 c})$ is significantly less stable and, as a consequence, its formation in the reaction between $\mathrm{MCl}_{3}$ and $\mathbf{L H}$ (Eq. 1) can be ruled out.

Table 2

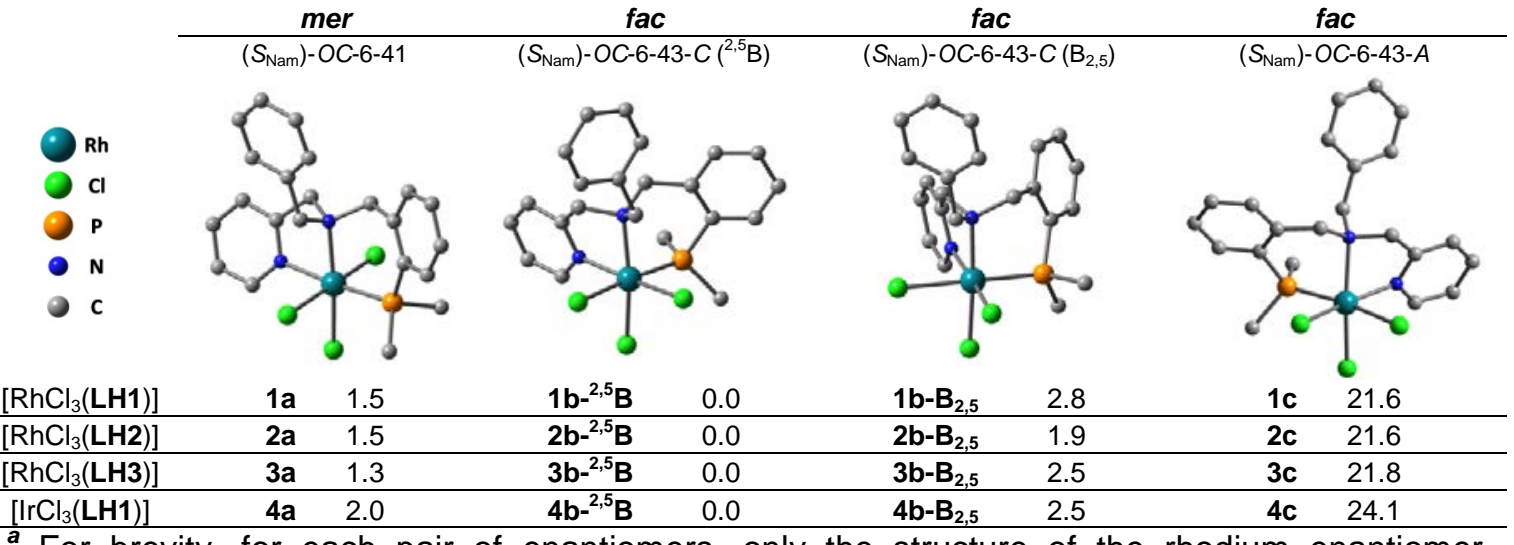

For brevity, for each pair of enantiomers, only the structure of the rhodium enantiomer containing LH1 with an S configuration of the aminic nitrogen is shown, the others being similar (see ESI). For clarity, all hydrogen atoms are omitted.

The mechanism of the conformational equilibrium ${ }^{2,5} \mathrm{~B} \leftrightarrows \mathrm{B}_{2,5}$ has been elucidated only in the case of complex $\left[\mathrm{RhCl}_{3}\left(\kappa^{3} N, N^{\prime}, P-\mathbf{L H 1}\right)\right](\mathbf{1 b})$. On one hand, the $\mathrm{Rh}-\mathrm{P}$ dissociation in $\mathbf{1 b}-{ }^{2,5} \mathbf{B}$ is highly endoergonic $\left(\Delta \mathrm{G}_{\mathrm{dis}}=33.9 \mathrm{kcal} \cdot \mathrm{mol}^{-1}\right.$, vide infra $)$, thus a dissociative mechanism could not be operative. On the other hand, a non-dissociative mechanism with a transition state exhibiting an almost planar six-membered Rh-P-C-CC-N ring (TS_ ${ }_{-}^{2,5} \mathbf{B}-\mathbf{B}_{2,5}$, Figure 2 ) has been found to be kinetically accessible $\left(\Delta \mathrm{G}^{\ddagger}=\right.$ $16.9 \mathrm{kcal} \cdot \mathrm{mol}^{-1}$, $298 \mathrm{~K}$ ). Also, the low activation barrier for the equilibrium ${ }^{2,5} \mathrm{~B} \leftrightarrows \mathrm{B}_{2,5}$ suggests that it should be fast at room temperature thus causing averaged NMR spectra and preventing the direct observation of the two non-equivalent conformers. 

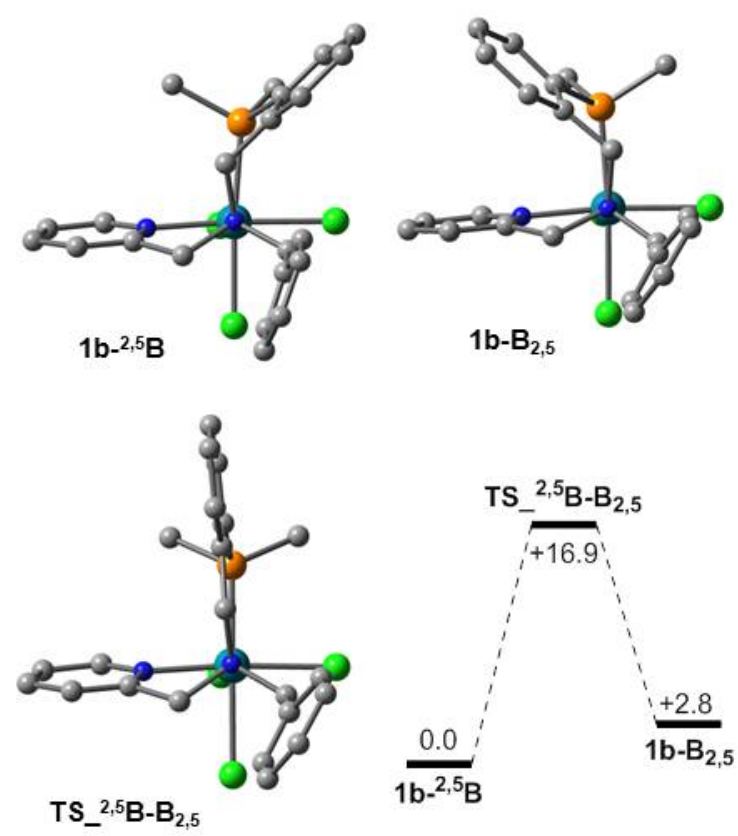

$\mathrm{Rh} \odot \mathrm{Cl} \bigcirc \mathrm{P} \odot \mathrm{N} \odot \mathrm{C}$

Fig. 2 View along the $N_{a m}-R h$ bond of $1 \mathbf{b}^{-}{ }^{2,5} \mathbf{B}, \mathbf{1} \mathbf{b}-\mathbf{B}_{2,5}$ and of the transition state of the equilibrium ${ }^{2,5} \mathrm{~B} \leftrightarrows \mathrm{B}_{2,5}$, and its free energy profile $\left(\mathrm{kcal} \cdot \mathrm{mol}^{-1}, 298 \mathrm{~K}\right.$, ethanol). For clarity all hydrogen atoms have been omitted and only the ipso carbon atoms of the $\mathrm{PPh}_{2}$ moieties are shown.

The mechanism of the mer $\rightarrow f a c$ isomerization of $\left[\mathrm{MCl}_{3}\left(\kappa^{3} N, N^{\prime}, P-\mathbf{L H}\right)\right](\mathbf{1 - 4})$, namely the transformation of the isomer $\left(S_{\mathrm{Nam}}\right)-O C-6-41$ into the isomer $\left(S_{\mathrm{Nam}}\right)-O C-6$ 43- $C\left({ }^{2,5} \mathrm{~B}\right)$ was also elucidated. As mentioned before, in spite of the similar structure determined for the rhodium and iridium complexes, the isomerization is observed only for the rhodium complexes 1a-3a but not for the iridium derivative 4a. On this background, mer-[RhCl $\left.{ }_{3}\left(\kappa^{3} N, N^{\prime}, P-\mathbf{L H 1}\right)\right]$ (1a) and $\operatorname{mer}-\left[\operatorname{IrCl}_{3}\left(\kappa^{3} N, N^{\prime}, P-\mathbf{L H 1}\right)\right]$ (4a) have been chosen as the reference compounds and three different dissociative pathways have been considered. Figure 3 shows the intermediates and their relative free energies 

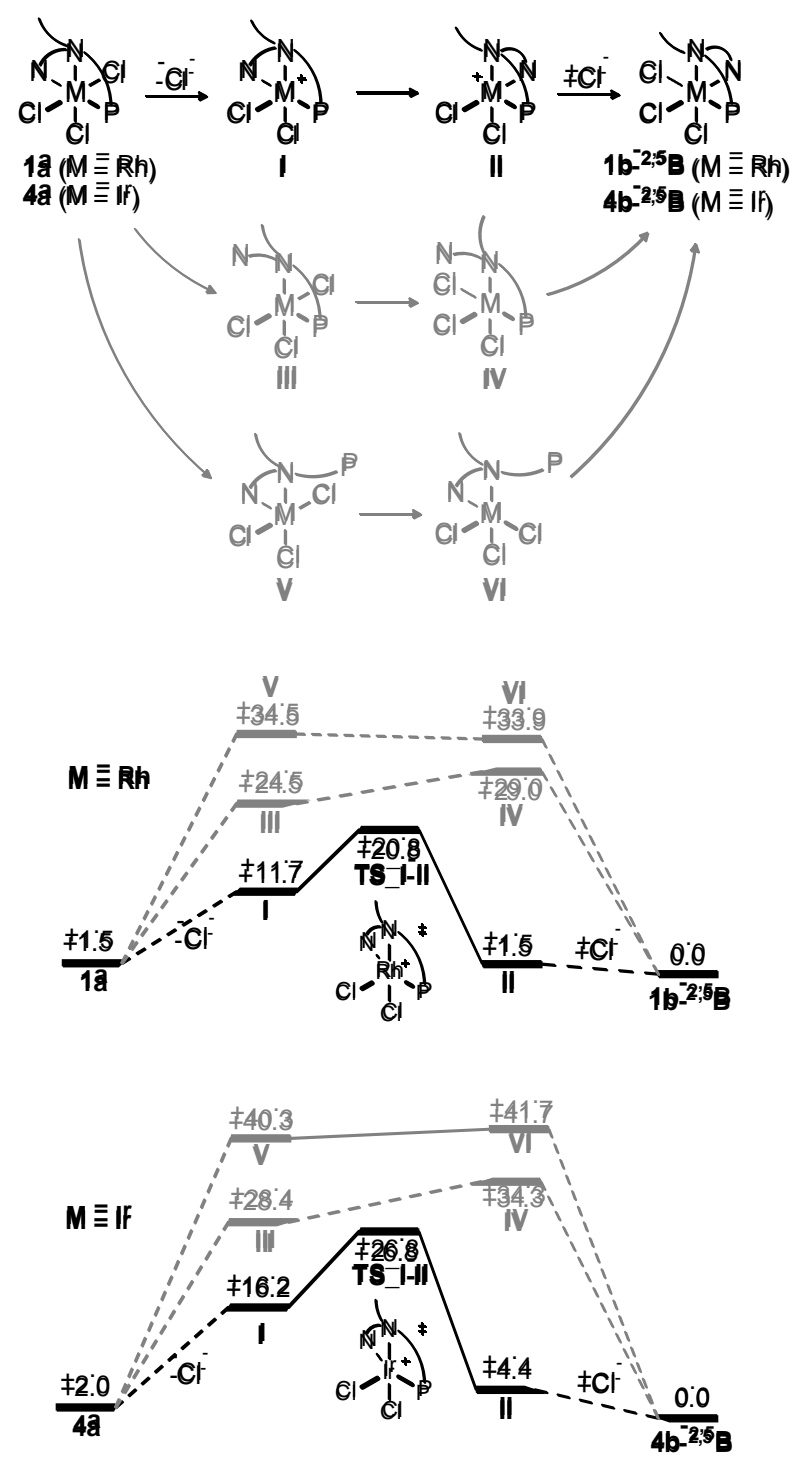

Fig. 3 Dissociative pathways for the isomerization mer-[MCl $\left.\mathrm{MC}_{3}\left(\kappa^{3} N, N^{\prime}, P-\mathrm{LH} \mathbf{1}\right)\right] \leftrightarrows$ fac$\left[\mathrm{MCl}_{3}\left(\mathrm{~K}^{3} \mathrm{~N}, \mathrm{~N}^{\prime}, P-\mathrm{LH} 1\right)\right](\mathrm{M}=\mathrm{Rh}, \mathrm{Ir})$ and the corresponding free energy profiles $\left(\mathrm{kcal} \cdot \mathrm{mol}^{-1}, 298\right.$ $\mathrm{K}$, ethanol).

for the pathways via chlorido dissociation (intermediates I and II), via pyridinic nitrogen dissociation (intermediates III and IV) and via phosphorus dissociation (intermediates $\mathbf{V}$ and $\mathbf{V I}$ ). In addition, the transition state for the isomerization $\mathbf{I} \rightarrow \mathbf{I I}$ (see Figure 3) has been calculated (TS_I-II: +19.3 (Rh) or +24.8 (Ir) $\mathrm{kcal} \cdot \mathrm{mol}^{-1}$ vs. the isomer 1a or $\mathbf{4 a}$, respectively). ${ }^{22}$

The data given in Figure 3 indicate that for both rhodium and iridium the most favourable isomerization pathway starts from the dissociation of one chlorido ligand from the mer isomer 1a or $\mathbf{4 a}$ and is followed by the isomerization of the resulting 
cationic intermediate I to II through the transition state TS_I-II. Eventually, the pentacoordinated cation II reacts with chloride yielding the fac isomer $\mathbf{1} \mathbf{b}_{-}{ }^{2,5} \mathbf{B}$ or $\mathbf{4 b}$ ${ }^{2,5}$ B. Not surprisingly, despite the fact that the reaction pathways for rhodium and iridium are similar, the activation barrier for iridium is significantly higher than for rhodium $\left(\Delta \Delta \mathrm{G}^{\ddagger}=5.5 \mathrm{kcal} \cdot \mathrm{mol}^{-1}\right)$. This value reasonably accounts for the experimentally not observed isomerization of $\operatorname{mer}-\left[\operatorname{IrCl}_{3}\left(\kappa^{3} N, N^{\prime}, P-\mathbf{L H 1}\right)\right](\mathbf{4 a})$ in the mixture obtained from the reaction of $\operatorname{IrCl}_{3} \cdot \mathrm{xH}_{2} \mathrm{O}$ and $\mathbf{L H 1}$ (Eq. 1). ${ }^{23}$

Synthesis of the cyclometallated dichloride compounds $\left[\mathrm{MCl}_{2}\left(\kappa^{4} C, N, N^{\prime}, P-\mathrm{L}\right)\right](\mathrm{M}$ = Rh, L = L1 (5), L2 (6), L3 (7); M = Ir, L = L1 (8))

Refluxing in ethanol for $3 \mathrm{~h}$ suspensions of the fac isomers $\mathbf{1 b}$-3b or of mer/fac mixtures of the rhodium trichlorido complexes $\left[\mathrm{RhCl}_{3}\left(\kappa^{3} N, N^{\prime}, P-\mathbf{L H}\right)\right]$ in the presence of 3 equivalents of $\mathrm{NaOAc}$ afforded the corresponding cyclometallated dichloridos $\left[\mathrm{RhCl}_{2}\left(\kappa^{4} C, N, N^{\prime}, P-\mathbf{L}\right)\right](\mathbf{L}=\mathbf{L 1}$ (5), $\mathbf{L 2}$ (6), $\mathbf{L 3}$ (7)). The iridium analogue $\left[\operatorname{IrCl}_{2}\left(\kappa^{4} C, N, N^{\prime}, P-\mathbf{L 1}\right)\right](8)$ was prepared by heating a solution of a mer/fac mixture of $\left[\operatorname{IrCl}_{3}\left(\kappa^{3} N, N^{\prime}, P-\mathbf{L H 1}\right)\right](\mathbf{4 a}+\mathbf{4 b})$, at $170{ }^{\circ} \mathrm{C}$, in decahydronaphthalene, for $48 \mathrm{~h}$, in the presence of 3 equivalents of $\mathrm{CF}_{3} \mathrm{COONa}$. Under these conditions, complex 8 was isolated together with about a $30 \%$ of an uncharacterized $\mathrm{CF}_{3} \mathrm{COO}^{-}$containing iridium complex. Treatment of this mixture with excess of $\mathrm{HCl}$ gave pure 8 in $72 \%$ isolated yield. Taking into account that the mer to fac isomerization of the iridium compound $\mathbf{4}$ was scant even under harsh conditions (see above), the high yield achieved for the cyclometallated compound $\mathbf{8}$ suggests that a direct pathway from the mer iridium isomer was operating. ${ }^{24}$

Metallation of the methoxo and trifluoromethyl substituted ligands LH2 and LH3 could take place at the C-2 or at C-4 carbons of the benzyl arm (see Schemes 3 and 4). 
However, in the formation of complexes 6 and 7 only metallation at C-4 carbon has been observed in both cases (see DFT calculations below).

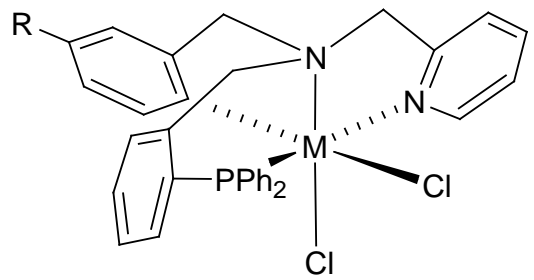

$\left(R_{\mathrm{Nam}}\right)-\mathrm{OC}-6-54-\mathrm{C}$

$M=R h ; R=H(5), O M e(6), C F_{3}(7)$ $M=I r ; R=H(8)$

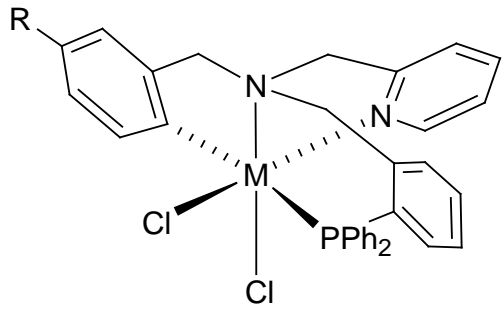

$\left(R_{\mathrm{Nam}}\right)-O C-6-43-\mathrm{C}$

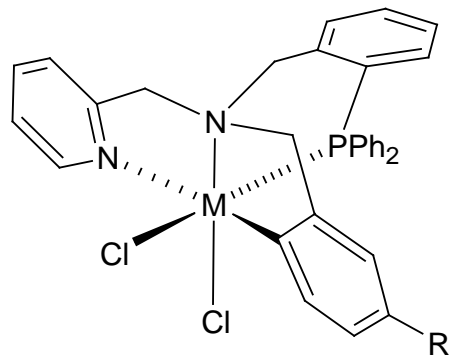

$\left(R_{\text {Nam }}\right)-O C-6-42-A$

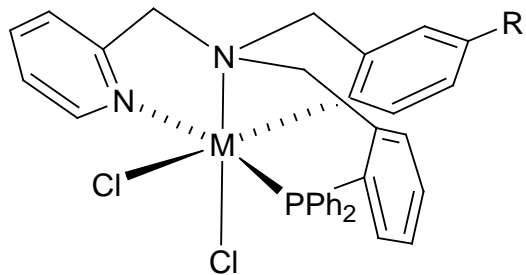

$\left(S_{\text {Nam }}\right)-O C-6-54-A$

$\mathrm{M}=\mathrm{Rh} ; \mathrm{R}=\mathrm{H}\left(\mathbf{5}^{\prime}\right), \mathrm{OMe}\left(6^{\prime}\right), \mathrm{CF}_{3}\left(7^{\prime}\right)$

$\mathrm{M}=\mathrm{Ir} ; \mathrm{R}=\mathrm{H}\left(\mathbf{8}^{\prime}\right)$

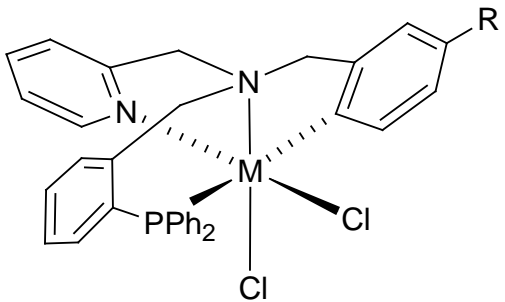

$\left(S_{\mathrm{Nam}}\right)-O C-6-43-A$

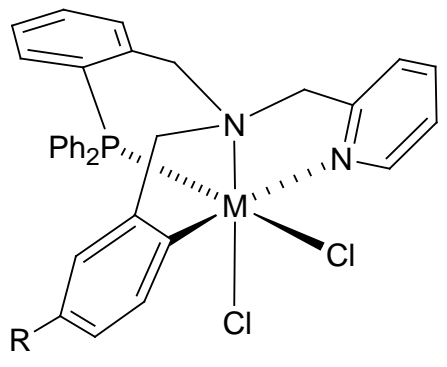

$\left(S_{\mathrm{Nam}}\right)-O C-6-42-C$

Scheme 4 Cyclometallated dichlorido isomers.

Scheme 4 shows the three pairs of diastereomeric enantiomers that could form by metallation of the trichloridos 1-4. However, only the isomers 5/5'-8/8' were detected. The new complexes were characterized by analytical and spectroscopic means (see Experimental Section). The three methylene groups of protons are diastereotopic and, at a spectrometer frequency of $500 \mathrm{MHz}$, resonate as AX systems. The value of the $J(\mathrm{PH})$ coupling constant together with COSY, HSQC and HMBC experiments permit the 
assignment of the six protons which have been labelled as $\mathrm{CH}_{2}(\mathrm{Py}), \mathrm{CH}_{2}(\mathrm{Ph})$ and $\mathrm{CH}_{2}(\mathrm{P})$ (see Scheme 5A). The NOE pattern for the six methylene protons (Scheme 5B, see ESI) is only compatible with the pair of enantiomers $\left(R_{\mathrm{Nam}}\right)-O C-6-54-C$ and $\left(S_{\mathrm{Nam}}\right)$ OC-6-54-A in which the phosphorus and the pyridinic nitrogen atoms are mutually trans (see Scheme 4). Accordingly, a $J(\mathrm{PH})$ coupling constant of about $5 \mathrm{~Hz}$ was measured in all cases for the proton- 6 of the pyridine moiety. Hence, we propose that the only obtained compounds are racemic mixtures of the isomers $\left(R_{\mathrm{Nam}}\right)-O C-6-54-C$ and $\left(S_{\mathrm{Nam}}\right)$ OC-6-54-A shown in Scheme 4.

A: Methylene descriptors

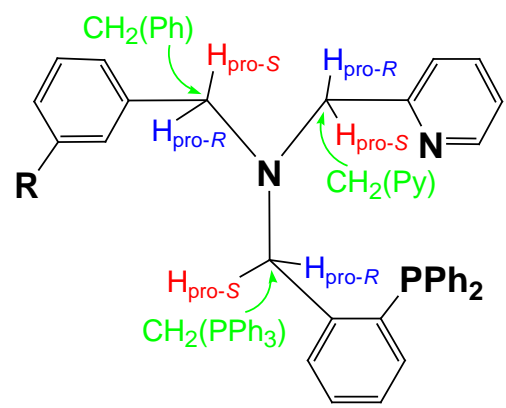

B: NOE pattern

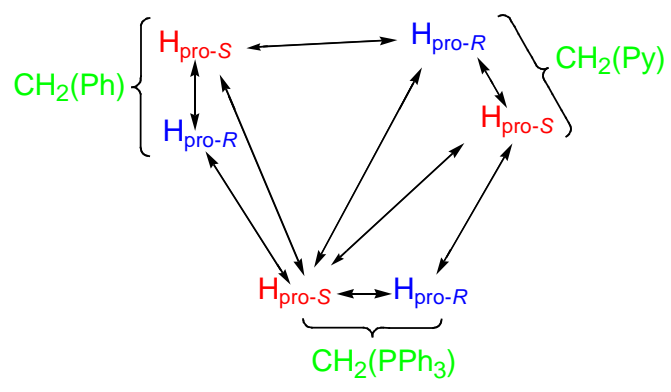

Scheme 5 Assignment of the methylene descriptors $(A)$ and NOE pattern (B) on $\left(R_{\text {Nam }}\right)$-OC-654- $C$ isomers.

The ${ }^{31} \mathrm{P}\left\{{ }^{1} \mathrm{H}\right\}$ NMR spectra consist of a doublet, around 35 ppm with a $J(\mathrm{RhP})$ coupling constant of 126-129 Hz for the rhodium complexes 5-7, and a singlet at -10.07 ppm, for the iridium complex 8 .

Molecular structures of the compounds $\left[\mathrm{MCl}_{2}\left(\kappa^{4} C, N, N^{\prime}, P-\mathrm{L}\right)\right](\mathrm{M}=\mathrm{Rh}, \mathrm{L}=\mathrm{L} 1$ (5/5'), L2 (6'), L3 (7/7'); M = Ir, L = L1 (8(8'))

The crystal structures of the four cyclometallated complexes 5-8 have been determined by X-ray diffraction means. Most of the features of the four molecules are similar. A view of the molecular structure of the four complexes is depicted in Figure 4 and some structural parameters of the metal coordination are listed in Table 3. Their molecular 
structure illustrated distorted-octahedral coordination geometries around the central metal atom. Two chlorido ligands occupy two cis coordination sites and the four donating atoms of the tetradentate ligand complete the coordination metal sphere. As indicated by solution NMR data, the phosphorus atom is trans to the pyridinic nitrogen $\mathrm{N}(2)$, while the chlorine atoms are found to be trans to the aminic nitrogen $\mathrm{N}(1)$ and to the aromatic $\mathrm{C}(28)$ atoms.
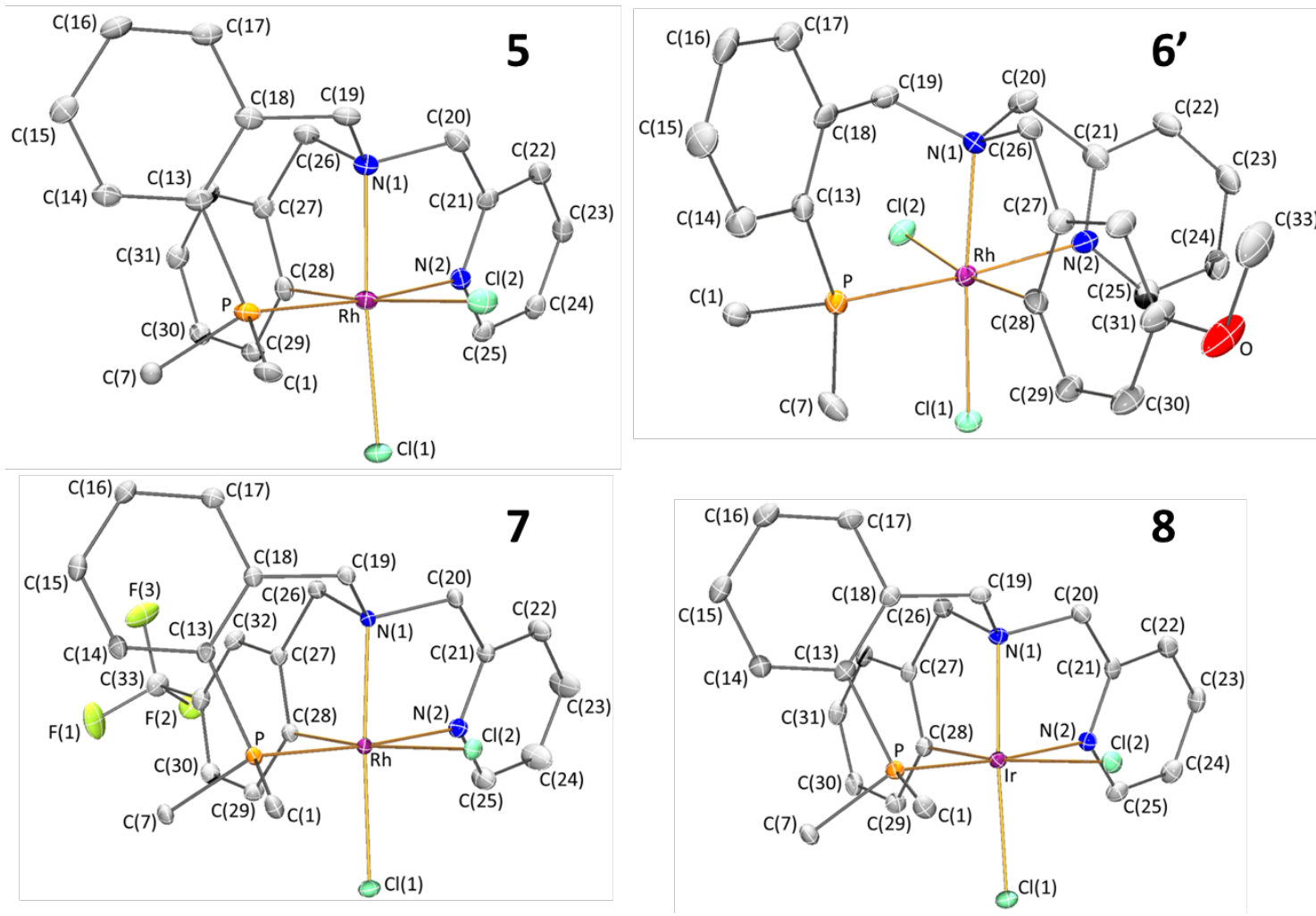

Fig. 4 Molecular structure of the $\left(R_{\text {Nam }}\right)-O C-6-54-C(5,7$ and 8$)$ and $\left(S_{N a m}\right)-O C-6-54-A\left(6^{\prime}\right)$ enantiomers. For clarity hydrogen atoms have been omitted and only the ipso carbons of the $\mathrm{PPh}_{2}$ groups are shown.

The aminic nitrogen and the metal are stereogenic centres. The crystal structure of complexes 5, 7 and 8 contains symmetry planes and, therefore, the enantiomeric pairs of diastereomers 5/5', 7/7' and 8/8' (see Scheme 4) are present in their unit cells (only the unprimed isomers 5, 7 and $\mathbf{8}$ are shown in Figure 4). In contrast, complex 6 crystallizes as a conglomerate: the observed space group is non-centrosymmetric and the unit cell of the chosen crystal only contains the $\mathbf{6}^{\text {' isomer. }}$ 
Due to the strong trans influence of the $\mathrm{sp}^{2}$ carbon atom, the $\mathrm{M}-\mathrm{Cl}(2)$ bond length is significantly longer (by 0.11-0.16 $\AA$ ) than the $\mathrm{M}-\mathrm{Cl}(1)$ bond length.

The tetradentate coordination of the ligand $\mathbf{L}$ leads to the formation of two fivemembered and one six-membered metallacycles. The M-N(1)-C(20)-C(21)-N(2) metallacycle exhibits and ${ }^{2} \mathrm{E}$ envelope conformation (enantiomorphic $\mathrm{E}_{2}$ conformation

Table 3 Bond lengths $(\AA)$ and angles $\left(^{\circ}\right)$ for complexes $5 / 5^{\prime}, 6^{\prime}, 7 / 7^{\prime}$ $(\mathrm{M}=\mathrm{Rh})$ and $\mathbf{8} / \mathbf{8}^{\prime}(\mathrm{M}=\mathrm{Ir})$

\begin{tabular}{|l|c|c|c|c|}
\hline & $\mathbf{5 / 5}$ & $\mathbf{6}^{\prime}$ & $\mathbf{7 / 7}$ & $\mathbf{8 / 8}$ \\
\hline $\mathrm{M}-\mathrm{Cl}(1)$ & $2.3634(13)$ & $2.367(2)$ & $2.3615(7)$ & $2.3714(8)$ \\
\hline $\mathrm{M}-\mathrm{Cl}(2)$ & $2.5221(12)$ & $2.528(2)$ & $2.4794(7)$ & $2.4847(9)$ \\
\hline $\mathrm{M}-\mathrm{P}$ & $2.2728(14)$ & $2.258(3)$ & $2.2620(7)$ & $2.2584(9)$ \\
\hline $\mathrm{M}-\mathrm{N}(1)$ & $2.081(4)$ & $2.084(8)$ & $2.087(2)$ & $2.092(3)$ \\
\hline $\mathrm{M}-\mathrm{N}(2)$ & $2.108(4)$ & $2.112(10)$ & $2.114(3)$ & $2.110(3)$ \\
\hline $\mathrm{M}-\mathrm{C}(28)$ & $2.012(5)$ & $1.997(9)$ & $1.993(3)$ & $2.022(3)$ \\
\hline $\mathrm{Cl}(1)-\mathrm{M}-\mathrm{Cl}(2)$ & $90.68(5)$ & $89.85(8)$ & $92.24(2)$ & $90.10(3)$ \\
\hline $\mathrm{Cl}(1)-\mathrm{M}-\mathrm{P}$ & $92.58(5)$ & $90.50(9)$ & $91.54(2)$ & $91.87(3)$ \\
\hline $\mathrm{Cl}(1)-\mathrm{M}-\mathrm{N}(1)$ & $172.63(14)$ & $175.5(2)$ & $172.66(6)$ & $173.83(8)$ \\
\hline $\mathrm{Cl}(1)-\mathrm{M}-\mathrm{N}(2)$ & $92.21(14)$ & $95.4(3)$ & $92.60(7)$ & $92.96(8)$ \\
\hline $\mathrm{Cl}(1)-\mathrm{M}-\mathrm{C}(28)$ & $94.07(14)$ & $94.6(3)$ & $92.82(8)$ & $94.98(10)$ \\
\hline $\mathrm{Cl}(2)-\mathrm{M}-\mathrm{P}$ & $91.76(5)$ & $98.71(9)$ & $93.40(2)$ & $95.05(3)$ \\
\hline $\mathrm{Cl}(2)-\mathrm{M}-\mathrm{N}(1)$ & $90.60(12)$ & $91.0(2)$ & $90.16(6)$ & $90.55(8)$ \\
\hline $\mathrm{Cl}(2)-\mathrm{M}-\mathrm{N}(2)$ & $92.10(11)$ & $85.5(2)$ & $88.16(7)$ & $84.28(8)$ \\
\hline $\mathrm{Cl}(2)-\mathrm{M}-\mathrm{C}(28)$ & $174.94(15)$ & $172.1(3)$ & $173.75(8)$ & $170.49(10)$ \\
\hline $\mathrm{P}-\mathrm{M}-\mathrm{N}(1)$ & $94.64(14)$ & $93.7(2)$ & $95.24(6)$ & $94.19(8)$ \\
\hline $\mathrm{P}-\mathrm{M}-\mathrm{N}(2)$ & $173.82(13)$ & $172.8(3)$ & $175.52(6)$ & $175.12(9)$ \\
\hline $\mathrm{P}-\mathrm{M}-\mathrm{C}(28)$ & $89.75(13)$ & $87.8(3)$ & $90.12(7)$ & $92.81(10)$ \\
\hline $\mathrm{N}(1)-\mathrm{M}-\mathrm{N}(2)$ & $80.50(19)$ & $80.3(3)$ & $80.54(9)$ & $80.99(11)$ \\
\hline $\mathrm{N}(1)-\mathrm{M}-\mathrm{C}(28)$ & $84.46(18)$ & $84.2(4)$ & $84.37(10)$ & $83.55(13)$ \\
\hline $\mathrm{N}(2)-\mathrm{M}-\mathrm{C}(28)$ & $86.00(17)$ & $87.6(4)$ & $87.96(10)$ & $87.42(12)$ \\
\hline
\end{tabular}

in complex $\mathbf{6}$ ') with puckering parameters similar to those found for complexes $\mathbf{1 b}$ and 3b. ${ }^{25}$ The M-N(1)-C(26)-C(27)-C(28) metallacycle is almost planar, as indicated by the value of the puckering amplitude (a maximal value of 0.045(5) $\AA$ is observed in 5). ${ }^{25 b}$ The six-membered metallacycle in the dichlorido complexes 5-8 is less distorted from planarity than that of the trichlorido compounds $\mathbf{1 b}$ and $\mathbf{3 b}$, as the puckering amplitudes found in 5-8, in the range 0.531(5)-0.695(9) $\AA$, ${ }^{25 c}$ are significantly smaller than the values reported in complexes $\mathbf{1 b}$ and $\mathbf{3 b}, 0.816(2)$ and $0.825(3) \AA$, respectively. The conformation of this six-membered ring in $\mathbf{5}, \mathbf{7}$ and $\mathbf{8}$ shows a skew disposition $\left({ }^{5} \mathrm{~S}_{6}\right)$ 
with a slight distortion towards a ${ }^{2,5} \mathrm{~B}$ conformation. As expected, complex 6' shows an enantiomeric ${ }^{6} \mathrm{~S}_{5}$ (slighted distorted towards $\mathrm{B}_{2,5}$ ) conformation.

Taking into account the potential application of these compounds as catalyst precursors in asymmetric transformations, it is interesting to point out that the phenyl groups of the phosphano arm of the ligand $\mathbf{L}$ shields one of the faces of the coordination plane containing both chlorido ligands. However, the other face of this plane remains essentially clear. Hence, if a prochiral planar chelate replaces the chlorido ligands, one of its enantiofaces would be better shielded than the other and, therefore, enantioselective attacks would be anticipated.
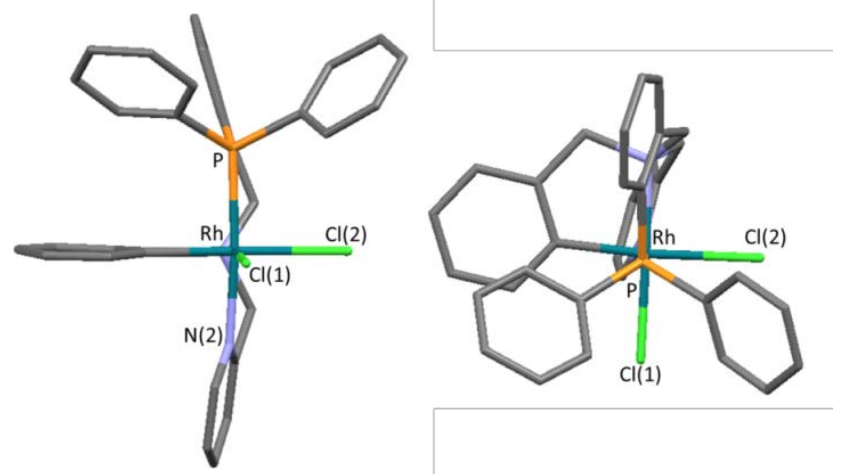

Fig. 5 Views of isomer 5 , $\left(R_{\mathrm{Nam}}\right)-O C-6-54-C$, along the $\mathrm{Cl}(1)-\mathrm{Rh}$ and $\mathrm{P}-\mathrm{Rh}$ directions. Similar projections are obtained for complexes 6-8.

\section{DFT calculations on the dichlorido complexes $\operatorname{MCl}_{2}\left(\kappa^{4} C, N, N^{\prime}, P-\mathrm{L}\right)$}

Table 4 shows the relative free energies of the isomers of $\left[\mathrm{MCl}_{2}\left(\kappa^{4} C, N, N^{\prime}, P-\mathbf{L}\right)\right](\mathrm{M}=$ Rh, $\mathbf{L}=\mathbf{L 1}, \mathbf{L 2}, \mathbf{L 3} ; \mathbf{M}=\mathrm{Ir}, \mathbf{L}=\mathbf{L 1}$ ) taking into account the configurations of the metal centre $(A, C)$ and of the aminic nitrogen atom $(S, R)$. Notably, in agreement with the crystal structure of 5-8, for all the ligands, the pair $\left(R_{\mathrm{Nam}}\right)-O C-6-54-C /\left(S_{\mathrm{Nam}}\right)-O C-6-54-A$ is the most stable. In addition, as far as $\mathbf{L} \mathbf{2}$ and $\mathbf{L 3}$ are concerned, the higher stability of the derivatives in which the C-4 carbon is metallated in comparison with the corresponding C-2 carbon metallated isomers (Table 4) fairly holds with the observed 
regioselectivity of the cyclometallation reaction in both $\left[\mathrm{RhCl}_{3}\left(\kappa^{3} N, N^{\prime}, P-\mathbf{L H} 2\right)\right]$ and $\left[\mathrm{RhCl}_{3}\left(\kappa^{3} N, N^{\prime}, P-\mathbf{L H} 3\right)\right]$.

Table 4
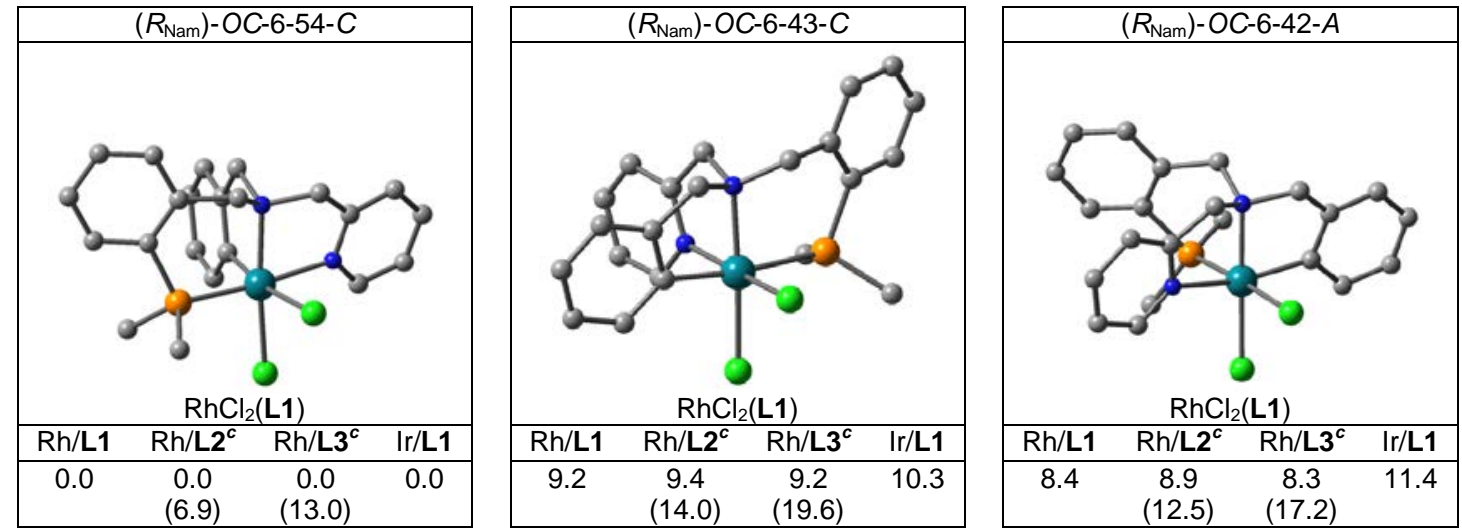

Rh

${ }^{a}$ At $298 \mathrm{~K}$, ethanol for rhodium complexes, cyclohexane for iridium complexes. ${ }^{b}$ For brevity, for each pair of enantiomers only the structure of the rhodium enantiomer containing L1 with an $R$ configuration of the aminic nitrogen is shown, the others being similar (see ESI). For clarity, all hydrogen atoms are omitted and only ipso carbon atoms of the $\mathrm{PPh}_{2}$ moieties are shown. ${ }^{c}$ The first free energy value given for $\mathbf{L} \mathbf{2}$ and $\mathbf{L} 3$ corresponds to the regioisomer containing metallated $\mathrm{C}-4$ and the other (between brackets) corresponds to the regioisomer containing metallated C2.

\section{DFT calculations on the metallation mechanism}

When dealing with the mechanism of the cyclometallation reaction in the complexes $\left[\mathrm{MCl}_{3}\left(\kappa^{3} N, N^{\prime}, P-\mathbf{L H}\right)\right]$ (1-4), DFT calculations indicate that it follows the acetateassisted mechanism which has already been described for late transition metal acetato complexes. ${ }^{25}$ Figure 6 (A, B) shows the independent pathways for both the mer and fac isomers of $\left[\mathrm{RhCl}_{3}\left(\kappa^{3} N, N^{\prime}, P-\mathbf{L H 1}\right)\right]$. Starting from the fac isomer $\left(\mathbf{1 b}-{ }^{2,5} \mathbf{B}\right)$, the $\kappa^{2} \mathrm{O}, \mathrm{O}^{\prime}$-acetato derivative $\left[\mathrm{RhCl}\left(\kappa^{2} \mathrm{O}, \mathrm{O}^{\prime}-\mathrm{CH}_{3} \mathrm{COO}\right)\left(\kappa^{3} N, N^{\prime}, P-\mathbf{L H 1}\right)\right]^{+}$(VIIb) forms and eventually converts into VIIIb. Remarkably the acetato ligand of VIIIb exhibits a monodentate coordination mode and takes part in an intramolecular $\mathrm{CH} \cdots \mathrm{O}$ interaction (Figure 6C). In addition, a weak $\mathrm{CH} \cdots \mathrm{Rh}$ agostic interaction is present as well. Selected bond lengths and angles of VIIIb are given in Figure 6 and are similar to those already 
reported in related systems. ${ }^{25 a, d-g}$ In the following step, the metallation reaction takes place via a concerted mechanism with the transition state TS_VIII-IXb shown in Figure 6C. As a result of the activation, the cation $\left[\mathrm{RhCl}\left(\kappa^{4} C, N, N^{\prime}, P-\mathbf{L 1}\right)\left(\kappa O-\mathrm{CH}_{3} \mathrm{COOH}\right)\right]^{+}(\mathbf{I X b})$ is obtained, which finally reacts with

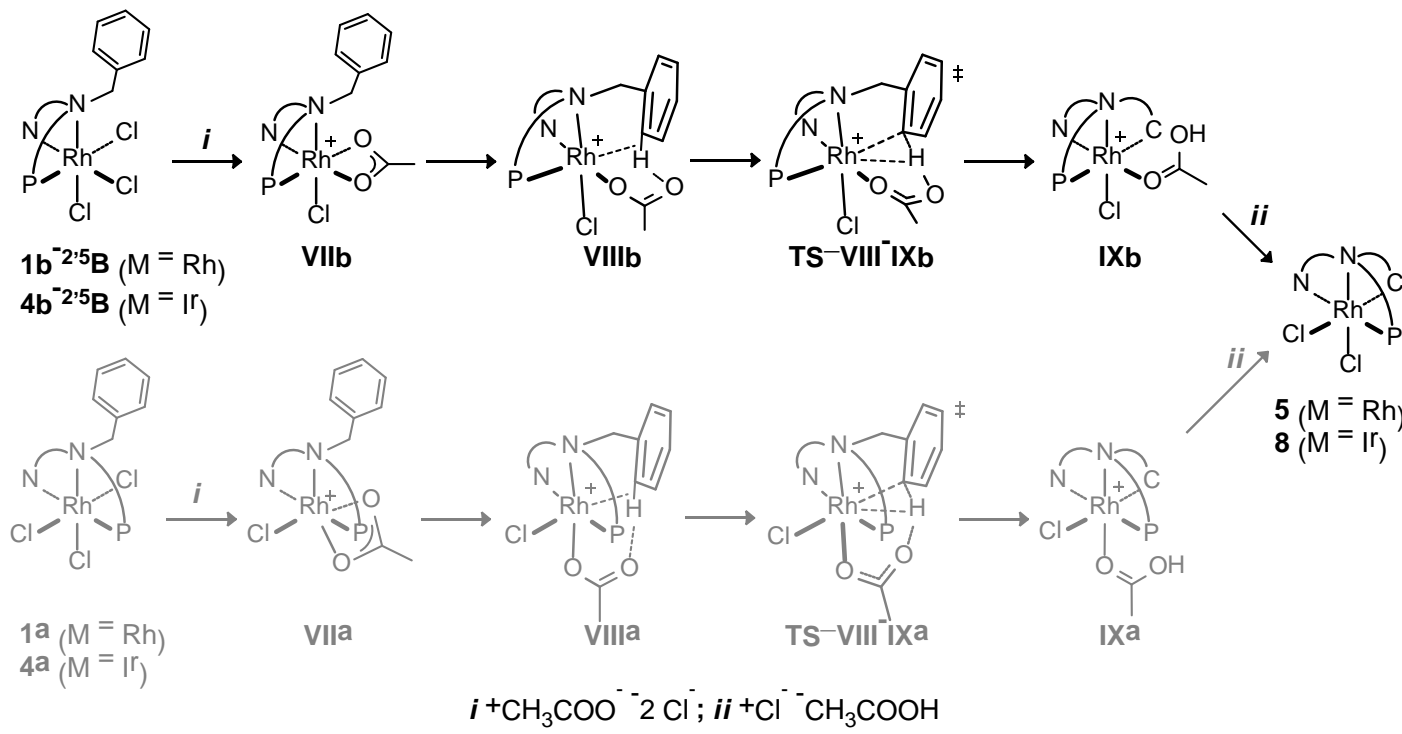

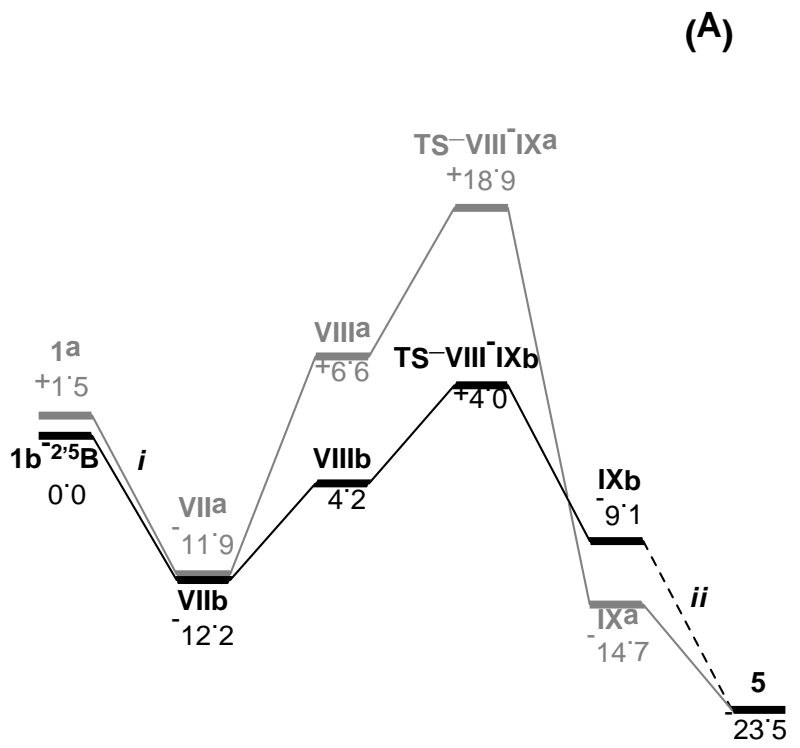

(B)
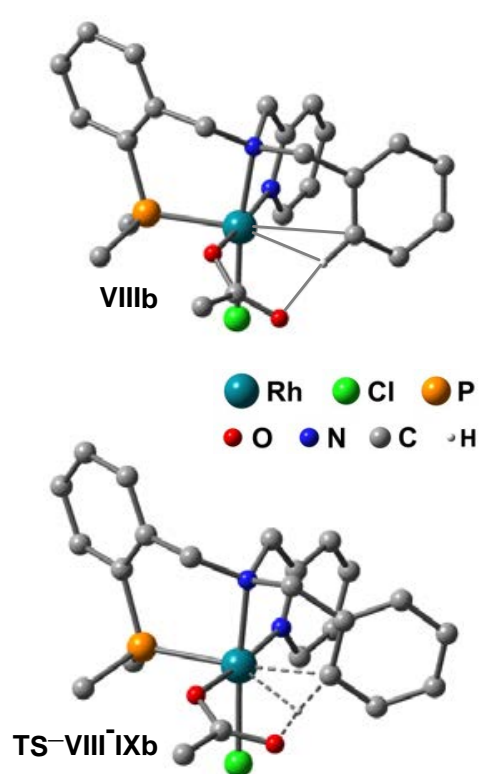

(C)

Fig. 6 (A) Intermediates and transition states of the acetate-assisted cyclometallation of fac$\left[\mathrm{RhCl}_{3}\left(\mathrm{~K}^{3} \mathrm{~N}, \mathrm{~N}^{\prime}, P-\mathrm{LH} \mathbf{1}\right)\right]$ (black, $\left.\mathbf{1} \mathbf{b}_{-}{ }^{2,5} \mathrm{~B}\right)$ and mer-[RhCl $\left.{ }_{3}\left(\mathrm{~K}^{3} \mathrm{~N}, \mathrm{~N}^{\prime}, P-\mathrm{LH} 1\right)\right]$ (grey, 1a). (B) Free energy profiles (kcal. $\mathrm{mol}^{-1}, 298 \mathrm{~K}$, ethanol). (C) Calculated structures of the cation VIIIlb and of TS_VIII-IXb. For clarity, most hydrogen atoms are omitted and only ipso carbon atoms of the $\mathrm{PPh}_{2}$ moieties are shown. Selected bond lengths $(\AA)$ and angles $\left(^{\circ}\right)$ are: VIIIb Rh...C 2.83,

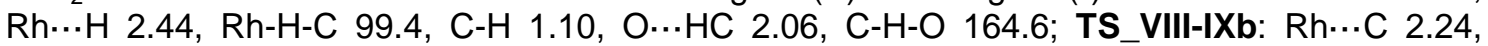

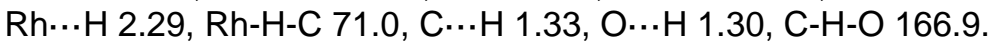


chloride releasing acetic acid and yielding the final product $\left[\mathrm{RhCl}_{2}\left(\kappa^{4} C, N, N^{\prime}, P-\mathbf{L 1}\right)\right]$ (5). It is noteworthy that in the course of the transformation of $\mathbf{I X b}$ into $\mathbf{5}$ a rearrangement of the metallated ligand should take place (vide infra).

The pathway from mer-[RhCl $\left.3\left(\kappa^{3} N, N^{\prime}, P-\mathbf{L H 1}\right)\right]$ (Figure 6A, B) fairly parallels the pathway described for the fac isomer. Indeed, the acetato derivative VIIa forms and converts into the intermediate VIIIa containing a $\mathrm{CH} \cdots \mathrm{O}$ interaction, which gives place to the concerted transition state TS_VIII-IXa. In the following step, the cationic intermediate $\left[\mathrm{RhCl}\left(\kappa^{4} C, N, N^{\prime}, P-\mathbf{L 1}\right)\left(\kappa O-\mathrm{CH}_{3} \mathrm{COOH}\right)\right]^{+}$(IXa) is obtained which finally undergoes a substitution reaction with chloride, losing the coordinated acetic acid and yielding $\mathbf{5}$. At variance with the step $\mathbf{I X b}+\mathrm{Cl}^{-} \rightarrow \mathbf{5}+\mathrm{CH}_{3} \mathrm{COOH}$, no rearrangement of the metallated ligand takes place in the reaction of IXa with chloride.

On this background, despite the fact that the pathway from mer$\left[\mathrm{RhCl}_{3}\left(\kappa^{3} N, N^{\prime}, P-\mathbf{L H 1}\right)\right]$ (1a) is more straightforward than that starting from fac$\left[\mathrm{RhCl}_{3}\left(\kappa^{3} N, N^{\prime}, P-\mathbf{L H 1}\right)\right](\mathbf{1 b})$, the difference between the calculated activation barriers of the $\mathrm{CH}$ cleavage $\left(\Delta \Delta \mathrm{G}^{\ddagger}=14.6 \mathrm{kcal} \cdot \mathrm{mol}^{-1}\right)$ makes the pathway from the mer isomer not operative. Thus, on one hand, when a pure sample of $\mathbf{1 b}$ is used, $\mathbf{5}$ should be obtained straightforwardly through the pathway $\mathbf{1 b} \rightarrow$ VIIb $\rightarrow$ VIIIb $\rightarrow$ TS_VIII$\mathbf{I X b} \rightarrow \mathbf{I X b} \rightarrow \mathbf{5}$ depicted in Figure 6A. On the other hand, when the mer/fac mixture $\mathbf{1 a}+\mathbf{1 b}$ obtained from the reaction between $\mathrm{RhCl}_{3} \cdot \mathrm{xH}_{2} \mathrm{O}$ and $\mathbf{L H 1}$ (Eq. 1) is used as the starting material, the isomerization of the mer isomer $\mathbf{1 a}$ to the fac isomer $\mathbf{1 b}$ should take place in the first place and thereafter the resulting fac isomer should undergo the cyclometallation reaction.

With respect to the rearrangement of the metallated ligand from $\left[\mathrm{RhCl}\left(\kappa^{4} C, N, N^{\prime}, P-\mathbf{L 1}\right)\left(\kappa O-\mathrm{CH}_{3} \mathrm{COOH}\right)\right]^{+}(\mathbf{I X b})$ to $\left[\mathrm{RhCl}_{2}\left(\kappa^{4} C, N, N^{\prime}, P-\mathbf{L 1}\right)\right]$ (5), the proposed acetate catalysed mechanism is depicted in Figure 7. The coordinated acetic 
acid in $\mathbf{I X b}$ is deprotonated by free acetate affording the acetato derivative $\mathbf{X b}$, which undergoes the stepwise isomerization $\mathbf{X b} \rightarrow \mathbf{X I} \mathbf{b} \rightarrow \mathbf{X I I} \mathbf{b}$ in which the coordination mode of the acetato ligand goes through the sequence $\kappa O(\mathbf{X b}) \rightarrow \kappa^{2} O, O^{\prime}(\mathbf{X I b}) \rightarrow \kappa O^{\prime}(\mathbf{X I I b})$ and, in a simultaneous way, the phosphorus atom, initially trans to carbon ( $\mathbf{X b})$, dissociates and eventually coordinates to rhodium occupying the coordination site trans to nitrogen (XIIb). In the final step, a chloride ion replaces the acetato ligand of XIIb yielding 5.

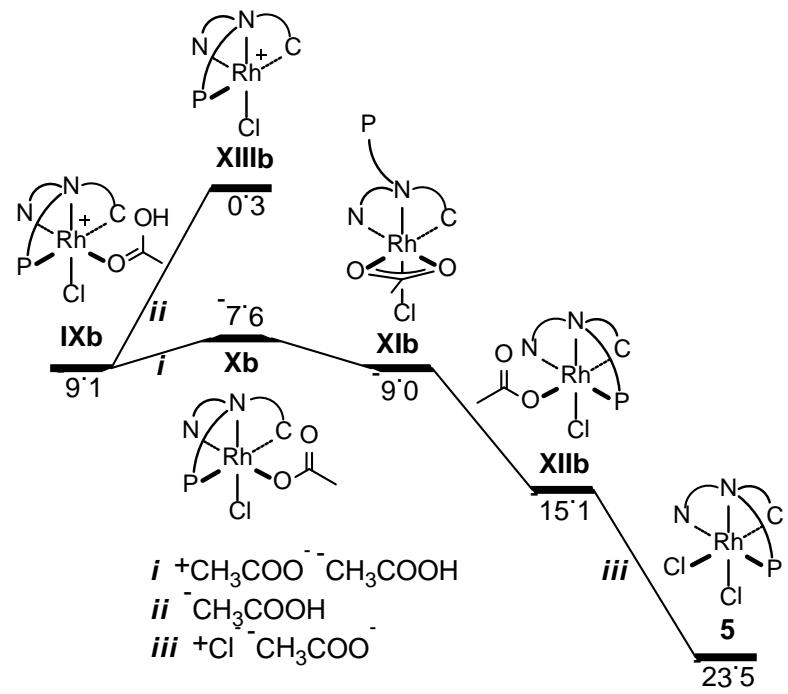

Fig. 7 Free energy profile $\left(\mathrm{kcal} \cdot \mathrm{mol}^{-1}, 298 \mathrm{~K}\right.$, ethanol) for the reaction $\mathbf{I X b}+\mathrm{Cl}^{-} \rightarrow \mathbf{5}+$ $\mathrm{CH}_{3} \mathrm{COOH}$.

It is worth mentioning that a dissociative pathway should be ruled out since the formation of the pentacoordinated cation $\left[\mathrm{RhCl}\left(\kappa^{4} C, N, N^{\prime}, P-\mathbf{L 1}\right)\right]^{+}$(XIIIb) is prohibitively endoergonic $\left(\Delta \mathrm{G}_{\mathbf{I X b}_{\rightarrow} \mathbf{X I I I b}}=8.8 \mathrm{kcal} \cdot \mathrm{mol}^{-1}\right.$, Figure 7).

With respect to the formation of $\left[\operatorname{IrCl}_{2}\left(\kappa^{4} C, N, N^{\prime}, P-\mathbf{L 1}\right)\right]$ (8) in decahydronaphthalene at $170{ }^{\circ} \mathrm{C}$, experimental data indicate that, at variance with $\mathbf{1 a}$, a direct cyclometallation pathway from the mer isomer 4a should exist (vide supra). In this regard, Figure 8A reports the calculated energy profiles for the acetato-assisted $\mathrm{CH}$ cleavage for the acetato intermediates XIVa and XIVb coming from the $\mathbf{4 a}$ and $\mathbf{4 b}$, respectively. Notably, similar to $\left[\mathrm{RhCl}_{3}\left(\kappa^{3} N, N^{\prime}, P-\mathbf{L H 1}\right)\right]$, the $\mathrm{CH}$ cleavage reaction for 
the iridium fac isomer $\mathbf{X I V b}$ presents a lower barrier than for the mer isomer XIVa $\left(\Delta \Delta \mathrm{G}^{\ddagger}=13.2 \mathrm{kcal} \cdot \mathrm{mol}^{-1}\right)$. Nevertheless, the activation barrier for the $\mathrm{CH}$ cleavage in the iridium mer isomer $\mathbf{X I V a}\left(\Delta \mathrm{G}^{\ddagger}=25.7 \mathrm{kcal} \cdot \mathrm{mol}^{-1}\right)$ is found to be smaller than that for the rhodium analogue VIIa $\left(\Delta \mathrm{G}^{\ddagger}=30.8 \mathrm{kcal} \cdot \mathrm{mol}^{-1}\right)$ thus confirming that, in contrast with 1a, the cyclometallation of the iridium mer isomer $\mathbf{4 a}$ could be operating under the experimental reaction conditions and should take place along with the cyclometallation of $\mathbf{4 b}$ when the mixture $\mathbf{4 a}+\mathbf{4 b}$ converts to $\mathbf{8}$.

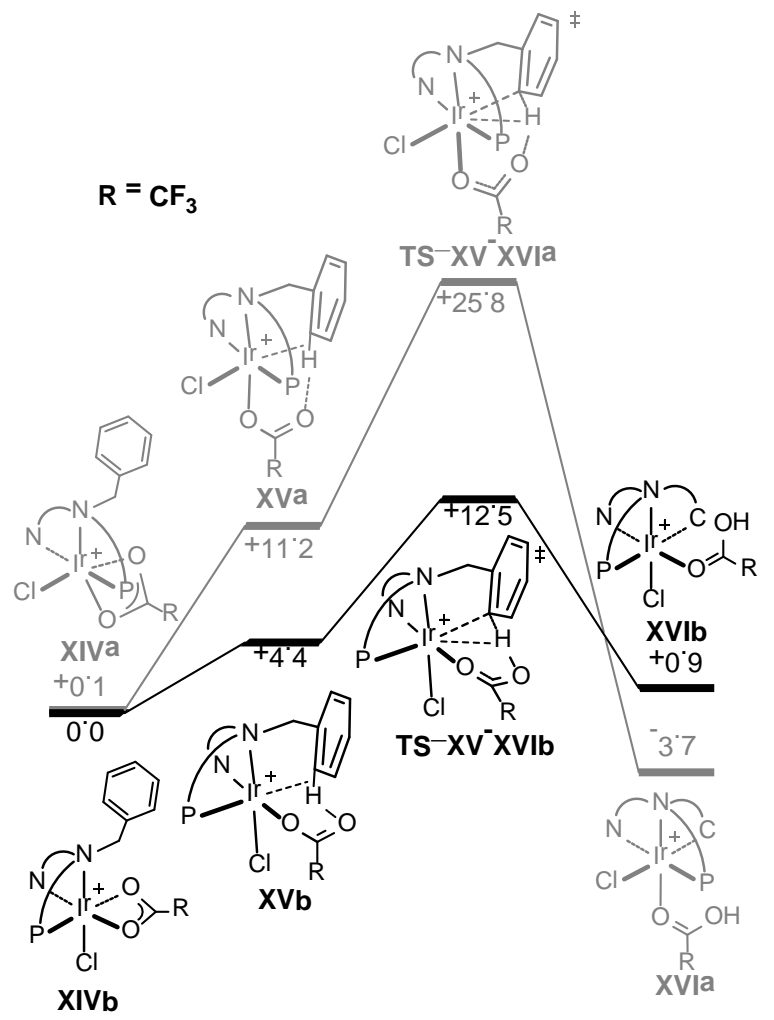

(A)
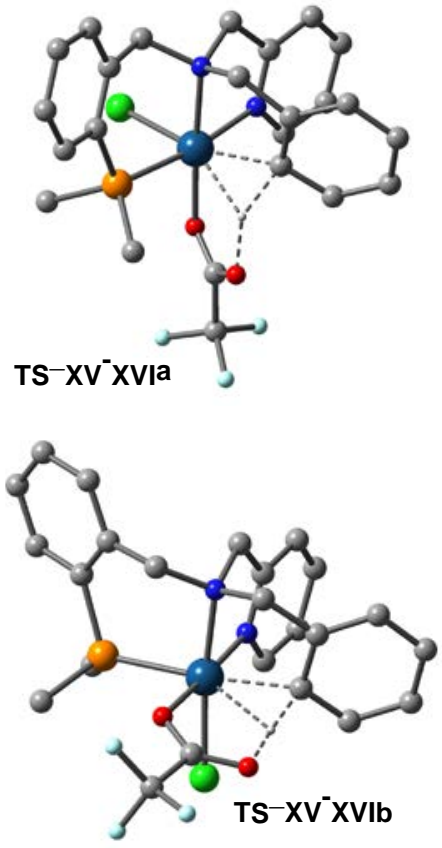

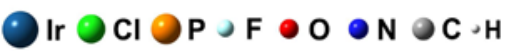

(B)

Fig. 8 (A) Free energy profiles ( $\mathrm{kcal} \cdot \mathrm{mol}^{-1}, 298 \mathrm{~K}$, cyclohexane) of the acetate-assisted $\mathrm{CH}$ cleavage in $\left[\mathrm{IrCl}\left(\kappa^{2} \mathrm{O}, \mathrm{O}^{\prime}-\mathrm{CF}_{3} \mathrm{COO}\right)\left(\mathrm{K}^{3} \mathrm{~N}, \mathrm{~N}^{\prime}, P-\mathrm{LH} 1\right)\right]$. (B) Calculated structures of the transition states TS_XV-XVla and TS_XV-XVIb. For clarity, most hydrogen atoms are omitted and only ipso carbon atoms of the $\mathrm{PPh}_{2}$ moieties are shown. Selected bond lengths $(\AA)$ and angles $\left(^{\circ}\right)$

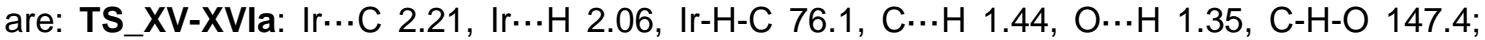

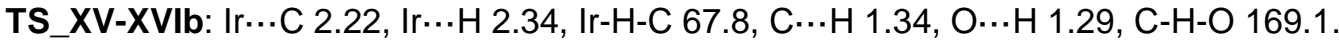

For the sake of comparison, Figure 9 shows the free energy profiles for the formation of the rhodium derivatives $\left[\mathrm{RhCl}_{2}\left(\kappa^{4} C, N, N^{\prime}, P-\mathbf{L 2}\right)\right]$ (6) and $\left[\mathrm{RhCl}_{2}\left(\kappa^{4} C, N, N^{\prime}, P-\mathbf{L} 3\right)\right](7)$. In both cases, the intermediates and the transition state of 
the $\mathrm{CH}$ bond cleavage are similar to those described for the formation of $\left[\mathrm{RhCl}_{2}\left(\kappa^{4} C, N, N^{\prime}, P-\mathbf{L 1}\right)\right]$ (5) starting from the fac isomer (Figure 6).

Interestingly, the activation barriers of the metallation of the C-2 carbon and of the C-4 carbon of the substituted phenyl group are significantly different $\left(\Delta \Delta \mathrm{G}^{\ddagger}=2.8\right.$, LH2; $3.5 \mathrm{kcal} \cdot \mathrm{mol}^{-1}$, LH3), which along with the above mentioned different stability of the regioisomers (Table 4) definitely indicate that the regioselective formation of isomers $\mathbf{6}$ and $\mathbf{7}$ is favoured both kinetically and thermodynamically.

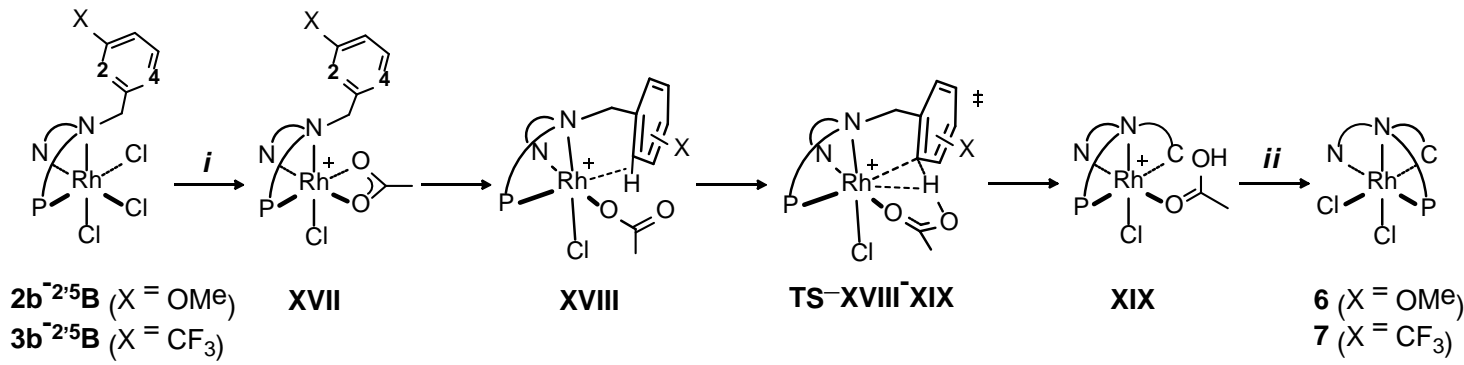

$i^{+} \mathrm{CH}_{3} \mathrm{COO} ;{ }^{-} 2 \mathrm{Cl} ; \mathrm{ii}^{+} \mathrm{Cl} ;{ }^{-} \mathrm{CH}_{3} \mathrm{COOH}$

TS-XVIII'XIX

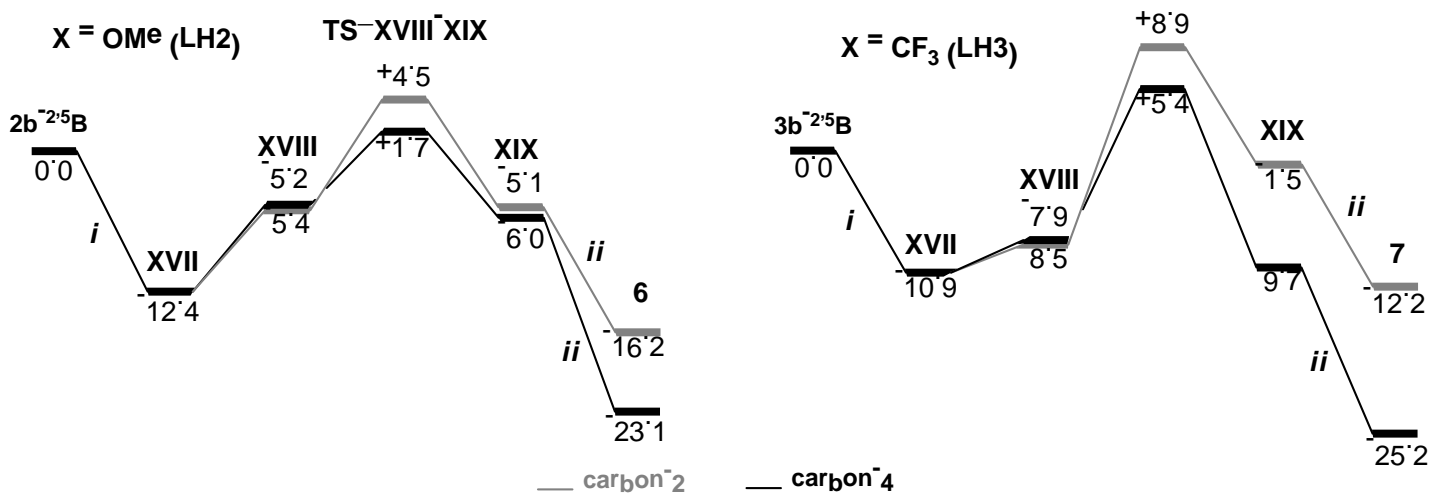

Fig. 9 (top) Intermediates and transition state of the cyclometallation reaction of fac$\left[\mathrm{RhCl}_{3}\left(\mathrm{~K}^{3} \mathrm{~N}, \mathrm{~N}^{\prime}, P-\mathbf{L H}\right)\right](\mathbf{L H}=\mathbf{L H 2}, \mathbf{L H 3}) .($ bottom $)$ Free energy profiles $\left(\mathrm{kcal} \cdot \mathrm{mol}^{-1}, 298 \mathrm{~K}\right.$, ethanol). In both cases, "carbon-2" and "carbon-4" profiles refer to the cyclometallation at C-2 and C-4 carbons, respectively. 


\section{CONCLUSIONS}

Ligands LH1-LH3 give tri and tetracoordinated complexes of $\mathrm{d}^{6} \mathrm{Rh}^{+3}$ and $\mathrm{Ir}^{+3}$ ions of general formulae $\left[\mathrm{MCl}_{3}\left(\kappa^{3} N, N^{\prime}, P-\mathbf{L H}\right)\right]$ and $\left[\mathrm{MCl}_{2}\left(\kappa^{4} C, N, N^{\prime}, P-\mathbf{L}\right)\right]$, in which the aminic nitrogen and the metal atoms are stereogenic centres. Except for $\left[\operatorname{IrCl}_{3}\left(\kappa^{3} N, N^{\prime}, P-\mathbf{L H}\right)\right]$ (4) the metallic compounds could be obtained as racemic mixtures of only one isomer. Notably, the absolute configuration of the centres is predetermined in the sense that given a configuration at nitrogen ( $S$ or $R$ ) only one configuration at the metal ( $A$ or $C$ ) is observed. In particular, for the trichlorido complexes $\left[\operatorname{RhCl}_{3}\left(\kappa^{3} N, N^{\prime}, P-\mathbf{L H}\right)\right]$, the pair of fac enantiomers of configuration $\left(S_{\mathrm{Nam}}\right)$ OC-6-43-C and ( $\left.R_{\text {Nam }}\right)-O C-6-43-A$ was obtained and, for the dichloridos $\left[\mathrm{MCl}_{2}\left(\kappa^{4} C, N, N^{\prime}, P-\mathbf{L}\right)\right](\mathrm{M}=\mathrm{Rh}, \mathrm{Ir})$ the sole isolated isomers presented $\left(R_{\mathrm{Nam}}\right)-O C-6$ 54-C and ( $\left.S_{\mathrm{Nam}}\right)-O C-6-54-A$ configurations.

DFT calculations clearly indicate that the observed isomers are the most stable, thus suggesting that thermodynamic factors are responsible for their selective formation and isolation. Further, the cyclometallation of $\left[\mathrm{MCl}_{3}\left(\kappa^{3} N, N^{\prime}, P-\mathbf{L H}\right)\right]$ follows an acetateassisted mechanism in which an intramolecular hydrogen transfer from the phenyl $\mathrm{CH}$ bond to the coordinated acetate takes place through a six-membered transition state.

Inspection of the molecular structure of the cyclometallated compounds reveals that the asymmetry generated by the centred chiralities results in a strong stereodifferentiation between the two semi-spaces above and below the virtual triangle formed by the metal and the two chlorido ligands. This dissymmetry makes the cyclometallated compounds potentially good starting materials for the preparation of enantioselective catalysts after optical resolution and exchange of the coordinated chlorido ligands by more labile ligands. We are currently working in these lines in our laboratory. 


\section{EXPERIMENTAL SECTION}

\section{General Information}

All preparations have been carried out under argon, unless otherwise stated. All solvents were treated in a PS-400-6 Innovative Technologies Solvent Purification System (SPS) and degassed prior to use. Carbon, hydrogen and nitrogen analyses were performed using a Perkin-Elmer $240 \mathrm{~B}$ microanalyzer. ${ }^{1} \mathrm{H},{ }^{13} \mathrm{C},{ }^{31} \mathrm{P}$ and ${ }^{19} \mathrm{~F}$ spectra were recorded on a Varian UNITY 300, a Bruker AV-300 (300.13 MHz), a Bruker AV-400 (400.16 MHz) or a Bruker AV-500 (500.13 MHz) spectrometers. Chemical shifts are expressed in ppm up field from $\mathrm{SiMe}_{4}, 85 \% \mathrm{H}_{3} \mathrm{PO} 4\left({ }^{31} \mathrm{P}\right)$ or $\mathrm{CFCl}_{3}\left({ }^{19} \mathrm{~F}\right) . J$ values are given in $\mathrm{Hz}$. COSY, NOESY, HSQC, HMQC, and HMBC ${ }^{1} \mathrm{H}-\mathrm{X}\left(\mathrm{X}={ }^{1} \mathrm{H},{ }^{13} \mathrm{C},{ }^{31} \mathrm{P}\right)$ correlation spectra were obtained using standard procedures. Mass spectra were obtained with a Micro Tof-Q Bruker Daltonics spectrometer.

Rhodium and iridium trichlorides were purchased from Johnson Matthey.

Preparation and characterization of the ligands LH1-LH3. To a solution of the corresponding amine A1-A3 (12.6 mmol) in $40 \mathrm{~mL}$ of $\mathrm{CH}_{2} \mathrm{Cl}_{2}$, $3.68 \mathrm{~g}$ (12.6 mmol) of 2diphenylphosphinobenzaldehyde and $4.00 \mathrm{~g}$ (18.9 mmol) of $\mathrm{NaBH}(\mathrm{AcO})_{3}$ were added. The resulting solution was stirred for $15 \mathrm{~min}$ at room temperature and then, $80 \mathrm{~mL}$ of a saturated solution of $\mathrm{NaHCO}_{3}$ in water were added. After 20 min of additional stirring the organic phase was separated by decantation, washed with water $(3 \times 75 \mathrm{~mL})$ and dried $\left(\mathrm{MgSO}_{4}\right)$. The insoluble materials were removed by filtration and all the volatiles were removed under vacuum. The addition of $15 \mathrm{~mL}$ of $n$-hexane to the oily residue affords LH1-LH3 as analytical pure solid compounds. Yield: LH1, 5.54 g (93 \%); LH2, 5.24 g (83 \%); LH3, 5.94 g (87 \%). 


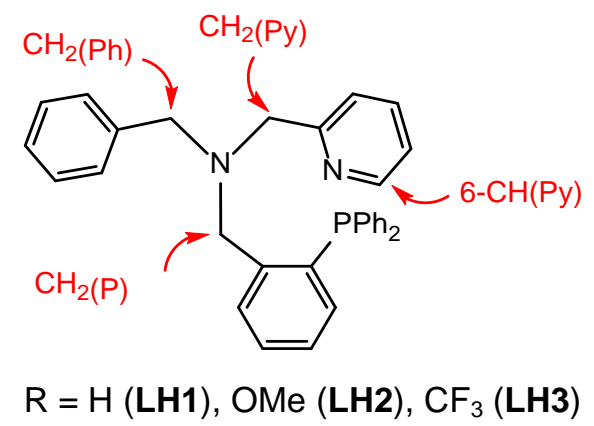

LH1. ${ }^{1} \mathrm{H} N \mathrm{NR}$ (300.13 MHz, $C D_{2} \mathrm{Cl}_{2}, \mathrm{RT}$, ppm): $\delta=8.55$ (ddd, $J=4.9,1.6,0.9 \mathrm{~Hz}, 1 \mathrm{H}$, 6-CH(Py)), 7.99 (dd, $J$ = 7.6, 4.3 Hz, 1H, H(Ar)), 7.73-6.87 (m, 21H, H(Ar)), 4.06 (d, $J$ $\left.=2.4 \mathrm{~Hz}, 2 \mathrm{H}, \mathrm{CH}_{2}(\mathrm{P})\right), 3.87$ (s, 2H, $\left.\mathrm{CH}_{2}(\mathrm{Py})\right)$, and $3.72\left(\mathrm{~s}, 2 \mathrm{H}, \mathrm{CH}_{2}(\mathrm{Ph})\right) .{ }^{13} \mathrm{C}\left\{{ }^{1} \mathrm{H}\right\} N M R$ (75.48 MHz, $\mathrm{CD}_{2} \mathrm{Cl}_{2}, \mathrm{RT}$, ppm): $\delta=160.11$ (s, 2-C(Py)), 148.89 (s, 6-CH(Py)), 144.09 (d, $J=22.8 \mathrm{~Hz}, 2 \mathrm{C}, \mathrm{C}(\mathrm{Ar})), 139.11$ (s, C(Ar)), 136.99 (d, $J=10.8 \mathrm{~Hz}, 2-\mathrm{C}(\mathrm{PhP})$ ), 136.50 (d, $J=13.7 \mathrm{~Hz}, \mathrm{C}(\mathrm{Ar})$ ), 136.41 (s, CH(Ar)), 134.21 (s, 2C, CH(Ar)), 133.94 (s, 2C, CH(Ar)), 133.68 (s, CH(Ar)), 129.05 (s, 3C, CH(Ar)), 129.03 (d, J = $13.7 \mathrm{~Hz}$, CH(Ar)), 128.82 (s, 2C, CH(Ar)), 128.75 (d, $J=11.1$ Hz, 4C, CH(Ar)), 128.36 (s, 2C, CH(Ar)), 127.27 (s, CH(Ar)), 127.07 (s, CH(Ar)), 122.87 (s, CH(Ar)), 121.91 (s, $\mathrm{CH}(\mathrm{Ar})$ ), 59.69 (s, $\mathrm{CH}_{2}(\mathrm{Py})$ ), 58.31 (s, $\mathrm{CH}_{2}(\mathrm{Ph})$ ), and 56.50 (d, $J=22.9 \mathrm{~Hz}, \mathrm{CH}_{2}(\mathrm{P})$ ). ${ }^{31} P\left\{{ }^{1} H\right\} N M R\left(121.42 \mathrm{MHz}, \mathrm{CD}_{2} \mathrm{Cl}_{2}, \mathrm{RT}, \mathrm{ppm}\right): \delta=-16.04$ (s). HRMS ( $\mu$-TOF): $\mathrm{C}_{32} \mathrm{H}_{29} \mathrm{~N}_{2} \mathrm{P},[\mathrm{M}+\mathrm{H}]^{+}$: calc. 473.2141, found 473.2126.

LH2. ${ }^{1} \mathrm{H} N \mathrm{NR}$ (300.13 MHz, $C D_{2} \mathrm{Cl}_{2}, \mathrm{RT}$, ppm): $\delta=8.50$ (ddd, $J=4.9,1.7,0.9 \mathrm{~Hz}, 1 \mathrm{H}$, 6-CH(Py)), 7.89 (dd, $J=7.5,4.3$ Hz, 1H, H(Ar)), 7.69-6.75 (m, 20H, H(Ar)), 3.92 (d, $J$ $\left.=2.5 \mathrm{~Hz}, 2 \mathrm{H}, \mathrm{CH}_{2}(\mathrm{P})\right), 3.82(\mathrm{~s}, 3 \mathrm{H}, \mathrm{OMe}), 3.75\left(\mathrm{~s}, 2 \mathrm{H}, \mathrm{CH}_{2}(\mathrm{Py})\right)$, and $3.60(\mathrm{~s}, 2 \mathrm{H}$, $\left.\mathrm{CH}_{2}(\mathrm{Ph})\right) .{ }^{13} \mathrm{C}\left\{{ }^{1} \mathrm{H}\right\} \mathrm{NMR}\left(75.48 \mathrm{MHz}, \mathrm{CD}_{2} \mathrm{Cl}_{2}, \mathrm{RT}, \mathrm{ppm}\right): \delta=160.08$ (s, 2-C(Py)), 159.60 (s, C(OMe)), 148.79 (s, 6-CH(Py)), 143.91 (d, $J=21.6$ Hz, 2C, C(Ar)), 140.86 (s, C(Ar)), 136.78 (d, $J=10.7 \mathrm{~Hz}, 2-\mathrm{C}(\mathrm{PhP})$ ), 136.33 (s, CH(Ar)), 136.30 (d, $J=14.4$ Hz, C(Ar)), 134.09 (s, 2C, CH(Ar)), 133.83 (s, 2C, CH(Ar)), 133.41 (s, CH(Ar)), 129.18 (s, CH(Ar)), 128.90 (s, CH(Ar)), 128.84 (d, $J=5.2$ Hz, CH(Ar)), 128.68 (s, 2C, CH(Ar)), 128.57 (d, $J=6.0$ Hz, 4C, CH(Ar)), 127.07 (s, CH(Ar)), 122.70 (s, CH(Ar)), 
121.78 (s, CH(Ar)), 121.24 (s, CH(Ar)), 114.49 (s, CH(Ar)), 112.25 (s, CH(Ar)), 59.74 (s, $\mathrm{CH}_{2}(\mathrm{Py})$ ), 58.20 (s, $\mathrm{CH}_{2}(\mathrm{Ph})$ ), 56.25 (d, $J=23.1 \mathrm{~Hz}, \mathrm{CH}_{2}(\mathrm{P})$ ), and 55.19 (s, $\mathrm{OMe}$ ). ${ }^{31} P\left\{{ }^{1} H\right\} N M R\left(121.42 \mathrm{MHz}, C D_{2} C l_{2}, R T, p p m\right): \delta=-15.99$ (s). HRMS ( $\mu$-TOF): $\mathrm{C}_{33} \mathrm{H}_{31} \mathrm{~N}_{2} \mathrm{OP},[\mathrm{M}+\mathrm{H}]^{+}$: calc. 503.2247, found 503.2266.

LH3. ${ }^{1} \mathrm{H} N \mathrm{NR}$ (500.13 MHz, $C D_{2} \mathrm{Cl}_{2}, \mathrm{RT}$, ppm): $\delta=8.50$ (ddd, $J=4.8,1.8,0.9 \mathrm{~Hz}, 1 \mathrm{H}$, 6-CH(Py)), 7.83 (ddd, $J$ = 7.7, 3.4, 0.8 Hz, 1H, H(Ar)), 7.72-7.07 (m, 19H, H(Ar)), 6.93 (ddd, $J=7.7,4.3,1.1 \mathrm{~Hz}, 1 \mathrm{H}, \mathrm{H}(\mathrm{Ar})$ ), 3.92 (d, $J=2.6 \mathrm{~Hz}, 2 \mathrm{H}, \mathrm{CH}_{2}(\mathrm{P})$ ), 3.71 (s, 2H, $\mathrm{CH}_{2}(\mathrm{Py})$ ), and 3.67 (s, 2H, $\left.\mathrm{CH}_{2}(\mathrm{Ph})\right) .{ }^{13} C\left\{{ }^{1} \mathrm{H}\right\} \mathrm{NMR}$ (125.77 MHz, $\left.\mathrm{CD}_{2} \mathrm{Cl}_{2}, \mathrm{RT}, \mathrm{ppm}\right): \delta$ = 159.43 (s, 2-C(Py)), 148.80 (s, 6-CH(Py)), 143.61 (d, $J=22.8$ Hz, 2C, C(Ar)), 140.44 (s, C(Ar)), 136.90 (d, $J=10.5$ Hz, 2-C(PhP)), 136.50 (d, $J=14.7$ Hz, C(Ar)), 136.14 (s, CH(Ar)), 133.96 (s, 2C, CH(Ar)), 133.92 (s, 2C, CH(Ar)), 133.50 (s, CH(Ar)), 130.11 (q, $\left.J=31.9 \mathrm{~Hz}, \mathrm{C}\left(\mathrm{CF}_{3}\right)\right), 129.2-128.3(\mathrm{~m}, 10 \mathrm{C}, \mathrm{CH}(\mathrm{Ar})), 124.42$ (q, $\left.J=270.1 \mathrm{~Hz}, \mathrm{CF}_{3}\right)$, 127.12 (s, CH(Ar)), 125.50 (q, $J=3.9 \mathrm{~Hz}, \mathrm{CH}(\mathrm{Ar})$ ), 123.62 (q, $J=3.8 \mathrm{~Hz}, \mathrm{CH}(\mathrm{Ar})$ ), 122.83 (s, $\mathrm{CH}(\mathrm{Ar})$ ), 121.83 (s, $\mathrm{CH}(\mathrm{Ar})$ ), 59.61 (s, $\mathrm{CH}_{2}(\mathrm{Py})$ ), 57.68 (s, $\mathrm{CH}_{2}(\mathrm{Ph})$ ), and 56.51 (d, $\left.J=22.6 \mathrm{~Hz}, \mathrm{CH}_{2}(\mathrm{P})\right) .{ }^{19} \mathrm{~F}\left\{{ }^{1} \mathrm{H}\right\} \mathrm{NMR}$ (376.48 MHz, $\left.\mathrm{CD}_{2} \mathrm{Cl}_{2}, \mathrm{RT}, \mathrm{ppm}\right): \delta=$ -62.06 (s). ${ }^{31} P\left\{{ }^{1} H\right\} N M R\left(161.98 M H z, C D_{2} C l_{2}, R T, p p m\right): \delta=-16.05$ (s). HRMS ( $\mu-$ TOF): $\mathrm{C}_{33} \mathrm{H}_{28} \mathrm{~F}_{3} \mathrm{~N}_{2} \mathrm{P},[\mathrm{M}+\mathrm{H}]^{+}$: calc. 541.2015, found 541.2047.

\section{Preparation and characterization of the complexes $\left[\operatorname{RhCl}_{3}\left(\kappa^{3} N, N^{\prime}, P-\mathbf{L H}\right)\right](\mathrm{LH}=$}

LH1 (1), LH2 (2), LH3 (3)). To a suspension of $\mathrm{RhCl}_{3} \cdot \mathrm{xH}_{2} \mathrm{O}$ (3.50 g, $13.41 \mathrm{mmol}$ ) in $35 \mathrm{~mL}$ of ethanol, $13.41 \mathrm{mmol}$ of $\mathbf{L H}$ (6.33 g of LH1, $6.74 \mathrm{~g}$ of LH2 and $7.25 \mathrm{~g}$ of LH3) were added. The resulting suspension was stirred under reflux overnight. During this time, the colour of the suspension gradually changes from pink-red to yellow. After the reaction time, the suspension was cooled to room temperature and the yellow precipitate was separated by filtration, washed with $\mathrm{Et}_{2} \mathrm{O}(3 \times 10 \mathrm{~mL})$ and vacuum dried. The isolated solid consists of a mixture of mer and fac isomers in ca. 31:69 
(1a:1b), 40:60 (2a:2b) and 29:71 (3a:3b) molar ratio. Yield: 1, 8.23 g (90 \%); 2, 7.35 g (77 \%); 3, 7.94 g (79 \%).

The mer isomers 1a-3a (100 mg, $0.147 \mathrm{mmol}$ (1a), $0.140 \mathrm{mmol}$ (2a) and 0.133 mmol (3a)) isomerize to the corresponding fac isomers $\mathbf{1 b}$-3b by refluxing EtOH (20 $\mathrm{mL})$ or $\mathrm{CH}_{2} \mathrm{Cl}_{2}(20 \mathrm{~mL})$ suspensions overnight. The resulting suspension was cooled to room temperature and the yellow precipitate was vacuum dried and analyzed by NMR. Crystals, suitable for X-ray analysis, of the complexes $\mathbf{1 b}$ and $\mathbf{3 b}$ were obtained by crystallization from $\mathrm{CH}_{2} \mathrm{Cl}_{2}$ solutions.

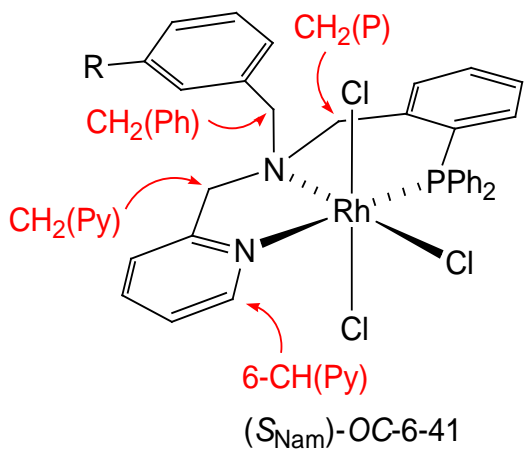

$\mathrm{R}=\mathrm{H}(\mathbf{1} \mathbf{a}), \mathrm{OMe}(\mathbf{2 a}), \mathrm{CF}_{3}(\mathbf{3} \mathbf{a})$

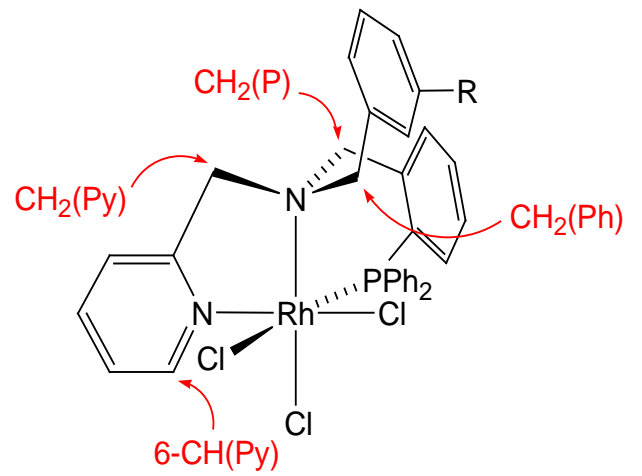

$\left(S_{\mathrm{Nam}}\right)-\mathrm{OC}-6-43-\mathrm{C}$

$\mathrm{R}=\mathrm{H}(\mathbf{1} \mathbf{b}), \mathrm{OMe}(\mathbf{2 b}), \mathrm{CF}_{3}(\mathbf{3 b})$

Compound 1. Anal. calcd. for $\mathrm{C}_{32} \mathrm{H}_{29} \mathrm{Cl}_{3} \mathrm{~N}_{2} \mathrm{PRh} \cdot \mathrm{H}_{2} \mathrm{O}$ : C, 54.92; H, 4.46; N, 4.00. Found: C, 54.88; H, 4.28; N, 3.99. HRMS ( $\mu-\mathrm{TOF}): \mathrm{C}_{32} \mathrm{H}_{29} \mathrm{Cl}_{3} \mathrm{~N}_{2} \mathrm{PRh},[\mathrm{M}-\mathrm{Cl}]^{+}$: calc. 645.0495, found 645.0490 .

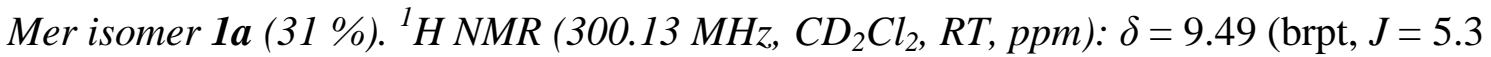
Hz, 1H, 6-CH(Py)), 5.36 (d, overlapped, 1H, $\mathrm{CH}_{2}(\mathrm{P})$ ), 5.07 (d, $J=13.5 \mathrm{~Hz}, 1 \mathrm{H}$, $\mathrm{CH}_{2}(\mathrm{Py})$ ), 4.02 (d, $J=13.5 \mathrm{~Hz}, 1 \mathrm{H}, \mathrm{CH}_{2}(\mathrm{Py})$ ), 3.82 (dd, $J=14.7,1.6 \mathrm{~Hz}, 1 \mathrm{H}, \mathrm{CH}_{2}(\mathrm{P})$ ), 3.73 (br, $1 \mathrm{H}, \mathrm{CH}_{2}(\mathrm{Ph})$ ), and 3.57 (br, $\left.1 \mathrm{H}, \mathrm{CH}_{2}(\mathrm{Ph})\right) .{ }^{31} \mathrm{P}\left\{{ }^{1} \mathrm{H}\right\}$ NMR (121.42 MHz, $\left.C D_{2} \mathrm{Cl}_{2}, \mathrm{RT}, \mathrm{ppm}\right): \delta=30.58(\mathrm{~d}, J=112.6 \mathrm{~Hz})$.

Fac isomer $1 \boldsymbol{b}(69 \%) .{ }^{1} \mathrm{H} N M R\left(500.13 \mathrm{MHz}, \mathrm{CD}_{2} \mathrm{Cl}_{2}, \mathrm{RT}, \mathrm{ppm}\right): \delta=9.53$ (br, $1 \mathrm{H}$, H(Ar)), 9.02 (d, $J=5.7$ Hz, 1H, 6-CH(Py)), 7.80-6.73 (m, 21H, H(Ar)), 6.05 (brd, $J=$ 
14.2 Hz, 1H, $\mathrm{CH}_{2}(\mathrm{Py})$ ), 5.23 (d, $J=14.5 \mathrm{~Hz}, 1 \mathrm{H}, \mathrm{CH}_{2}(\mathrm{Ph})$ ), 4.03 (d, $J=14.5 \mathrm{~Hz}, 1 \mathrm{H}$, $\mathrm{CH}_{2}(\mathrm{Ph})$ ), 3.76 (br, 1H, $\left.\mathrm{CH}_{2}(\mathrm{P})\right), 3.60$ (d, $\left.J=14.0 \mathrm{~Hz}, 1 \mathrm{H}, \mathrm{CH}_{2}(\mathrm{P})\right)$, and 3.23 (d, $J=$ 14.2 Hz, 1H, CH $2(\mathrm{Py})) .{ }^{13} C\left\{{ }^{1} H\right\} N M R\left(125.77 M H z, C D_{2} C l_{2}, R T, p p m\right): \delta=159.69$ (s, 2-C(Py)), 152.04 (s, 6-CH(Py)), 138.11 (s, CH(Ar)), 136.63 (br, 2-C(PhP)), 136.2 (br, 2C, CH(Ar)), 133.53 (brd, $J$ = 7.1 Hz, 2C, CH(Ar)), 132.77 (s, 2C, CH(Ar)), 132.49 (d, $J=8.8 \mathrm{~Hz}, 2 \mathrm{C}, \mathrm{CH}(\mathrm{Ar})), 131.84$ (d, $J=2.7 \mathrm{~Hz}, \mathrm{CH}(\mathrm{Ar})), 131.71$ (d, $J=2.8 \mathrm{~Hz}$, CH(Ar)), 131.39 (s, 1-C(Ph)), 131.14 (d, $J=2.9$ Hz, CH(Ar)), 130.6-129.9 (m, 4C, $3 \times$ CH(Ar), C(Ar)), 129.01 (s, CH(Ar)), 128.67 (s, 2C, CH(Ar)), 128.55 (d, J = $10.1 \mathrm{~Hz}$, 2C, CH(Ar)), 127.15 (d, $J=46.2$ Hz, C(Ar)), 123.95 (s, CH(Ar)), 123.42 (br, C(Ar)), 121.32 (s, $\mathrm{CH}(\mathrm{Ar})$ ), 67.57 (s, $\mathrm{CH}_{2}(\mathrm{Py})$ ), and 61.22 (m, 2C, $\left.\mathrm{CH}_{2}(\mathrm{Ph}), \mathrm{CH}_{2}(\mathrm{P})\right) .{ }^{31} \mathrm{P}\left\{{ }^{1} \mathrm{H}\right\}$ $\operatorname{NMR}$ (202.46 MHz, $\left.C D_{2} \mathrm{Cl}_{2}, R T, p p m\right): \delta=27.45$ (d, $\left.J=115.6 \mathrm{~Hz}\right)$.

Compound 2. Anal. calcd. for $\mathrm{C}_{33} \mathrm{H}_{31} \mathrm{Cl}_{3} \mathrm{~N}_{2} \mathrm{OPRh}$ : C, 55.68; H, 4.39; N, 3.93. Found: C, 55.46; H, 4.52; N, 3.66. HRMS ( $\mu-\mathrm{TOF}$ ): $\mathrm{C}_{33} \mathrm{H}_{31} \mathrm{Cl}_{3} \mathrm{~N}_{2} \mathrm{OPRh},[\mathrm{M}-\mathrm{Cl}]^{+}$: calc. 675.0601, found 675.0609 .

Mer isomer $2 a(40 \%) .{ }^{1} \mathrm{H} N \mathrm{NR}$ (400.16 MHz, $\left.C D_{2} \mathrm{Cl}_{2}, \mathrm{RT}, \mathrm{ppm}\right): \delta=9.43$ (pt, $J=4.9$ Hz, 1H, 6-CH(Py)), 8.10-6.50 (m, 20H, H(Ar)), 5.35 (d, J = 15.1 Hz, 1H, $\mathrm{CH}_{2}(\mathrm{Py})$ ), $5.11\left(\mathrm{~d}, J=13.5 \mathrm{~Hz}, 1 \mathrm{H}, \mathrm{CH}_{2}(\mathrm{P})\right), 4.13$ (d, $\left.J=15.1 \mathrm{~Hz}, 1 \mathrm{H}, \mathrm{CH}_{2}(\mathrm{Py})\right), 4.07$ (d, $J=14.4$ $\mathrm{Hz}, 1 \mathrm{H}, \mathrm{CH}_{2}(\mathrm{Ph})$ ), 3.81 (s, 3H, OMe), 3.77 (d, $J=14.4 \mathrm{~Hz}, 1 \mathrm{H}, \mathrm{CH}_{2}(\mathrm{Ph})$ ), and 3.63 (brd, $\left.J=13.5 \mathrm{~Hz}, 1 \mathrm{H}, \mathrm{CH}_{2}(\mathrm{P})\right) .{ }^{13} C\left\{{ }^{1} H\right\} N M R\left(100.62 \mathrm{MHz}, \mathrm{CD}_{2} \mathrm{Cl}_{2}, \mathrm{RT}, \mathrm{ppm}\right): \delta=$ 159.80 (s, C(OMe)), 157.67 (d, $J$ = 2.3 Hz, 2-C(Py)), 150.72 (s, 6-CH(Py)), 140.65 (d, $J$ = 16.6 Hz, 2-C(PhP)), 139.13 (s, CH(Ar)), 136.31 (d, $J=8.5$ Hz, 2C, CH(Ar)), 135.71 (d, $J=1.6 \mathrm{~Hz}, \mathrm{CH}(\mathrm{Ar})$ ), 134.74 (d, $J=9.8 \mathrm{~Hz}, \mathrm{CH}(\mathrm{Ar})), 134.63$ (d, $J=8.3 \mathrm{~Hz}, 2 \mathrm{C}$, CH(Ar)), 133.50 (br, CH(Ar)), 132.83 (s, 1-C(Ph)), 131.69 (d, J = 2.9 Hz, CH(Ar)), 130.64 (d, $J=3.0 \mathrm{~Hz}, \mathrm{CH}(\mathrm{Ar})$ ), 130.49 (d, $J=2.9 \mathrm{~Hz}, \mathrm{CH}(\mathrm{Ar})$ ), 129.61 (s, CH(Ar)), 128.70-128.26 (m, 2C, C(Ar)), 127.40 (d, $J=10.7 \mathrm{~Hz}, 2 \mathrm{C}, \mathrm{CH}(\mathrm{Ar})), 126.90$ (d, $J=$ 
$11.0 \mathrm{~Hz}, 2 \mathrm{C}, \mathrm{CH}(\mathrm{Ar})), 125.11$ (d, $J=46.9 \mathrm{~Hz}, \mathrm{C}(\mathrm{Ar})), 125.04$ (d, $J=4.0 \mathrm{~Hz}, \mathrm{CH}(\mathrm{Ar})$ ), 124.60 (s, CH(Ar)), 122.15 (d, $J=3.3 \mathrm{~Hz}, \mathrm{CH}(\mathrm{Ar})$ ), 118.26 (s, CH(Ar)), 114.44 (s, CH(Ar)), 63.82 (s, $\mathrm{CH}_{2}(\mathrm{Py})$ ), 61.01 (d, $\left.J=4.4 \mathrm{~Hz}, \mathrm{CH}_{2}(\mathrm{P})\right), 60.45$ (s, $\mathrm{CH}_{2}(\mathrm{Ph})$ ), and 53.37 (s, OMe). ${ }^{31} P\left\{{ }^{1} H\right\} N M R\left(161.98 \mathrm{MHz}, C_{2} C l_{2}, R T, p p m\right): \delta=30.83$ (d, $J=107.5$ $\mathrm{Hz})$.

Fac isomer $2 \boldsymbol{b}(60 \%){ }^{1} \mathrm{H} N M R\left(400.16 \mathrm{MHz}, \mathrm{CD}_{2} \mathrm{Cl}_{2}, \mathrm{RT}, \mathrm{ppm}\right): \delta=9.52$ (br, $1 \mathrm{H}$, H(Ar)), 9.01 (d, $J=5.7$ Hz, 1H, 6-CH(Py)), 8.10-6.50 (m, 20H, H(Ar)), 6.03 (brd, $J=$ 14.3 Hz, 1H, $\mathrm{CH}_{2}(\mathrm{Py})$ ), 5.18 (d, $J=14.2 \mathrm{~Hz}, 1 \mathrm{H}, \mathrm{CH}_{2}(\mathrm{Ph})$ ), 4.00 (brd, $J=14.2 \mathrm{~Hz}, 1 \mathrm{H}$, $\mathrm{CH}_{2}(\mathrm{Ph})$ ), 3.82 (br, 1H, $\mathrm{CH}_{2}(\mathrm{P})$ ), 3.87 (s, 3H, OMe), 3.60 (brd, $J=13.2 \mathrm{~Hz}, 1 \mathrm{H}$, $\mathrm{CH}_{2}(\mathrm{P})$ ), and 3.29 (brd, $J=14.3 \mathrm{~Hz}, 1 \mathrm{H}, \mathrm{CH}_{2}(\mathrm{Py})$ ). ${ }^{13} C\left\{{ }^{1} \mathrm{H}\right\} N M R$ (100.62 MHz, $\left.\mathrm{CD}_{2} \mathrm{Cl}_{2}, \mathrm{RT}, \mathrm{ppm}\right): \delta=159.70$ (brs, 2C, 2-C(Py)), C(OMe)), 151.99 (s, 6-CH(Py)), 138.12 (s, CH(Ar)), 136.60 (d, $J=13.1$ Hz, 2-C(PhP)), 135.69 (br, 2C, CH(Ar)), 133.50 (br, 2C, CH(Ar)), 132.69 (s, 1-C(Ph)), 132.48 (d, $J=8.8$ Hz, 2C, CH(Ar)), 131.78 (d, $J$ = 2.2 Hz, CH(Ar)), 131.70 (d, $J=2.7 \mathrm{~Hz}, \mathrm{CH}(\mathrm{Ar})$ ), 131.15 (d, $J=2.9 \mathrm{~Hz}, \mathrm{CH}(\mathrm{Ar})$ ), 130.38 (brd, $J=8.3 \mathrm{~Hz}, \mathrm{CH}(\mathrm{Ar})$ ), 129.61 (s, CH(Ar)), 129.58 (d, $J=6.9 \mathrm{~Hz}, 2 \mathrm{C}$, CH(Ar)), 128.70-128.26 (m, 2C, C(Ar)), 128.56 (d, $J=10.0$ Hz, 2C, CH(Ar)), 124.82 (s, CH(Ar)), 123.95 (d, J = 46.8 Hz, C(Ar)), 123.93 (s, CH(Ar)), 121.36 (s, CH(Ar)), 118.36 (s, $\mathrm{CH}(\mathrm{Ar})$ ), 114.40 (s, $\mathrm{CH}(\mathrm{Ar})$ ), 67.64 (br, $\mathrm{CH}_{2}(\mathrm{Py})$ ), 61.24 (m, 2C, $\mathrm{CH}_{2}(\mathrm{P})$, $\mathrm{CH}_{2}(\mathrm{Ph})$ ), and 55.28 (s, OMe). ${ }^{31} \mathrm{P}\left\{{ }^{1} \mathrm{H}\right\} \mathrm{NMR}$ (161.98 MHz, $\left.\mathrm{CD}_{2} \mathrm{Cl}_{2}, \mathrm{RT}, \mathrm{ppm}\right): \delta=$ $27.65(\mathrm{~d}, J=115.6 \mathrm{~Hz})$.

Compound 3. Anal. calcd. for $\mathrm{C}_{33} \mathrm{H}_{28} \mathrm{Cl}_{3} \mathrm{~F}_{3} \mathrm{~N}_{2} \mathrm{PRh}$ : C, 52.86; H, 3.76; N, 3.73. Found: C, 52.56; $\mathrm{H}, 4.00 ; \mathrm{N}$, 3.63. HRMS ( $\mu-\mathrm{TOF}): \mathrm{C}_{33} \mathrm{H}_{28} \mathrm{Cl}_{3} \mathrm{~F}_{3} \mathrm{~N}_{2} \mathrm{PRh},[\mathrm{M}-\mathrm{Cl}]^{+}$: calc. 713.0369, found 713.0355 . 
Mer isomer $3 \boldsymbol{a}$ (29 \%). ${ }^{1} \mathrm{H} N \mathrm{NM}\left(300.16 \mathrm{MHz}, \mathrm{CDCl}_{3}, \mathrm{RT}, \mathrm{ppm}\right): \delta=9.56$ (ptd, $J=5.2$, $1.6 \mathrm{~Hz}, 1 \mathrm{H}, 6-\mathrm{CH}(\mathrm{Py})) .{ }^{31} \mathrm{P}\left\{{ }^{1} \mathrm{H}\right\} N M R\left(121.42 \mathrm{MHz}, \mathrm{CDCl}_{3}, \mathrm{RT}, \mathrm{ppm}\right): \delta=30.41$ (d, $J=$ 107.4 Hz).

Fac isomer $3 \boldsymbol{b}(71 \%) .{ }^{1} \mathrm{H} N M R\left(500.13 \mathrm{MHz}, \mathrm{CD}_{2} \mathrm{Cl}_{2}, \mathrm{RT}, \mathrm{ppm}\right): \delta=9.52$ (br, $1 \mathrm{H}$, H(Ar)), 9.01 (d, $J=5.9$ Hz, 1H, 6-CH(Py)), 7.82-6.78 (m, 20H, H(Ar)), 6.09 (d, $J=$ 14.1 Hz, 1H, $\mathrm{CH}_{2}(\mathrm{Py})$ ), 5.31 (d, overlapped, $1 \mathrm{H}, \mathrm{CH}_{2}(\mathrm{Ph})$ ), 4.13 (d, $J=14.7 \mathrm{~Hz}, 1 \mathrm{H}$, $\mathrm{CH}_{2}(\mathrm{Ph})$ ), 3.65 (bs, 2H, CH$(\mathrm{P})$ ), and 3.27 (d, $\left.J=14.1 \mathrm{~Hz}, 1 \mathrm{H}, \mathrm{CH}_{2}(\mathrm{Py})\right) .{ }^{13} C\left\{{ }^{1} \mathrm{H}\right\} N M R$ (125.77 MHz, $C D_{2} \mathrm{Cl}_{2}, \mathrm{RT}, \mathrm{ppm}$ ): $\delta=159.86$ (s, 2-C(Py)), 152.65 (s, 6-CH(Py)), 141.23 (br, 2-C(PhP)), 138.85 (s, CH(Ar)), 136.81 (brs, 2C, CH(Ar)), 134.23 (s, CH(Ar)), 133.93 (d, $J=9.1 \mathrm{~Hz}, \mathrm{CH}(\mathrm{Ar})$ ), 133.04 (br, 1-C(Ph)), 133.03 (brd, $J=7.9 \mathrm{~Hz}, 2 \mathrm{C}$, CH(Ar)), 132.54 (d, $J=2.3 \mathrm{~Hz}, \mathrm{CH}(\mathrm{Ar})), 132.37$ (d, $J=2.9 \mathrm{~Hz}, \mathrm{CH}(\mathrm{Ar})), 131.83$ (d, $J$ $=2.8 \mathrm{~Hz}, \mathrm{CH}(\mathrm{Ar})), 131.36$ (d, $J=41.1 \mathrm{~Hz}, \mathrm{C}(\mathrm{Ar})), 131.25$ (d, $J=9.3 \mathrm{~Hz}, \mathrm{CH}(\mathrm{Ar})$ ), 130.07 (s, CH(Ar)), 130.06 (br, 2C, CH(Ar)), 129.85 (q, $J=3.6$ Hz, 3-CH(Ph)), 129.22 (d, 2C, $J=10.2 \mathrm{~Hz}, \mathrm{CH}(\mathrm{Ar})), 127.56$ (d, $J=47.2 \mathrm{~Hz}, \mathrm{C}(\mathrm{Ar})$ ), 126.50 (q, $J=3.6 \mathrm{~Hz}, 3-$ CH(Ph)), 125.20 (br, C(Ar)), 124.68 (s, CH(Ar)), 124.63 (q, J = 272.0 Hz, CF $), 122.09$ (s, $\mathrm{CH}(\mathrm{Ar})$ ), 110.58 (s, $\mathrm{CH}(\mathrm{Ar})$ ), $\mathrm{C}\left(\mathrm{CF}_{3}\right)$ (not observed), 68.12 (s, $\mathrm{CH}_{2}(\mathrm{Py})$ ), 62.00 (d, J $\left.=8.4 \mathrm{~Hz}, \mathrm{CH}_{2}(\mathrm{P})\right)$, and $61.19\left(\mathrm{~s}, \mathrm{CH}_{2}(\mathrm{Ph})\right) .{ }^{19} \mathrm{~F}\left\{{ }^{1} \mathrm{H}\right\} \mathrm{NMR}$ (282.33 $\mathrm{MHz}, \mathrm{CD}_{2} \mathrm{Cl}_{2}, \mathrm{RT}$, ppm): $\delta=-62.82$ (s). ${ }^{31} P\left\{{ }^{1} H\right\} N M R\left(202.46 \mathrm{MHz}, \mathrm{CD}_{2} \mathrm{Cl}_{2}, \mathrm{RT}, \mathrm{ppm}\right): \delta=27.55$ (d, $J=$ $115.2 \mathrm{~Hz})$.

Preparation of the complex $\left[\operatorname{IrCl}_{3}\left(\kappa^{3} N, N^{\prime}, P-L H 1\right)\right]$ (4). To a suspension of $\mathrm{IrCl}_{3} \cdot \mathrm{xH}_{2} \mathrm{O}$ (3.50 g, $\left.9.52 \mathrm{mmol}\right)$ in $35 \mathrm{~mL}$ of ethanol, $4.50 \mathrm{~g}$ (9.52 mmol) of $\mathbf{L H 1}$ were added. The resulting suspension was stirred under reflux for 4 days. During this time, the colour of the suspension gradually changes from dark green to yellow. After the reaction time, the suspension was cooled to room temperature and the yellow precipitate was separated by filtration, washed with pentane $(3 \times 10 \mathrm{~mL})$ and vacuum dried. The 
isolated solid consists of a mixture of mer and fac isomers in $c a$. 80:20 (4a:4b) molar ratio. Yield: $5.14 \mathrm{~g}$ (70 \%).

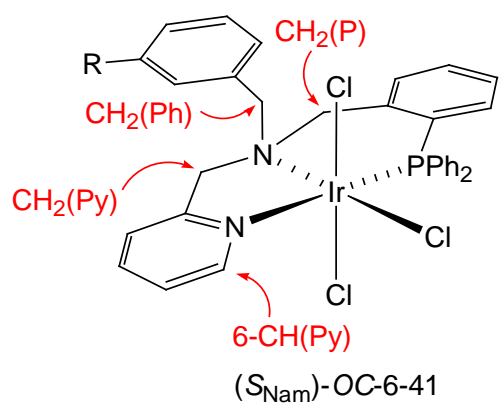

$4 a$

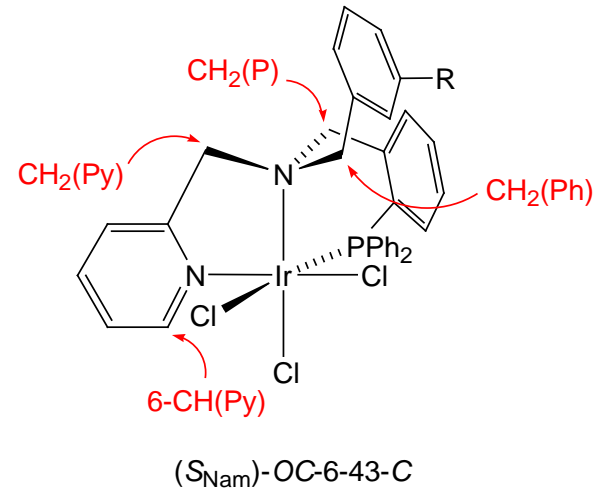

4b

Compound 4. Anal. calcd. for $\mathrm{C}_{32} \mathrm{H}_{29} \mathrm{Cl}_{3} \mathrm{IrN}_{2} \mathrm{P}$ : C, 49.84; H, 3.80; N, 3.63. Found: C, 49.49; $\mathrm{H}, 3.76$; $\mathrm{N}, 3.56$. HRMS ( $\mu-\mathrm{TOF}): \mathrm{C}_{32} \mathrm{H}_{29} \mathrm{Cl}_{3} \mathrm{IrN}_{2} \mathrm{P},[\mathrm{M}+\mathrm{Na}]^{+}$: calc. 793.0638, found 793.0684 .

Mer isomer $4 a(80 \%) .{ }^{1} \mathrm{H} N M R\left(500.13 \mathrm{MHz}, \mathrm{CD}_{2} \mathrm{Cl}_{2}, \mathrm{RT}, \mathrm{ppm}\right): \delta=9.46$ (ptdd, $J=$ 5.6, 1.5, $0.8 \mathrm{~Hz}, 1 \mathrm{H}, 6-\mathrm{CH}(\mathrm{Py})$ ), 8.15-7.30 (m, 22H, H(Ar)), 5.40 (d, $J=13.7 \mathrm{~Hz}, 1 \mathrm{H}$, $\mathrm{CH}_{2}(\mathrm{P})$ ), 5.37 (d, $\left.J=14.8 \mathrm{~Hz}, 1 \mathrm{H}, \mathrm{CH}_{2}(\mathrm{Py})\right), 4.33$ (d, $J=14.8 \mathrm{~Hz}, 1 \mathrm{H}, \mathrm{CH}_{2}(\mathrm{Py})$ ), 4.20 (brd, $J=14.9 \mathrm{~Hz}, 1 \mathrm{H}, \mathrm{CH}_{2}(\mathrm{Ph})$ ), 4.00 (dd, $J=13.7,1.9 \mathrm{~Hz}, 1 \mathrm{H}, \mathrm{CH}_{2}(\mathrm{P})$ ), and 3.90 (dd, $\left.J=14.9,1.9 \mathrm{~Hz}, 1 \mathrm{H}, \mathrm{CH}_{2}(\mathrm{Ph})\right) .{ }^{13} C\left\{{ }^{1} \mathrm{H}\right\} \mathrm{NMR}\left(125.77 \mathrm{MHz}, \mathrm{CD}_{2} \mathrm{Cl}_{2}, \mathrm{RT}, \mathrm{ppm}\right): \delta=$ 158.51 (s, 2-C(Py)), 149.71 (s, 6-CH(Py)), 140.40 (d, $J=15.2$ Hz, 2-C(PhP)), 139.29 (s, CH(Ar)), 136.05 (d, $J=8.9$ Hz, 2C, CH(Ar)), 135.08 (s, CH(Ar)), 134.64 (d, $J=9.7$ Hz, CH(Ar)), 134.51 (d, $J=8.9$ Hz, 2C, CH(Ar)), 133.42 (br, CH(Ar)), 132.61 (s, 2C, CH(Ar)), 131.78 (s, CH(Ar)), 130.36 (d, $J=1.6 \mathrm{~Hz}, \mathrm{CH}(\mathrm{Ar})), 130.16$ (d, $J=1.7 \mathrm{~Hz}$, CH(Ar)), 129.26 (s, CH(Ar)), 128.60 (s, 2C, CH(Ar)), 128.26 (d, $J=60.5$ Hz, C(Ar)), 127.74 (d, $J=63.1 \mathrm{~Hz}, \mathrm{C}(\mathrm{Ar})), 127.31$ (d, $J=10.7 \mathrm{~Hz}, 2 \mathrm{C}, \mathrm{CH}(\mathrm{Ar})), 126.90$ (d, $J=$ 10.7 Hz, 2C, CH(Ar)), 125.15 (d, $J=3.3 \mathrm{~Hz}, \mathrm{CH}(\mathrm{Ar})$ ), 124.89 (d, $J=56.6 \mathrm{~Hz}, \mathrm{C}(\mathrm{Ar})$ ), 122.03 (d, $J=2.3 \mathrm{~Hz}, \mathrm{CH}(\mathrm{Ar})$ ), 65.01 (s, $\mathrm{CH}_{2}(\mathrm{Py})$ ), 61.11 (s, $\mathrm{CH}_{2}(\mathrm{Ph})$ ), and 61.73 (d, $J$ $\left.=2.7 \mathrm{~Hz}, \mathrm{CH}_{2}(\mathrm{P})\right) .{ }^{31} \mathrm{P}\left\{{ }^{1} \mathrm{H}\right\} N \mathrm{NM}\left(202.46 \mathrm{MHz}, \mathrm{CD}_{2} \mathrm{Cl}_{2}, \mathrm{RT}, \mathrm{ppm}\right): \delta=-20.96(\mathrm{~s})$. 
Fac isomer $4 \boldsymbol{b}(20 \%) .{ }^{1} \mathrm{H} N M R\left(500.13 \mathrm{MHz}, \mathrm{CD}_{2} \mathrm{Cl}_{2}, \mathrm{RT}, \mathrm{ppm}\right): \delta=9.17$ (d, $J=5.7$ Hz, 1H, 6-CH(Py)), 5.94 (br, 1H, $\mathrm{CH}_{2}(\mathrm{Py})$ ), 5.26 (d, $J=14.3 \mathrm{~Hz}, 1 \mathrm{H}, \mathrm{CH}_{2}(\mathrm{Ph})$ ), 4.16 (brd, $J=12.4 \mathrm{~Hz}, 1 \mathrm{H}, \mathrm{CH}_{2}(\mathrm{Ph})$ ), 4.04 (br, 1H, $\mathrm{CH}_{2}(\mathrm{P})$ ), 3.77 (d, $J=13.4 \mathrm{~Hz}, 1 \mathrm{H}$, $\mathrm{CH}_{2}(\mathrm{P})$ ), and 3.42 (d, $\left.J=14.4 \mathrm{~Hz}, 1 \mathrm{H}, \mathrm{CH}_{2}(\mathrm{Py})\right) .{ }^{13} \mathrm{C}\left\{{ }^{1} \mathrm{H}\right\} \mathrm{NMR}\left(125.77 \mathrm{MHz}, \mathrm{CD}_{2} \mathrm{Cl}_{2}\right.$, $R T, p p m): \delta=151.21$ (s, 6-CH(Py)). ${ }^{31} \mathrm{P}\left\{{ }^{1} \mathrm{H}\right\}$ NMR (202.46 MHz, $\left.C D_{2} \mathrm{Cl}_{2}, \mathrm{RT}, \mathrm{ppm}\right): \delta$ $=-22.76(\mathrm{~s})$.

Preparation and characterization of the complexes $\left[\operatorname{RhCl}_{2}\left(\kappa^{4} N, N^{\prime}, C, P-\mathrm{L}\right)\right](\mathrm{L}=\mathrm{L1}$

(5), L2 (6), L3 (7)). To suspensions of fac isomer or mer-fac mixtures of $\left[\mathrm{RhCl}_{3}\left(\kappa^{3} N, N^{\prime}, P-\mathbf{L H}\right)\right](1.00 \mathrm{~g}, 1.47 \mathrm{mmol}$ of $\mathbf{1 b}, 1.40 \mathrm{mmol}$ of $\mathbf{2 b}$ and $1.33 \mathrm{mmol}$ of 3b) in $40 \mathrm{~mL}$ of ethanol, $360.9 \mathrm{mg}$ (4.40 mmol, 1b), $345.7 \mathrm{mg}$ (4.21 mmol, 2b) and $328.2 \mathrm{mg}$ (4.00 mmol, $3 \mathbf{b}$ ) of $\mathrm{NaAcO}$ were added. The resulting suspension was stirred for $3 \mathrm{~h}$ under reflux. During this time, the solid was dissolved and a yellow precipitate was formed. The solid was filtered off and was extracted with $\mathrm{CH}_{2} \mathrm{Cl}_{2}$. The resulting yellow solution was vacuum-dried to give an analytical pure compound. Yield: 5, 719.4 mg (76 \%); 6, 626.2 mg (66 \%); 7, $675.7 \mathrm{mg}$ (71 \%). Crystals, suitable for X-ray analysis, of the complexes 5-7 were obtained by crystallization from $\mathrm{CH}_{2} \mathrm{Cl}_{2} / \mathrm{Et}_{2} \mathrm{O}$ solutions.

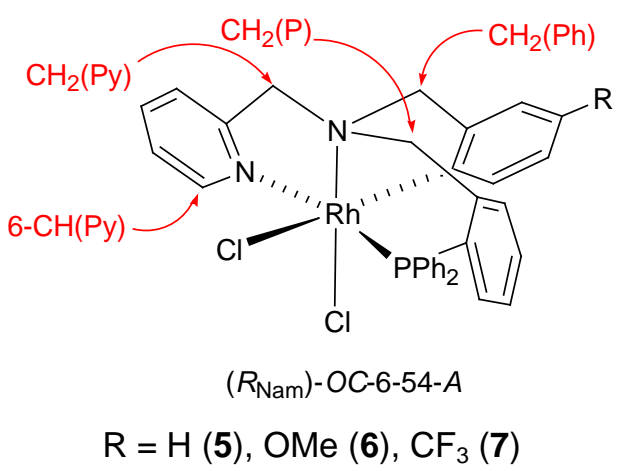

Compound 5. Anal. calcd. for $\mathrm{C}_{32} \mathrm{H}_{28} \mathrm{Cl}_{2} \mathrm{~N}_{2} \mathrm{PRh}$ : C, 59.56; H, 4.37; N, 4.34. Found: C, 59.33; H, 4.40; N, 4.40. HRMS ( $\mu-\mathrm{TOF}$ ): $\mathrm{C}_{32} \mathrm{H}_{28} \mathrm{Cl}_{2} \mathrm{~N}_{2} \mathrm{PRh},[\mathrm{M}-\mathrm{Cl}]^{+}$: calc. 609.0728, found 609.0729. 
${ }^{1} \mathrm{H} N M R\left(500.13 \mathrm{MHz}, C D_{2} \mathrm{Cl}_{2}, R T, p p m\right): \delta=9.10$ (brpt, $J=4.6 \mathrm{~Hz}, 1 \mathrm{H}, 6-\mathrm{CH}(\mathrm{Py})$ ), 8.03 (m, 2H, H(Ar)), 7.78 (ptd, $J=7.7,1.5$ Hz, 1H, H(Ar)), 7.63 (ptpt, $J$ = 7.5, $1.5 \mathrm{~Hz}$, 1H, H(Ar)), 7.53-7.39 (m, 6H, H(Ar)), 7.34-7.26 (m, 3H, H(Ar)), 7.18 (d, $J=7.7 \mathrm{~Hz}$, 1H, H(Ar)), 7.06 (m, 2H, H(Ar)), 6.68 (pt-d, $J=7.3,1.2$ Hz, 1H, H(Ar)), 6.61 (m, 3H, H(Ar)), 6.42 (brd, $J=7.4 \mathrm{~Hz}, 1 \mathrm{H}, \mathrm{H}(\mathrm{Ar})$ ), 5.99 (d, $J=14.3 \mathrm{~Hz}, 1 \mathrm{H}$, pro-S-CH$(\mathrm{Py})$ ), $5.88\left(\mathrm{~d}, J=13.3 \mathrm{~Hz}, 1 \mathrm{H}\right.$, pro- $\left.R-\mathrm{CH}_{2}(\mathrm{P})\right), 4.54\left(\mathrm{~d}, J=16.8 \mathrm{~Hz}, 1 \mathrm{H}\right.$, pro- $R-\mathrm{CH}_{2}(\mathrm{Ph})$ ), 4.12 (d, $J=14.3 \mathrm{~Hz}, 1 \mathrm{H}$, pro- $R-\mathrm{CH}_{2}(\mathrm{Py})$ ), 3.98 (ddd, $J=13.4,3.6,2.2 \mathrm{~Hz}, 1 \mathrm{H}$, pro-S$\mathrm{CH}_{2}(\mathrm{P})$ ), and $3.78(\mathrm{~d}, J=16.7 \mathrm{~Hz}, 1 \mathrm{H}$, pro-S-CH$(\mathrm{Ph})) .{ }^{13} C\left\{{ }^{1} H\right\} N M R(125.77 \mathrm{MHz}$, $\left.C D_{2} \mathrm{Cl}_{2}, R T, p p m\right): \delta=157.01$ (d, $J=2.3 \mathrm{~Hz}, 2-\mathrm{C}(\mathrm{Py})$ ), 153.66 (dd, $J_{R h C}=29.1 \mathrm{~Hz}, J_{P-C}$ = 9.8 Hz, CRh), 148.59 (s, 6-CH(Py)), 147.06 (d, $J=0.9$ Hz, 2-C(Ph)), 141.46 (d, $J=$ $17.6 \mathrm{~Hz}, 2-\mathrm{C}(\mathrm{PhP})$ ), 138.03 (s, CH(Ar)), 136.19 (s, $\mathrm{CH}(\mathrm{Ar})$ ), 136.09 (s, CH(Ar)), 135.40 (d, $J=9.1 \mathrm{~Hz}, 2 \mathrm{C}, \mathrm{CH}(\mathrm{Ar})), 134.12$ (d, $J=8.7 \mathrm{~Hz}, 2 \mathrm{C}, \mathrm{CH}(\mathrm{Ar})), 133.37$ (d, $J=$ 9.3 Hz, CH(Ar)), 132.01 (d, $J=2.2 \mathrm{~Hz}, \mathrm{CH}(\mathrm{Ar})$ ), 130.39 (d, $J=2.6 \mathrm{~Hz}, \mathrm{CH}(\mathrm{Ar})$ ), 129.70 (d, $J=59.0 \mathrm{~Hz}, \mathrm{C}(\mathrm{Ar})$ ), 129.57 (d, $J=2.7 \mathrm{~Hz}, \mathrm{CH}(\mathrm{Ar})$ ), 128.83 (d, $J=6.5 \mathrm{~Hz}$, CH(Ar)), 128.72 (d, $J=51.2 \mathrm{~Hz}, \mathrm{C}(\mathrm{Ar})$ ), 127.34 (d, $J=10.6 \mathrm{~Hz}, 2 \mathrm{C}, \mathrm{CH}(\mathrm{Ar})$ ), 126.63 (d, $J=10.8 \mathrm{~Hz}, 2 \mathrm{C}, \mathrm{CH}(\mathrm{Ar})$ ), 126.57 (s, $\mathrm{CH}(\mathrm{Ar})$ ), 126.12 (d, $J=47.1 \mathrm{~Hz}, \mathrm{C}(\mathrm{Ar})$ ), 124.20 (d, $J=3.6 \mathrm{~Hz}, \mathrm{CH}(\mathrm{Ar})$ ), 122.54 (s, CH(Ar)), 121.24 (d, $J=2.7 \mathrm{~Hz}, \mathrm{CH}(\mathrm{Ar})$ ), 118.32 (s, $\mathrm{CH}(\mathrm{Ar})$ ), 73.96 (s, $\mathrm{CH}_{2}(\mathrm{Py})$ ), 67.10 (s, $\mathrm{CH}_{2}(\mathrm{Ph})$ ), and 66.37 (d, $J=5.8 \mathrm{~Hz}$, $\left.\mathrm{CH}_{2}(\mathrm{P})\right) .{ }^{31} \mathrm{P}\left\{{ }^{1} \mathrm{H}\right\} \mathrm{NMR}\left(202.46 \mathrm{MHz}, \mathrm{CD}_{2} \mathrm{Cl}_{2}, \mathrm{RT}, \mathrm{ppm}\right): \delta=34.68$ (d, $\left.\mathrm{J}=128.6 \mathrm{~Hz}\right)$.

Compound 6. Anal. calcd. for $\mathrm{C}_{33} \mathrm{H}_{30} \mathrm{Cl}_{2} \mathrm{~N}_{2} \mathrm{OPRh} \cdot 2 \mathrm{CH}_{2} \mathrm{Cl}_{2}$ : C, 49.73; H, 4.05; N, 3.31 . Found: C, 50.08; $\mathrm{H}, 4.34 ; \mathrm{N}, 3.43$. HRMS ( $\mu-\mathrm{TOF}): \mathrm{C}_{33} \mathrm{H}_{30} \mathrm{Cl}_{2} \mathrm{~N}_{2} \mathrm{OPRh},[\mathrm{M}-\mathrm{Cl}]^{+}$: calc. 639.0834, found 639.0829.

${ }^{1} \mathrm{H} N \mathrm{NR}\left(500.13 \mathrm{MHz}, C D_{2} \mathrm{Cl}_{2}, \mathrm{RT}, \mathrm{ppm}\right): \delta=9.09$ (ptdd, $J=4.7,1.6,0.8 \mathrm{~Hz}, 1 \mathrm{H}, 6-$ CH(Py)), 8.02 (m, 2H, H(Ar)), 7.78 (pt-d, $J=7.7,1.6$ Hz, 1H, H(Ar)), 7.63 (pt-pt, $J=$ 7.5, 1.5 Hz, 1H, H(Ar)), 7.53-7.39 (m, 6H, H(Ar)), 7.37-7.26 (m, 3H, H(Ar)), 7.08 (m, 
2H, H(Ar)), 7.01 (d, $J=8.8 \mathrm{~Hz}, 1 \mathrm{H}, \mathrm{H}(\mathrm{Ar})$ ), 6.66 (pt, $J=9.3 \mathrm{~Hz}, 2 \mathrm{H}, \mathrm{H}(\mathrm{Ar})$ ), 6.28 (dd, $J=8.9,2.9 \mathrm{~Hz}, 1 \mathrm{H}, \mathrm{H}(\mathrm{Ar})), 6.06$ (d, $J=2.9 \mathrm{~Hz}, 1 \mathrm{H}, \mathrm{H}(\mathrm{Ar})$ ), 5.99 (d, $J=14.3 \mathrm{~Hz}, 1 \mathrm{H}$, pro-S-CH$(\mathrm{Py})$ ), 5.86 (d, $J=13.3 \mathrm{~Hz}, 1 \mathrm{H}$, pro- $\left.R-\mathrm{CH}_{2}(\mathrm{P})\right), 4.49$ (d, $J=16.9 \mathrm{~Hz}, 1 \mathrm{H}$, pro- $R-\mathrm{CH}_{2}(\mathrm{Ph})$ ), 4.09 (d, $J=14.3 \mathrm{~Hz}, 1 \mathrm{H}$, pro- $R-\mathrm{CH}_{2}(\mathrm{Py})$ ), 3.97 (ddd, $J=13.3$, 3.5, 2.1 $\mathrm{Hz}, 1 \mathrm{H}$, pro-S-CH$(\mathrm{P})), 3.73$ (d, $J=16.9 \mathrm{~Hz}, 1 \mathrm{H}$, pro-S-CH$(\mathrm{Ph})$ ), and 3.59 (s, 3H, OMe). ${ }^{13} C\left\{{ }^{1} H\right\}$ NMR (125.77 MHz, $\left.C D_{2} C l_{2}, R T, p p m\right): \delta=156.92$ (d, $J=2.4 \mathrm{~Hz}, 2-$ C(Py)), 156.53 (s, C(OMe)), 148.60 (s, 6-CH(Py)), 147.05 (s, 2-C(Ph)), 142.02 (dd, $J_{R h-}$ $\left.C_{C}=29.6 \mathrm{~Hz}, J_{P-C}=10.3 \mathrm{~Hz}, \mathrm{CRh}\right), 141.38(\mathrm{~d}, J=17.6 \mathrm{~Hz}, 2-\mathrm{C}(\mathrm{PhP})), 137.97(\mathrm{~s}$, CH(Ar)), 136.26 (s, CH(Ar)), 136.22 (s, CH(Ar)), 135.39 (d, J = 9.1 Hz, 2C, CH(Ar)), 134.19 (d, $J=8.7 \mathrm{~Hz}, 2 \mathrm{C}, \mathrm{CH}(\mathrm{Ar})), 133.36$ (d, $J=9.3 \mathrm{~Hz}, \mathrm{CH}(\mathrm{Ar})), 131.96$ (d, $J=2.2$ Hz, CH(Ar)), 130.35 (d, $J=2.7$ Hz, CH(Ar)), 129.80 (d, $J=58.8$ Hz, C(Ar)), 129.55 (d, $J=2.7 \mathrm{~Hz}, \mathrm{CH}(\mathrm{Ar})$ ), 128.83 (d, $J=6.5 \mathrm{~Hz}, \mathrm{CH}(\mathrm{Ar})$ ), 128.75 (d, $J=50.8 \mathrm{~Hz}$, C(Ar)), 127.32 (d, $J=10.6 \mathrm{~Hz}, 2 \mathrm{C}, \mathrm{CH}(\mathrm{Ar})), 126.58$ (d, $J=10.6 \mathrm{~Hz}, 2 \mathrm{C}, \mathrm{CH}(\mathrm{Ar})$ ), 126.25 (d, $J=47.0 \mathrm{~Hz}, \mathrm{C}(\mathrm{Ar})$ ), 124.20 (d, $J=3.7 \mathrm{~Hz}, \mathrm{CH}(\mathrm{Ar})$ ), 121.19 (d, $J=2.8 \mathrm{~Hz}$, CH(Ar)), 112.33 (s, $\mathrm{CH}(\mathrm{Ar})$ ), 104.78 (s, $\mathrm{CH}(\mathrm{Ar})$ ), 73.89 (s, $\mathrm{CH}_{2}(\mathrm{Py})$ ), 67.03 (s, $\left.\mathrm{CH}_{2}(\mathrm{Ph})\right), 66.41$ (d, $\left.J=5.7 \mathrm{~Hz}, \mathrm{CH}_{2}(\mathrm{P})\right)$, and 54.94 (s, OMe). ${ }^{31} P\left\{{ }^{1} H\right\} N M R$ (202.46 $\left.M H z, C D_{2} \mathrm{Cl}_{2}, \mathrm{RT}, \mathrm{ppm}\right): \delta=36.68(\mathrm{~d}, \mathrm{~J}=128.7 \mathrm{~Hz})$.

Compound 7. Anal. calcd. for $\mathrm{C}_{33} \mathrm{H}_{27} \mathrm{Cl}_{2} \mathrm{~F}_{3} \mathrm{~N}_{2} \mathrm{PRh} \cdot 0.5 \mathrm{H}_{2} \mathrm{O}$ : C, 54.86; H, 3.90; N, 3.90. Found: C, 54.66; H, 4.03; N, 3.94. HRMS ( $\mu-\mathrm{TOF}): \mathrm{C}_{33} \mathrm{H}_{27} \mathrm{Cl}_{2} \mathrm{~F}_{3} \mathrm{~N}_{2} \mathrm{PRh},[\mathrm{M}-\mathrm{Cl}]^{+}$: calc. 677.0602, found 677.0594.

${ }^{1} \mathrm{H} N \mathrm{NR}\left(500.13 \mathrm{MHz}, \mathrm{CD}_{2} \mathrm{Cl}_{2}, \mathrm{RT}, \mathrm{ppm}\right): \delta=9.10$ (ptdd, $J=5.6,2.5,0.9 \mathrm{~Hz}, 1 \mathrm{H}, 6-$ CH(Py)), 8.15-6.55 (m, 21H, H(Ar)), 5.94 (d, $J=14.5$ Hz, 1H, pro-S-CH C $_{2}$ Py)), 5.92 (d, $J=13.5 \mathrm{~Hz}, 1 \mathrm{H}$, pro- $\left.R-\mathrm{CH}_{2}(\mathrm{P})\right), 4.59$ (d, $J=17.1 \mathrm{~Hz}, 1 \mathrm{H}$, pro- $\left.R-\mathrm{CH}_{2}(\mathrm{Ph})\right), 4.23(\mathrm{~d}, J=$ 14.5 Hz, 1H, pro- $R-\mathrm{CH}_{2}(\mathrm{Py})$ ), 4.06 (ddd, $J=13.5,1.9,1.0 \mathrm{~Hz}, 1 \mathrm{H}, \operatorname{pro}-\mathrm{S}-\mathrm{CH}_{2}(\mathrm{P})$ ), and $3.88(\mathrm{~d}, J=17.1 \mathrm{~Hz}, 1 \mathrm{H}$, pro-S-CH$(\mathrm{Ph})) .{ }^{13} C\left\{{ }^{1} \mathrm{H}\right\} \mathrm{NMR}\left(125.77 \mathrm{MHz}, \mathrm{CD}_{2} \mathrm{Cl}_{2}, \mathrm{RT}\right.$, 
ppm): $\delta=161.10$ (dd, $\left.J_{R h-C}=29.6 \mathrm{~Hz}, J_{P-C}=9.7 \mathrm{~Hz}, \mathrm{CRh}\right), 156.76(\mathrm{~d}, J=2.3 \mathrm{~Hz}, 2-$ C(Py)), 148.41 (s, 6-CH(Py)), 147.39 (d, $J=1.0$ Hz, 2-C(Ph)), 141.36 (d, $J=17.6$ Hz, 2-C(PhP)), 138.33 (s, CH(Ar)), 136.42 (s, CH(Ar)), 136.31 (s, CH(Ar)), 135.38 (d, J = $9.5 \mathrm{~Hz}, 2 \mathrm{C}, \mathrm{CH}(\mathrm{Ar})), 133.80$ (d, $J=8.8 \mathrm{~Hz}, 2 \mathrm{C}, \mathrm{CH}(\mathrm{Ar})), 133.48$ (d, $J=9.5 \mathrm{~Hz}$, CH(Ar)), 132.33 (d, $J=1.9 \mathrm{~Hz}, \mathrm{CH}(\mathrm{Ar})$ ), 130.60 (d, $J=2.6 \mathrm{~Hz}, \mathrm{CH}(\mathrm{Ar})$ ), 129.99 (s, C(Ar)), 129.82 (d, $J=2.6 \mathrm{~Hz}, \mathrm{CH}(\mathrm{Ar})$ ), 129.75 (d, $J=59.4 \mathrm{~Hz}, \mathrm{C}(\mathrm{Ar})), 129.04$ (d, $J=$ 6.5 Hz, CH(Ar)), 128.49 (d, $J=52.0 \mathrm{~Hz}, \mathrm{C}(\mathrm{Ar})$ ), 127.49 (d, $J=10.7 \mathrm{~Hz}, 2 \mathrm{C}, \mathrm{CH}(\mathrm{Ar})$ ), 126.76 (d, $J=10.7 \mathrm{~Hz}, 2 \mathrm{C}, \mathrm{CH}(\mathrm{Ar})), 125.48$ (d, $J=47.3 \mathrm{~Hz}, \mathrm{C}(\mathrm{Ar})), 124.87$ (q, $J=$ $\left.271.3 \mathrm{~Hz}, \mathrm{CF}_{3}\right), 124.78$ (q, $\left.J=31.8 \mathrm{~Hz}, \mathrm{C}\left(\mathrm{CF}_{3}\right)\right), 124.44$ (d, $\left.J=3.6 \mathrm{~Hz}, \mathrm{CH}(\mathrm{Ar})\right)$, 122.56 (q, $J=3.4 \mathrm{~Hz}, \mathrm{CH}(\mathrm{Ar})$ ), 121.52 (d, $J=2.4 \mathrm{~Hz}, \mathrm{CH}(\mathrm{Ar})$ ), 114.63 (q, $J=3.5 \mathrm{~Hz}$, CH(Ar)), 73.98 (s, $\mathrm{CH}_{2}(\mathrm{Py})$ ), 66.98 (s, $\mathrm{CH}_{2}(\mathrm{Ph})$ ), and 66.27 (d, $J=5.6 \mathrm{~Hz}, \mathrm{CH}_{2}(\mathrm{P})$ ). ${ }^{19} \mathrm{~F}\left\{{ }^{1} \mathrm{H}\right\} \mathrm{NMR}$ (282.33 MHz, $\left.C D_{2} \mathrm{Cl}_{2}, \mathrm{RT}, \mathrm{ppm}\right): \delta=-61.87$ (s). ${ }^{31} \mathrm{P}\left\{{ }^{1} \mathrm{H}\right\} \mathrm{NMR}$ (202.46 $\left.M H z, C D_{2} \mathrm{Cl}_{2}, \mathrm{RT}, \mathrm{ppm}\right): \delta=34.01(\mathrm{~d}, \mathrm{~J}=126.3 \mathrm{~Hz})$.

Preparation and characterization of the complex $\left[\operatorname{IrCl}_{2}\left(\kappa^{4} N, N^{\prime}, C, P-L 1\right)\right](8)$. To a solution of a mixture of mer and fac $\left[\operatorname{IrCl}_{3}\left(\kappa^{3} N, N^{\prime}, P-\mathbf{L H 1}\right)\right](\mathbf{4 a}, \mathbf{4 b})(4.0 \mathrm{~g}, 5.19 \mathrm{mmol})$ in $40 \mathrm{~mL}$ of decahydronaphthalene, $2.12 \mathrm{~g}$ (15.6 mmol) of $\mathrm{CF}_{3} \mathrm{COONa}$ were added. The resulting suspension was stirred for $48 \mathrm{~h}$ at $170{ }^{\circ} \mathrm{C}$. After this time, the brown solid formed was filtered off and washed with pentane $(3 \times 10 \mathrm{~mL})$. The residue was extracted in $30 \mathrm{~mL}$ of $\mathrm{CH}_{2} \mathrm{Cl}_{2}$. To the solution, $10 \mathrm{~mL}$ of $\mathrm{MeOH}$ and $2 \mathrm{~mL}$ of $12 \mathrm{M}$ $\mathrm{HCl}(\mathrm{aq})$ were added and then was vacuum-concentrated until ca. $5 \mathrm{~mL}$. Addition of pentane led to the precipitation of a yellow solid that was filtered off, washed with water, $\mathrm{Et}_{2} \mathrm{O}$ and pentane and vacuum-dried. Yield: $2.75 \mathrm{~g}$ (72 \%). 


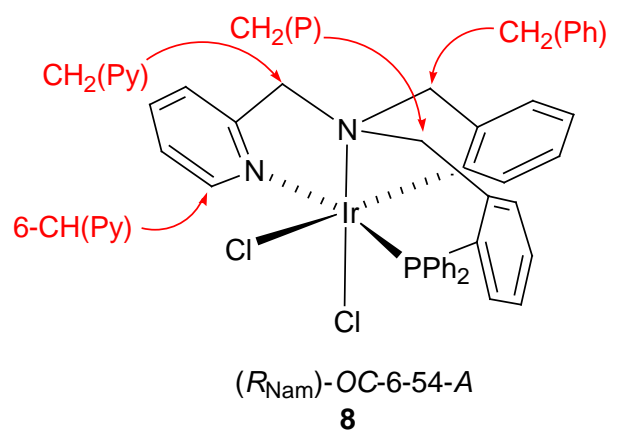

Crystals, suitable for X-ray analysis, of the complex $\mathbf{8}$ were obtained by crystallization from $\mathrm{CH}_{2} \mathrm{Cl}_{2} / \mathrm{Et}_{2} \mathrm{O}$ solutions.

Compound 8. Anal. calcd. for $\mathrm{C}_{32} \mathrm{H}_{28} \mathrm{Cl}_{2} \mathrm{IrN}_{2} \mathrm{P} \cdot \mathrm{H}_{2} \mathrm{O}$ : C, 51.06; H, 4.02; N, 3,72. Found: C, 51.16; H, 3.63; N, 3.80. HRMS ( $\mu-\mathrm{TOF}): \mathrm{C}_{32} \mathrm{H}_{28} \mathrm{Cl}_{2} \mathrm{IrN}_{2} \mathrm{P},[\mathrm{M}-\mathrm{Cl}]^{+}$: calc. 699.1295, found 699.1325 .

${ }^{1} \mathrm{H} N \mathrm{NR}$ (500.13 MHz, $\left.C D_{2} \mathrm{Cl}_{2}, \mathrm{RT}, \mathrm{ppm}\right): \delta=9.14$ (dddd, $J=5.6,3.2,1.5,0.8 \mathrm{~Hz}, 1 \mathrm{H}$, 6-CH(Py)), 7.87 (m, 2H, H(Ar)), 7.78 (pt-d, $J=7.7,1.6$ Hz, 1H, H(Ar)), 7.57 (pt-pt, $J=$ 7.5, 1.4 Hz, 1H, H(Ar)), 7.49 (brd, $J=7.7$ Hz, 1H, H(Ar)), 7.46-7.35 (m, 5H, H(Ar)), 7.32-7.22 (m, 2H, H(Ar)), 7.18 (dpt, $J=7.7,1.2 \mathrm{~Hz}, 1 \mathrm{H}, \mathrm{H}(\mathrm{Ar})$ ), 7.02 (m, 2H, H(Ar)), 6.97 (brd, $J=7.1 \mathrm{~Hz}, 1 \mathrm{H}, \mathrm{H}(\mathrm{Ar})$ ), 6.55 (m, 4H, H(Ar)), 6.40 (dd, $J=7.4,1.0,1 \mathrm{H}$, $\mathrm{H}(\mathrm{Ar})), 5.96$ (d, $J=13.0 \mathrm{~Hz}, 1 \mathrm{H}$, pro- $\left.R-\mathrm{CH}_{2}(\mathrm{P})\right), 5.78$ (d, $J=14.2 \mathrm{~Hz}, 1 \mathrm{H}$, pro-S$\mathrm{CH}_{2}(\mathrm{Py})$ ), 4.48 (d, $J=16.5 \mathrm{~Hz}, 1 \mathrm{H}$, pro- $R-\mathrm{CH}_{2}(\mathrm{Ph})$ ), 4.36 (dd, $J=13.1,2.1 \mathrm{~Hz}, 1 \mathrm{H}$, pro-S-CH$(\mathrm{P})$ ), 4.24 (d, $J=14.3 \mathrm{~Hz}, 1 \mathrm{H}$, pro- $R-\mathrm{CH}_{2}(\mathrm{Py})$ ), and 3.64 (d, $J=16.7 \mathrm{~Hz}, 1 \mathrm{H}$, pro-S-CH $2(\mathrm{Ph})) .{ }^{13} C\left\{{ }^{1} \mathrm{H}\right\} \mathrm{NMR}\left(125.77 \mathrm{MHz}, \mathrm{CD}_{2} \mathrm{Cl}_{2}, \mathrm{RT}, \mathrm{ppm}\right): \delta=158.39$ (d, $J=2.1$ Hz, 2-C(Py)), 152.81 (s, 2-C(Ph)), 149.08 (s, 6-CH(Py)), 141.80 (d, J = 16.1 Hz, 2C(PhP)), 138.56 (s, CH(Ar)), 136.24 (d, $J=2.2 \mathrm{~Hz}, \mathrm{CH}(\mathrm{Ar})), 135.76$ (d, $J=9.1 \mathrm{~Hz}, 2 \mathrm{C}$, CH(Ar)), 136.22 (s, CH(Ar)), 134.58 (d, $J=8.8 \mathrm{~Hz}, 2 \mathrm{C}, \mathrm{CH}(\mathrm{Ar})$ ), 133.99 (d, $J=9.7$ Hz, CH(Ar)), 133.78 (d, $J=7.4$ Hz, CIr), 132.29 (d, $J=2.2$ Hz, CH(Ar)), 130.77 (d, $J=$ $2.5 \mathrm{~Hz}, \mathrm{CH}(\mathrm{Ar})$ ), 130.02 (d, $J=2.5 \mathrm{~Hz}, \mathrm{CH}(\mathrm{Ar})$ ), 129.68 (d, $J=63.6 \mathrm{~Hz}, \mathrm{C}(\mathrm{Ar})$ ), 129.62 (d, $J=7.3 \mathrm{~Hz}, \mathrm{CH}(\mathrm{Ar})$ ), 128.55 (d, $J=57.1 \mathrm{~Hz}, \mathrm{C}(\mathrm{Ar})$ ), 127.86 (d, $J=10.6 \mathrm{~Hz}$, 
2C, $\mathrm{CH}(\mathrm{Ar})$ ), 127.20 (d, $J=10.7 \mathrm{~Hz}, 2 \mathrm{C}, \mathrm{CH}(\mathrm{Ar})$ ), 126.76 (d, $J=54.7 \mathrm{~Hz}, \mathrm{C}(\mathrm{Ar})$ ), 126.17 (s, CH(Ar)), 125.01 (d, $J=3.4 \mathrm{~Hz}, \mathrm{CH}(\mathrm{Ar})$ ), 122.63 (s, CH(Ar)), 121.74 (d, $J=$ 1.7 Hz, $\mathrm{CH}(\mathrm{Ar})$ ), 118.05 (s, $\mathrm{CH}(\mathrm{Ar})$ ), 76.43 (s, $\mathrm{CH}_{2}(\mathrm{Py})$ ), 71.04 (s, $\mathrm{CH}_{2}(\mathrm{Ph})$ ), and 68.14 (d, $\left.J=4.8 \mathrm{~Hz}, \mathrm{CH}_{2}(\mathrm{P})\right) .{ }^{31} P\left\{{ }^{1} \mathrm{H}\right\} N \mathrm{NM}\left(202.46 \mathrm{MHz}, \mathrm{CD}_{2} \mathrm{Cl}_{2}, \mathrm{RT}, \mathrm{ppm}\right): \delta=-10.07$ (s).

Crystal Structure Determination of Complexes 1, 3, 5, 6, 7 and 8. X-Ray diffraction data were collected at $100(2) \mathrm{K}$ with graphite-monochromated Mo $\mathrm{K} \alpha$ radiation $(\lambda=$ $0.71073 \AA$ ) using narrow $\omega$ rotations $\left(0.3^{\circ}\right)$ on a Bruker Smart APEX (complexes 3, 6, 7 and 8) and Bruker DUO diffractometer (complexes 1 and 5). Intensities were integrated and corrected for absorption effects with SAINT-PLUS ${ }^{27}$ and SADABS ${ }^{28}$ programs, included in APEX2 package. The structures were solved by direct methods with SHEXLS-2013 ${ }^{29}$ and refined by full-matrix least-squares refinement on $F^{2}$ with SHELXL-2014 ${ }^{30}$ Flack parameter has been refined as a check on the correct absolute structure determination of non-centrosymmetric crystals. ${ }^{31}$ Particular details concerning the presence of solvent or disorder are listed below.

Crystal data for complex 1b/1b': $\mathrm{C}_{32} \mathrm{H}_{29} \mathrm{Cl}_{3} \mathrm{~N}_{2} \mathrm{PRh} \cdot \mathrm{CH}_{2} \mathrm{Cl}_{2} ; M=766.73$; yellow prism, $0.090 \times 0.109 \times 0.114 \mathrm{~mm}^{3}$; triclinic, $P-1 ; a=10.1484(5), b=10.2653(5), c=$ 17.2027(9) $\AA, \alpha=94.4090(10), \beta=99.2140(10), \gamma=117.8540(10)^{\circ} ; Z=2 ; V=$ 1540.23(13) $\AA^{3} ; D_{c}=1.653 \mathrm{~g} / \mathrm{cm}^{3} ; \mu=1.068 \mathrm{~mm}^{-1}$; min. and max. absorption correction factors 0.761 and $0.924 ; 2 \theta_{\max }=58.87^{\circ} ; 64867$ collected reflections, 8132 unique reflections; $R_{\text {int }}=0.0427$; number of data/restraint/parameters 8132/0/493; final GoF 1.045; $R_{1}=0.0280$ [7024 reflections, $I>2 \sigma(I)$ ]; $w R 2=0.0734$ all data; largest difference peak $1.259 \mathrm{e} \cdot \AA^{-3}$.

Crystal data for complex 3b/3b': $\mathrm{C}_{33} \mathrm{H}_{28} \mathrm{Cl}_{3} \mathrm{~F}_{3} \mathrm{~N}_{2} \mathrm{PRh} \cdot \mathrm{CH}_{2} \mathrm{Cl}_{2} ; M=834.73$; yellow prism, $0.060 \times 0.140 \times 0.160 \mathrm{~mm}^{3}$; triclinic, $P-1 ; a=7.5392(5), b=11.6573(7), c=$ 
19.4298(12) $\AA, \alpha=77.2720(10), \beta=89.8930(10), \gamma=88.6930(10)^{\circ} ; Z=2 ; V=$ 1665.22(18) $\AA^{3} ; D_{c}=1.665 \mathrm{~g} / \mathrm{cm}^{3} ; \mu=1.008 \mathrm{~mm}^{-1}$; min. and max. absorption correction factors 0.770 and $0.914 ; 2 \theta_{\max }=57.43^{\circ} ; 19581$ collected reflections, 7748 unique reflections; $R_{\text {int }}=0.0369$; number of data/restraint/parameters 7748/0/415; final GoF 1.080; $R_{1}=0.0443$ [6416 reflections, $I>2 \sigma(I)$ ]; $w R 2=0.1112$ all data; largest difference peak $1.528 \mathrm{e} \cdot \AA^{-3}$. Highest residual density peak is observed close to a chlorine atom of dichloromethane. Attempts to interpret it as a minor component of a disorder lead to unrealistic geometric parameters.

Crystal data for complex 5/5': $\mathrm{C}_{32} \mathrm{H}_{28} \mathrm{Cl}_{2} \mathrm{~N}_{2} \mathrm{PRh} \cdot 0.5\left(\mathrm{H}_{2} \mathrm{O}\right) ; M=654.35$; yellow prism, $0.055 \times 0.080 \times 0.087 \mathrm{~mm}^{3}$; orthorhombic, Pna2 ${ }_{1} ; a=21.2530(14), b=12.8028(8), c=$ 10.0452(7) $\AA ; Z=4 ; V=2733.3(3) \AA^{3} ; D_{c}=1.590 \mathrm{~g} / \mathrm{cm}^{3} ; \mu=0.907 \mathrm{~mm}^{-1}$; min. and max. absorption correction factors 0.840 and $0.951 ; 2 \theta_{\max }=56.12^{\circ} ; 25798$ collected reflections, 6513 unique reflections; $R_{\text {int }}=0.0565$; number of data/restraint/parameters 6513/3/335; final GoF 1.014; $R_{1}=0.0363$ [5372 reflections, $I>2 \sigma(I)$ ]; $w R 2=0.0757$ all data; largest difference peak $0.519 \mathrm{e} \cdot \AA^{-3}$. Flack parameter: $-0.012(19)$. A phenyl ring of the phosphane substituent has been found to be disordered. Carbon and hydrogen atoms have been included in the model in two sets of positions with complementary occupancy factors $(0.61 / 0.39(3))$ and isotropically refined. Half a water molecule has been included in the asymmetric unit, as the refinement of a whole water molecule leads to unrealistic thermal parameters and the appearance of density holes around the oxygen atom.

Crystal data for complex 6': $\mathrm{C}_{33} \mathrm{H}_{30} \mathrm{Cl}_{2} \mathrm{~N}_{2} \mathrm{OPRh} \cdot 2\left(\mathrm{CH}_{2} \mathrm{Cl}_{2}\right) ; M=845.22$; yellow needle, $0.060 \times 0.070 \times 0.200 \mathrm{~mm}^{3}$; monoclinic, $P 2_{1} ; a=12.2144(7), b=10.5575(6), c=$ 13.2353(8) $\AA, \beta=93.9580(10)^{\circ} ; Z=2 ; V=1702.67(17) \AA^{3} ; D_{c}=1.649 \mathrm{~g} / \mathrm{cm}^{3} ; \mu=$ $1.053 \mathrm{~mm}^{-1}$; min. and max. absorption correction factors 0.729 and $0.917 ; 2 \theta_{\max }=$ 
$57.16^{\circ} ; 15679$ collected reflections, 7829 unique reflections; $R_{\text {int }}=0.0348$; number of data/restraint/parameters 7829/1/416; final GoF 1.107; $R_{1}=0.0652$ [7179 reflections, $I$ $>2 \sigma(I)] ; w R 2=0.1729$ all data; largest difference peak $1.050 \mathrm{e} \cdot \AA^{-3}$. Flack parameter: $-0.01(2)$. A chlorine atom of dichloromethane has been found to be disordered. It has been included in the model in two sets of positions and isotropically refined with complementary occupancy factors $(0.70 / 0.30(2))$.

Crystal data for complex 7/7': $\mathrm{C}_{33} \mathrm{H}_{27} \mathrm{Cl}_{2} \mathrm{~F}_{3} \mathrm{~N}_{2} \mathrm{PRh} \cdot 0.5\left(\mathrm{H}_{2} \mathrm{O}\right) ; M=722.35$; yellow prism, $0.150 \times 0.320 \times 0.392 \mathrm{~mm}^{3}$; orthorhombic, Pca2 ${ }_{1} ; a=13.3199(6), b=11.3820(5), c=$ 20.6691(9) $\AA ; Z=4 ; V=3133.6(2) \AA^{3} ; D_{c}=1.531 \mathrm{~g} / \mathrm{cm}^{3} ; \mu=0.812 \mathrm{~mm}^{-1}$; min. and max. absorption correction factors 0.766 and $0.842 ; 2 \theta_{\max }=57.25^{\circ} ; 36228$ collected reflections, 7377 unique reflections; $R_{\text {int }}=0.0215$; number of data/restraint/parameters 7377/2/388; final GoF 0.974; $R_{1}=0.0207$ [7187 reflections, $\left.I>2 \sigma(I)\right] ; w R 2=0.0563$ all data; largest difference peak $0.834 \mathrm{e} \cdot \AA^{-3}$. Flack parameter: $-0.030(5)$. Half a disordered water molecule has been included in the asymmetric unit. The oxygen atom has been described in the model in two sets of positions with complementary occupancy factors (0.310/0.182(8)) and a common isotropic displacement parameter.

Crystal data for complex 8/8': $\mathrm{C}_{32} \mathrm{H}_{28} \mathrm{Cl}_{2} \mathrm{IrN}_{2} \mathrm{P} \cdot \mathrm{CH}_{2} \mathrm{Cl}_{2} ; M=819.56$; yellow plate, 0.060 $\times 0.200 \times 0.240 \mathrm{~mm}^{3} ;$ monoclinic, $P 2_{1} / c ; a=16.3535(7), b=9.8273(4), c=19.2962(9)$ $\AA, \beta=100.9780(10)^{\circ} ; Z=4 ; V=3044.4(2) \AA^{3} ; D_{c}=1.788 \mathrm{~g} / \mathrm{cm}^{3} ; \mu=4.817 \mathrm{~mm}^{-1} ; \mathrm{min}$. and max. absorption correction factors 0.409 and $0.562 ; 2 \theta_{\max }=57.28^{\circ} ; 34385$ collected reflections, 7324 unique reflections; $R_{\text {int }}=0.0284$; number of data/restraint/parameters 7324/0/480; final GoF 1.057; $R_{1}=0.0287$ [6693 reflections, $I>2 \sigma(I)$ ]; $w R 2=0.0631$ all data; largest difference peak $1.858 \mathrm{e} \cdot \AA^{-3}$. Dichloromethane solvent has been found to be disordered and isotropically refined in two positions with occupancy factors 
$(0.627 / 0.373(6))$. At the end of the refinement, highest residual density peaks are found close to disordered solvent region.

DFT calculations. Molecular structure optimizations, relaxed PSE calculations and free energy calculations were carried out at the DFT-B3LYP level using Gaussian09 program (revision D.01). ${ }^{32}$ The LanL2TZ(f) ${ }^{33}$ basis and pseudo potential were used for rhodium and iridium, and the 6-31G(d,p) basis set for the remaining atoms, including diffuse functions for chlorine. Stationary points were characterized by vibrational analysis (one imaginary frequency for transition states, only positive frequencies for minimum energy molecular structures) and IRC calculations were carried out on the calculated transition states in order to confirm their correct identification. All the structures were optimized in ethanol or cyclohexane using the CPCM method. ${ }^{34}$ Atomic coordinates of calculated structures and the energies of the relaxed PSE scan calculations are given in the ESI. 


\section{Acknowledgments}

We thank the Ministerio de Economía y Competitividad of Spain (CTQ2015-66079-P) and Gobierno de Aragón (Grupo Consolidado E-63: Catalizadores Organometálicos Enantioselectivos) for financial support. M. C. acknowledges Diputación General de Aragón, CSIC and European Social Fund for a grant. R. R. acknowledges the Ministerio de Economía y Competitividad of Spain for a Ramón y Cajal (RYC-2013-13800) grant. P. G.-O. acknowledges CSIC, European Social Fund and Ministerio de Economía y Competitividad of Spain for a PTA contract. V. P. thanks the resources of the supercomputer "Memento" and the technical expertise and assistance provided by the Institute for Biocomputation and Physics of Complex Systems (BIFI), Universidad de Zaragoza. 


\section{References and notes}

1 (a) Comprehensive Asymmetric Catalysis, E. N. Jacobsen, A. Pfaltz and H. Yamamoto, Eds.; Vol I-III, Springer: New York, 1999; Suppl. 1 and 2, Springer: New York, 2004. (b) Catalytic Asymmetric Synthesis, I. Ojima, Ed.; WileyVCH: Weinheim, 2000. (c) R. Noyori In Asymmetric Catalysis in Organic Synthesis, Wiley: Hoboken, 1994. (d) P. J. Walsh and M. C. Kozlowski In Fundamentals of Asymmetric Catalysis, University Science Books: Sausalito, 2009.

(a) Lewis Acids In Organic Synthesis, H. Yamamoto Ed.; Wiley-VCH: Weinheim, 2000. (b) Transition Metals for Organic Synthesis: Building Blocks and Fine Chemicals, $2^{\text {nd }}$ Edition, M. Beller and C. Bolm, Eds.; Wiley-VCH: Weinheim, 2008.

3 B. M. Trost, PNAS 2004, 101, 5348-5355.

4 See for example: (a) O. Cussó, X. Ribas and M. Costas, Chem. Commun. 2015, 51, 14285-14298. (b) M. Hechavarría Fonseca and B. König, Adv. Synth. Catal. 2003, 345, 1173-1185.

5 See for example: (a) T. Oguma and T. Katsuki In Transition Metal Catalysis in Aerobic Alcohol Oxidation, Ch. 9: Asymmetric Oxidation of Alcohols and Phenol Derivatives with Air as Oxidant. From series: RSC Green Chemistry, 2015, pp. 231-255. (b) K. Matsumoto, B. Saito and T. Katsuki, Chem. Commun. 2007, 3619-3627. (c) J. F. Larrow and E. N. Jacobsen, Top. Organomet. Chem. 2004, 6, 123-152. (d) T. Katsuki, Synlett 2003, 281-297. (e) T. Katsuki, Adv. Synth. Catal. 2002, 344, 131-147. (f) E. N. Jacobsen, Acc. Chem. Res. 2000, 33, 
421-431. (g) L. Canali and D. C. Sherrington, Chem. Soc. Rev. 1999, 28, 85-93. (h) T. Katsuki, Coord. Chem. Rev. 1995, 140, 189-214. See for example: (a) Y.-Y. Li, S.-L. Yu, W.-Y. Shen and J.-X. Gao, Acc. Chem. Res. 2015, 48, 2587-2598. (b) R. H. Morris, Acc. Chem. Res. 2015, 48, 14941502. (c) A. Mezzetti, Dalton Trans. 2010, 39, 7851-7869. (d) C. Bonaccorsi and A. Mezzetti, Curr. Org. Chem. 2006, 10, 225-240.

(a) E. B. Bauer, Chem. Soc. Rev. 2012, 41, 3153-3167. (b) H. Brunner, Angew. Chem. Int. Ed. 1999, 38, 1194-1208.

8 (a) B. Huang, L. Wang, L. Gong and E. Meggers, Chem. Asian J. 2013, 8, 22742280. (b) L. Gong, M. Wenzel and E. Meggers, Acc. Chem. Res. 2013, 46, 26352644. (c) E. Meggers, Eur. J. Inorg. Chem. 2011, 2911-2926. (d) E. Meggers, Chem. Eur. J. 2010, 16, 752-758. (e) M. Fontecabe, O. Hamelin and S. Ménage, Top. Organomet. Chem. 2005, 15, 271-288.

9 (a) J. Ma, X. Shen, K. Harms and E. Meggers, Dalton Trans. 2016, 45, 83208323. (b) X. Shen, H. Huo, C. Wang, B. Zhang, K. Harms and E. Meggers, Chem. Eur. J. 2015, 21, 9720-9726. (c) Z.-Y. Cao, W. D. G. Brittain, J. S. Fossey and F. Zhou, Catal. Sci. Technol. 2015, 5, 3441-3451. (d) C. Wang, L.A. Chen, H. Huo, X. Shen, K. Harms, L. Gong and E. Meggers, Chem. Sci. 2015, 6, 1094-1100. (e) H.-H. Huo, C. Fu, K. Harms and E. Meggers, J. Am. Chem. Soc. 2014, 136, 2990-2993. (f) M. Helms, Z.-J. Lin, L. Gong, K. Harms and E. Meggers, Eur. J. Inorg. Chem. 2013, 4164-4172.

10 Asymmetric catalysis mediated by the ligand sphere of octahedral only chiral at metal complexes is deliberately not considered here. For examples of these metal-templated asymmetric “organocatalysts” see: (a) W. Xu, X. Shen, Q. Ma, 
L. Gong and E. Meggers, ACS Catal. 2016, 6, 7641-7646. (b) L. Gong, L.-A. Chen and E. Meggers, Angew. Chem. Int. Ed. 2014, 53, 10868-10874. (c) J. Ma, X. Ding, Y. Hu, Y. Huang, L. Gong and E. Meggers, Nature Commun. 2014, 5, 4531-4536.

11 M. Chavarot, S. Ménage, O. Hamelin, F. Charnay, J. Pécaut and M. Fontecave, Inorg. Chem. 2003, 42, 4810-4816.

12 (a) Y. Zheng, K. Harms, L. Zhang and E. Meggers, Chem. Eur. J. 2016, 22, 11977-11981. (b) L. Song, L. Gong and E. Meggers, Chem. Commun. 2016, 52, 7699-7702. (c) Y. Tan, W. Yuan, L. Gong and E. Meggers, Angew. Chem. Int. Ed. 2015, 54, 13045-13048. (d) Y. Huang, L. Song, L. Gong and E. Meggers, Chem. Asian J. 2015, 10, 2738-2743.

13 (a) C. Tian, L. Gong and E. Meggers, 2016, 52, 4207-4210. (b) Z. Zhou, Y. Li, L. Gong and E. Meggers, Org. Lett. 2017, 19, 222-225.

14 (a) U. Knof and A. von Zelewsky, Angew. Chem. Int. Ed. 1999, 38, 302-322. (b) P. D. Knight and P. Scott, Coord. Chem. Rev. 2003, 242, 125-143.

15 (a) E. C. Volpe, P. T. Wolczanski and E. B. Lobkovsky, Organometallics 2010, 29, 364-377. (b) R. M. Ceder, G. Muller, M. Ordinas and J. I.Ordinas, Dalton Trans. 2007, 83-90. (c) T. V. Laine, U. Piironen, K. Lappalainen, K. Klinga. E. Aitola and M. Leskelä, J. Organomet. Chem. 2000, 606, 112-124.

16 R. O. Hutchins and A. B. Hutchin In Comprehensive Organic Chemistry, M. B. Trost and I. Fleming, Eds.; Pergamon: Oxford, 1991; Vol. 8, Chapter 1.2.

17 A. F. Abdel-Magid and S. J. A. Mehrman, Org. Process Res. Dev. 2006, 10, 971-1031. 
(a) R. S. Cahn, C. Ingold and V. Prelog, Angew. Chem., Int. Ed. Engl. 1966, 5, 385-415. (b) V. Prelog and G. Helmchen, Angew. Chem., Int. Ed. Engl. 1982, 21, 567-583. (c) C. Lecomte, Y. Dusausoy, J. Protas, J.Tirouflet and A. Dormond, J. Organomet. Chem. 1974, 73, 67-76. For the C/A convention for octahedral centres see: (d) N. G. Connelly, T. Damhus, R. H. Hartshorn and A. T. Hutton In Nomenclature of Inorganic Chemistry; IUPAC Recommendations 2005, RSC Publishing, Cambridge, UK. Chapter IR-9.3.4.8, p. 189.

19 H. Kotani, T. Sugiyama, T. Ishizuka, Y. Shiota, K. Yoshizawa and T. Kojima, J. Am. Chem. Soc. 2015, 137, 11222-11225.

20 D. Sardar, P. Datta, R. Saha, P. Raghavaiah and C. Sinha, J. Organomet. Chem. 2013, 732, 109-115.

21 (a) D. Cremer and J. A. Pople, J. Am. Chem. Soc. 1975, 97, 1354-1358. (b) G. Giacovazzo, H. L. Monaco, G. Artioli, D. Viterbo, G. Ferraris, G. Gilli and C. M. Zanotti, In Fundamentals of Crystallography, $2^{\text {nd }}$ ed.; Oxford University Press; Oxford, U. K., 2002. (c) Puckering parameters for the metallacycle Rh$\mathrm{N}(1)-\mathrm{C}(20)-\mathrm{C}(21)-\mathrm{N}(2)$ : complex 1b: $q=0.4014(16) \AA, \Phi=-142.4(3)^{\circ},{ }^{2} \mathrm{E}$ conformation; complex 3b: $q=0.397(3) \AA, \Phi=-135.5(4)^{\circ},{ }^{2} \mathrm{E} /{ }^{2} \mathrm{~T}_{3}$ conformation. (d) Puckering parameters for the metallacycle Rh-P-C(13)-C(18)-C(19)-N(1): complex 1b: $q=0.816(2) \AA, \varphi=-119.29(14)^{\circ}, \theta=94.92(13)^{\circ},{ }^{2,5} \mathrm{~B}$ conformation; complex 3b: $q=0.825(3) \AA, \varphi=-121.6(2)^{\circ}, \theta=91.9(2)^{\circ},{ }^{2,5} \mathrm{~B}$ conformation.

22 Any attempt to locate the transition state of the chlorido dissociation from the isomers 1a, $\mathbf{1 b}-{ }^{2,5} \mathbf{B}, \mathbf{4 a}$ and $\mathbf{4} \mathbf{b}^{-2,5} \mathbf{B}$ was unsuccessful. Nevertheless, relaxed PSE scan calculations varying the dissociating $\mathrm{M}-\mathrm{Cl}$ length from the bond length to 20 Å suggests that the $\mathrm{M}-\mathrm{Cl}$ dissociation should be almost barrierless (see ESI). 
23 In the case of iridium, reasonably the mer:fac molar ratio of 80:20 observed in the isolated mixture is the consequence of two independent reactions that take place between $\operatorname{IrCl}_{3} \cdot \mathrm{xH}_{2} \mathrm{O}$ and $\mathbf{L H 1}$, one leading to the mer isomer, and the other to the fac one.

24 Metallation attempts of the rhodium compounds, maintaining all the reaction conditions but in the absence of carboxylate ions, were unsuccessful: only about $8 \%$ of conversion to the cyclometallated product was observed when these additives were not used. When $\mathrm{NaAcO}$ was employed instead of $\mathrm{CF}_{3} \mathrm{COONa}$, in the preparation of the iridium compound $\mathbf{8}$, in decahydronaphthalene at $170{ }^{\circ} \mathrm{C}$, the product was formed in poor yield (less than $10 \%$ ). To obtain appreciable yields of the cyclometallated iridium compound it is necessary heating the reaction mixture above $150{ }^{\circ} \mathrm{C}$. Thus, no formation of the cyclometallated compound 8 was observed when a mer/fac mixture of $\left[\operatorname{IrCl}_{3}\left(\kappa^{3} N, N^{\prime}, P-\mathbf{L H 1}\right)\right]$ $(\mathbf{4 a}+\mathbf{4 b})$ was refluxed in ethanol for several hours in the presence of $\mathrm{NaAcO}$ and only about $8 \%$ of conversion was measured when refluxing 2-ethoxyethanol (b. p. $135^{\circ} \mathrm{C}$ ) was employed as solvent instead. However, treatment of the rhodium compounds at temperatures higher than $100{ }^{\circ} \mathrm{C}$ in solvents such as toluene, 2ethoxyethanol or diethylene glycol dimethyl ether afforded considerable amounts of uncharacterized decomposition products. We think that the bad results obtained in the preparation of the iridium complex at temperatures below $150{ }^{\circ} \mathrm{C}$ and when using $\mathrm{NaAcO}$ could be due to solubility issues.

25 (a) Puckering parameters for the metallacycle M-N(1)-C(20)-C(21)-N(2): complex 5: $q=0.436(4) \AA ⿻\left(\Phi=40.8(6)^{\circ}, \mathrm{E}_{2}\right.$ conformation; complex 6': $q=$

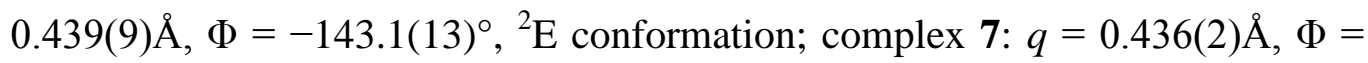
$39.9(3)^{\circ}, \mathrm{E}_{2}$ conformation; complex 8: $q=0.397(3) \AA, \Phi=38.2(4)^{\circ}, \mathrm{E}_{2}$ 
conformation. (b) metallacycle $\mathrm{M}-\mathrm{N}(1)-\mathrm{C}(26)-\mathrm{C}(27)-\mathrm{C}(28)$ : complex 5: $q=$ 0.045(5) $\AA, \Phi=130(6)^{\circ},{ }^{5} \mathrm{~T}_{4}$ conformation; complex 6’: $q=0.029(8) \AA, \Phi=$ $-151(20)^{\circ},{ }^{2} \mathrm{E} /{ }^{2} \mathrm{~T}_{1}$ conformation; complex 7: $q=0.035(2) \AA, \Phi=-9(4)^{\circ},{ }^{1} \mathrm{E} /{ }^{1} \mathrm{~T}_{5}$ conformation; complex 8: $q=0.040(3) \AA, \Phi=-123.4(4)^{\circ},{ }^{2} \mathrm{~T}_{3}$ conformation. (c) Puckering parameters for the metallacycle M-P-C(13)-C(18)-C(19)-N(1): complex 5: $q=0.573(5) \AA, \varphi=-91.1(5)^{\circ}, \theta=67.8(4)^{\circ},{ }^{5} \mathrm{~S}_{6}$ conformation; complex 6': $q=0.695(9) \AA, \varphi=87.0(6)^{\circ}, \theta=102.8(6)^{\circ},{ }^{6} \mathrm{~S}_{5} /{ }^{6} \mathrm{~T}_{2}$ conformation; complex 7: $q=0.615(2) \AA, \varphi=-96.7(2)^{\circ}, \theta=71.5(2)^{\circ},{ }^{5} \mathrm{~S}_{6}$ conformation; complex 8: $q=0.657(3) \AA, \varphi=-96.5(3)^{\circ}, \theta=74.9(2)^{\circ},{ }^{5} \mathrm{~S}_{6}$ conformation.

26 (a) D. A. Frasco, S. Mukherjee, R. D. Sommer, C. M. Perry, N. S. Lambic, K. A. Abboud, E. Jakubikova and E. A. Ison, Organometallics 2016, 35, 2435-2445. (b) F. J. Fernández-Álvarez, M. Iglesias, L. A. Oro and V. Passarelli, Bond Activation and Catalysis, In Comprehensive Inorganic Chemistry II (Second Edition), edited by Jan Reedijk and Kenneth Poeppelmeier, Elsevier, Amsterdam, 2013, 399-432, ISBN 9780080965291. (c) D. Balcells, E. Clot and O. Eisenstein, Chem. Rev. 2010, 110, 749-823. (d) Y. Boutadla, D. L. Davies, S. A. Macgregor and A. I. Poblador-Bahamonde, Dalton Trans. 2009, 5887-5893. (e) D. L. Davies, S. M. A. Donald and S.A. Macgregor, J. Am. Chem. Soc. 2005, 127, 13754-13755. (f) D. L. Davies, S. M. A. Donald, O. Al-Duaij, S. A. Macgregor and M. Pölleth, J. Am. Chem. Soc. 2006, 128, 4210-4211. (g) B. Biswas, M. Sugimoto and S. Sakaki, Organometallics 2000, 19, 3895-3908.

27 SAINT+, version 6.01: Area-Detector Integration Software, Bruker AXS, Madison, WI, 2001.

28 (a) R. H. Blessing, Acta Crystallogr. 1995, A51, 33-38. (b) SADABS, Area Detector Absorption Correction Program, Bruker AXS, Madison, WI, 1996. 
29 (a) G. M. Sheldrick, Acta Crystallogr. 1990, A46, 467-473. (b) G. M. Sheldrick, Acta Crystallogr. 2008, A64, 112-122.

30 G. M. Sheldrick, Acta Crystallogr. 2015, C71, 3-8.

31 (a) H. D. Flack, Acta Crystallogr. 1983, A39, 876-881. (b) G. Bernardinelli and H. D. Flack, Acta Crystallogr. 1985, A41, 500-511.

32 M. J. Frisch et al., Gaussian 09, Revision D.01; Gaussian, Inc.: Wallingford, CT, 2009.

33 L. E. Roy, P. J. Hay and R. L. Martin, J. Chem. Theory Comput. 2008, 4, 10291031.

34 (a) J. Tomasi, B. Mennucci and E. Cances, J. Mol. Struct.: THEOCHEM 1999, 464, 211-226. (b) E. Cancès, B. Mennucci and J. Tomasi, J. Chem. Phys. 1997, 107, 3032-3041. (c) B. Mennucci and J. Tomasi, J. Chem. Phys. 1997, 106, 5151-5158. 


\title{
For table of contents use only
}

\section{Stereospecific control of the metal-centred chirality of rhodium(III) and iridium(III) complexes bearing tetradentate CNN'P ligands}

\author{
María Carmona, ${ }^{\text {a }}$ Ricardo Rodríguez, ${ }^{\text {,a }}$ Isabel Méndez, ${ }^{\mathrm{a}}$ Vincenzo Passarelli,,,a,b \\ Fernando J. Lahoz, ${ }^{a}$ Pilar García-Orduña ${ }^{a}$ and Daniel Carmona*,a \\ ${ }^{a}$ Instituto de Síntesis Química y Catálisis Homogénea (ISQCH), CSIC - Universidad de Zaragoza, \\ Departamento de Química Inorgánica, Pedro Cerbuna 12, 50009 Zaragoza, Spain, E-mail: \\ dcarmona@unizar.es (D. C.), riromar@unizar.e, (R. R.), passarel@unizar.es (V. P.) \\ ${ }^{b}$ Centro Universitario de la Defensa, Ctra. Huesca s/n, 50090 Zaragoza, Spain
}

Complexes of formula $\left[\mathrm{MCl}_{2}\left(\kappa^{4} C, N, N^{\prime}, P-\mathbf{L}\right)\right](\mathrm{M}=\mathrm{Rh}, \mathrm{Ir})$ were diastereoselectively obtained with predetermined absolute configuration from $\mathrm{MCl}_{3} \cdot \mathrm{xH}_{2} \mathrm{O}$ and tripodal tetradentate ligands

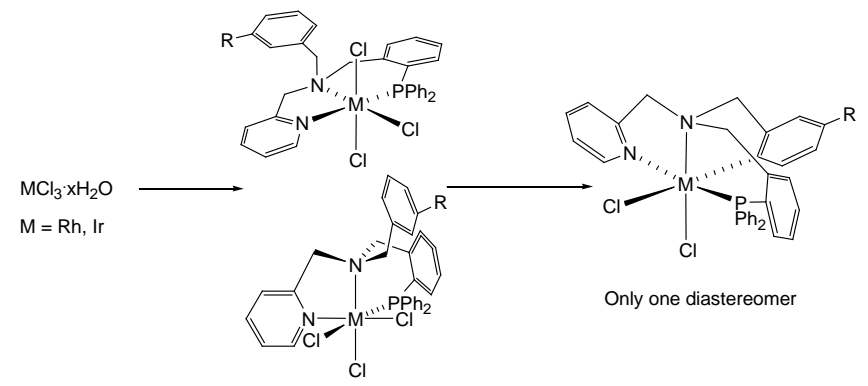

